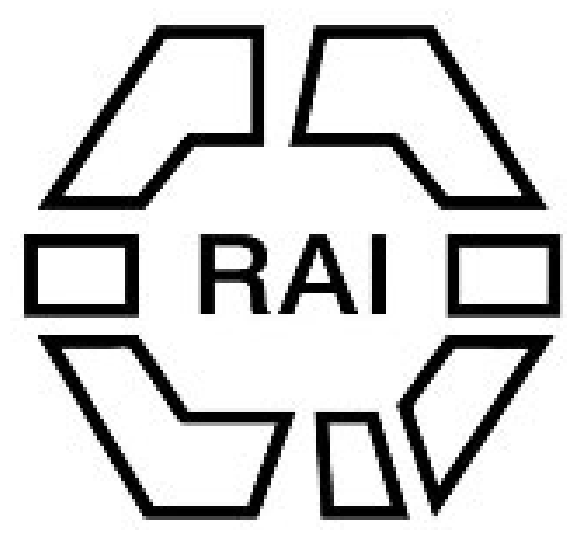

On the Aboriginal Inhabitants of the Andaman Islands. (Part III.)

Author(s): E. H. Man

Source: The Journal of the Anthropological Institute of Great Britain and Ireland, Vol. 12 (1883), pp. 327-434

Published by: Royal Anthropological Institute of Great Britain and Ireland

Stable URL: http://www.jstor.org/stable/2841948

Accessed: 16/06/2014 07:30

Your use of the JSTOR archive indicates your acceptance of the Terms \& Conditions of Use, available at http://www.jstor.org/page/info/about/policies/terms.jsp

JSTOR is a not-for-profit service that helps scholars, researchers, and students discover, use, and build upon a wide range of content in a trusted digital archive. We use information technology and tools to increase productivity and facilitate new forms of scholarship. For more information about JSTOR, please contact support@jstor.org. 
Mr. E. H. MaN then read the concluding part of his memoir on the Andamanese:-

\section{On the Aboriginal Inhabitants of the Andaman Islands.}

(Part III.) By E. H. Man, Esq., F.R.G.S., \&c.

(With Appendices A to M).

ON former occasions we have considered at some length the physical and mental peculiarities of the Andamanese, and have discussed their various beliefs, traditions, superstitions, and customs. This evening I propose to follow them into their daily life, and to tell you of the occupations, amusements, manufactures, \&c., in which they are ordinarily engaged.

social Relations, Education, and Infanticide.-1. Although it is true that the performance of most of the domestic duties falls to the lot of the women and children, it would be a great mistake to suppose that any compulsion is used by the head of the family; he usually leads quite as active a life as any of the females, and often shares certain of their labours, when necessity arises in consequence of sickness or other cause. As I have already stated, ${ }^{1}$ it is quite incorrect to say of these savages that with them "marriage is nothing more than taking a female slave," for one of the most striking features of their social relations is the marked equality and affection which subsists between husband and wife $;{ }^{2}$ careful observations extending over many years prove that not only is the husband's authority more or less nominal, but that it is not at all an uncommon occurrence for Andamanese Benedicts to be considerably at the beck and call of their better halves: in short, the consideration and respect with which women are treated might with advantage be emulated by certain classes in our own land.

2. The duties of the husband,-varying in the case of his being an $\bar{e} \cdot r e m-t a \cdot g a-$ or an àryôto-,-Consist chiefly in hunting, fishing, turtling, collecting honey, \&c., constructing canoes, building the better kinds of huts, ${ }^{3}$ and manufacturing the bows, arrows, and other implements needed in his various pursuits; he must also assist his wife in looking after the children, in keeping up the fire, and in providing the materials

1 Vide "Marriage," paragraph 1.

2 It has been correctly stated that "their mutual intercourse is courteous and genial, and the affection between parents and children is peculiarly tender" (Peschel, p. 148).

3 Vide ante "Habitations," paragraph 2. 
required in making their various weapons, utensils, \&c.; but though he has 110 hesitation in sharing and lightening his wife's labours up to this point, it is only in cases of stern necessity that he will condescend to procure either wood or water for the family requirements ; the supply of these essentials of daily life being considered as peculiarly feminine duties and derogatory to the lords of creation.

3. Every woman is supposed to be a proficient in shaving, ${ }^{1}$ tattooing, ${ }^{2}$ and scarifying ; she has also to prepare the kòi $\circ b$-, $t \hat{\alpha} \cdot l a-\bar{o} g-$, and $k \hat{\alpha} \cdot n g a t \hat{d}-b \bar{u} j_{-},{ }^{3}$, which are needed on so many occasions. The erection of the chàng-dar anga- ${ }^{4}$ and the manufacture of personal ornaments, ${ }^{5}$ and various other objects in constant use, ${ }^{6}$ is also confined to the fair (!) sex, and when to these are added their daily duties of procuring certain kinds of food, cooking and providing the water and fuel required for the family, it will be seen that the Andamanese materfamilias-who has not several children old enough to give her material assistance-has her time fully employed, or at least sufficiently so to prevent her getting into much mischief.

4. It is the duty of those men and women who remain at home to attend to the sick, infants, and others who are in a dependent position, to look after the fires in the various huts, and, of course if needs be, to protect the property of absentees: for all those who are not physically incapable are supposed to employ themselves in some way, either for their own benefit or that of the community to which they belong.

5. It is customary for every family to maintain a supply of provisions in excess of its own requirements for the use of friends who may chance to visit the encampment; but in the storage of their food-owing probably to the ease with which it is generally procured-much is often wasted which might without difficulty be preserved. The seeds of the Artocarpus chaplasha, and of a species of Semecarpus, are alone kept for any length of time. The manner in which this is effected will be described in the section treating of "Food."

6. Migrations and other events affecting the movements of a whole community are arranged by the chief and elders; women in such matters are not consulted, though while on the march

1 Vide ante "Hair," paragraph 4, and post "Shaving," paragraph 2.

2 Vide post "Tattooing," paragraph 2.

3 Vide Appendix $\mathrm{B}$, items 60, 58, 62.

4 Vide ante "Habitations," paragraph 4.

5 Vide post "Attire," paragraph 1.

6 In Appendix B will be found detailed the various objects manufactured by both men and women.

7 Vide post, "Food," paragraph 32. 
it is they who are expected to carry the heaviest loads: this arises from no want of consideration for the weaker vessel, but simply because, if unnecessarily encumbered, the men would be unable to shoot or pursue any animal which might cross their path.

7. Such training as the children receive is undertaken by their parents or guardians; in the case of boys it consists merely in providing them with miniature weapons suitable to their age, and instructing them in their use : as they advance in years they accompany the men in their hunting and fishing expeditions, and, being by nature intelligent and emulous, they speedily acquire sufficient skill to enable then to afford material assistance to their elders.

8. The girls, similarly, are taught by their mothers, or other female guardians, how to fulfil the various duties which are regarded as essentially pertaining to their sex, and which I have described in the foregoing.

9. It seems hardly necessary to add that the unnatural custom of infanticide is unknown to the Andamanese, ${ }^{1}$ and though the mortality among infants is excessive, ${ }^{2}$ it is traceable to no want of affection, but to the injudicious treatment and lavish attentions bestowed upon the little ones by their ignorant though well-intentioned elders. ${ }^{3}$

10. For the better security of their babies, when travelling, women are in the habit of hanging round their necks a string the ends of which have been previously fastened to the infant's wrists; the child being then placed in a $\operatorname{ch} \bar{p} p-{ }^{4}$ cannot by any accident meet with a serious fall.

Attire.-1. Madame de Staël speaks of certain children being "vêtu du climat:" the same expressive remark may be applied to the Andamanese, for no clothing, as we understand the word, is worn by either sex; there are, however, certain so-called ornamental circlets, garters, bracelets, cinctures, and necklaces of bones, ${ }^{5}$ wood, or shell, which are its substitute ${ }^{6}$ and serve to

1 The birth of a girl is usually as gratifying to the parents as that of a boy.

2 Vide ante "Reproduction," paragraph 4.

3 Dr. Day has correctly stated that "men and women seem equally fond of carrying the babies about; all pet them; when they cry for anything, they give it ; and over-kindness early consigns the little one to the grave."

${ }_{4}$ Vide Appendix B, item 24.

5 As far as we at present know, the jär awa- do not wear necklaces of bone, or the skulls of their deceased relatives. The males of this tribe wear round their heads, waists, knees, and arms, fringes of string attached to a cord or cane,

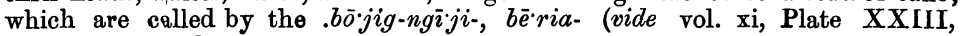
figs. 13, $13 a, 13 b$.

6 The relatives of a deceased person will commonly wear such of the ormaments as are in good condition, "in memoriam"; this is not, however, a distinguishing peculiarity, or one confined to savages. 
remove in some measure the impression that they are naked; ${ }^{1}$ these appendages are not worn as symbols of rank or (if we except the rōgun-) of status, and their manufacture devolves always upon the females of the community.

2. When fully attired ${ }^{2}$ the men are seen with peculiar shredded bunches of Pandanus leaves attached to their knees and wrists (termed $t a-\operatorname{ch} \hat{\sigma}^{\circ} n g a$ - and tô.go-chôn $n g \alpha$-), and a folded Pandanus leaf round their heads (called $i j \cdot i-g \overline{0} \cdot n g a_{-}{ }^{3}$ ), which, as well as the belt $\left(b \bar{o} d-^{4}\right)$, is common to both sexes; if, however, they (i.e. the men) were denuded of one and all, they would be in no way distressed, and in point of fact, often, as while hunting, when perfect freedom of action is needed, they strip themselves of all except the $b \bar{o} d-$, or other still lighter cincture, in which are inserted any portable objects, such as arrows and knives, that might be required at a moment's notice during the chase.

3. It is otherwise with women, who never ${ }^{5}$ appear without an $\bar{o} \cdot$ bunga $-{ }^{6}{ }^{6}$ or small apron of leaves, which is kept in position by the lowest $b \bar{o} d-$; while men are usually content with one $b \bar{o} d-$ women almost invariably wear four or five, and have'been seen with as many as eight round their waists : in addition to the $\bar{o} \cdot$ bung $\alpha$ - and $b \bar{o} d$-s married women ${ }^{7}$ wear the ro $\cdot$ gun-.

4. It seems probable that Colonel Colebrooke's remarks on the want of decency shown by the Andamanese women referred to the $. y \bar{e} \cdot r e w a-,^{8}$ or to the tribe we now know as $. j a ̈ r \cdot a w a-{ }^{9}$ for they alone answer to his description in going about perfectly nude : all my experience tends to prove that the females of the tribes of South Andaman are strikingly modest; indeed so particular are they

1 As bas been remarked by Peschel of other black-skinned races, their "dark colour almost removes the impression of nudity."

2 All ornaments are made by women, whether for themselves or their relatives. Sometimes at a "jeg-" (vide Games and Amusements) females exchange their girdles $(b \bar{o} d-\mathrm{s})$ and necklaces as keepsakes.

3 They wear no head covering, but carry a large leaf screen (kâa pa-jâtuga-) as a protection against sun and rain.

4 For a complete list of personal ornaments, vide Appendix B, items 25 to 43 .

5 "Nudity prevails among both sexes of the Australians, the Andaman Islanders, sundry tribes on the White Nile, the Red Negroes of the Soudan, and the Bushmen, all of which tribes have as yet no sense of shame" (Peschel, p. 173).

6 A description of these cinctures, aprons, \&c., will be found at Appendix B, items 25 to 43.

7 During pregnancy loose $b \bar{o} d$-s (bōd-lâr-gō'rob-) are worn by women in lieu of the ordinary kind, which are tight fitting; the ró ${ }^{*}$ gun- is also discarded when it becomes inconvenient: after the birth of the child both these cinctures are resumed, the former being fastened as tightly as possible for several days.

8 Vide Appendix B, item 79 and footnote.

9 The järava - women have hitherto been seen with only armlets and cinctures of string, to which a few short fibres were attached, obviously only for ornamental purposes. 
in this respect, that they will not remove or replace their $\bar{o} \cdot b_{\text {ung }} \mathrm{-}^{1}$ in the presence of any person, even though of their own sex. ${ }^{2}$

Tattooing.-1. With regard to the practice of tattooing, ${ }^{3}$ - so general among the eight tribes ${ }^{4}$ of Great Andaman, and which, as Peschel remarks, "is only another substitute for raiment,"-it has been erroneously asserted that its object is to "harden the skin against the stings of mosquitoes, sandflies, \&c., and also for jungle travelling;" but so far from any such benefit being derived therefrom the aborigines aver that the skin becomes more sensitive after undergoing the ordeal, which is considered, primarily, as ornamental, and secondly, as proving the courage of the individual, and his (or her) power of enduring pain.

2. There are no special ceremonies connected with the operation, which, except in the northern tribes, is almost invariably performed by women, who, however, receive no remuneration, but rest satisfied with the honour of being considered competent to fulfil the task; all the sex are not equally skilled, and therefore, those who have gained distinction by former successes are, it may be said, the recognised practitioners, though no special status, or profit, in a material sense, is gained thereby.

3. Very few children ${ }^{5}$ of either sex are allowed to remain untattooed after about the eighth year, and the final operation is often not attempted until the sixteenth or eighteenth year, the process being carried on gradually during the intervening period. ${ }^{6}$

4. The instrument used on these occasions is a flake of quartz, or, now-a-days, glass, ${ }^{7}$ which is not "inserted in a stick," but held between the forefinger and thumb; the markings are found chiefly on the back, shoulders, nape of the neck, chest,

1 The $\bar{o} \cdot b u n g a-$ is first worn by girls when they are about five or six years of age.

${ }_{2}$ Vide ante "Psychology and Morals," paragraph 8, and footnote.

3 The legend explaining its supposed origin has been given in Part II. (vide "Mythology," paragraph 26).

${ }^{4}$ So far as our present knowledge enables us to say, the jär awa- do not tattoo or shave themselves (vide "Tribal 1)istribution," paragraph 2).

5 Eren in the homes the practice is still observed, and one strong-minded youth, . $\bar{\imath} \cdot r a-j o$ do-, who has hitherto declined to undergo the operation, which he has ventured to stigmatise as unnecessary, has earned for himself the (to them) unenviable designation of " $a b-l \bar{u} \cdot t a-$," $i . e$. , the " untattooed."

6 The arms are generally the first part tattooed, and this is accomplished prior to the probationary period; the back is ornamented during the cuntiruance of the fast, and the chest, belly, legs, \&c., subsequently. Sometimes an $\hat{a} \cdot k \hat{a}-k \hat{a} \cdot d a k a-$, i.e., a youth about 11-12, requests that he may be tattooed on his back and on the nape of his neck before attaining the usual age; such a request from a lad is considered manly, and indeed almost heroic, for ordinarily the painful operation is postponed until some years later.

7 Vide post "Stone Implements," paragraphs 6 and 7. 
sides, abdomen, and also on the upper part of the feet and back of the hands.

5. Cicatrices are often observed on the persons of both sexes, but these are due to scarification $\left(t \bar{u} \cdot p k e^{1}\right)$, or some accidental circumstance whereby the cut has been obliterated, or has failed to heal in the same manner as the others forming the design. ${ }^{2}$

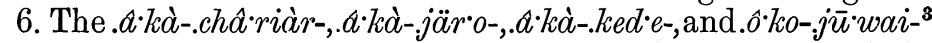
are most given to tattooing their persons, and may be specially distinguished by three rows of cuts down the back and chest: these latter marks are ordinarily much fainter than the former. Though women do the greater part of this work, the three lines down the back are almost exclusively made by some male friend with the $\bar{e} \cdot l a-{ }^{4}$ or pig arrow; except the three lines in front, the women of these tribes have no special marks, but are covered, like the females of South Andaman, with small raised cuts, which are inflicted by their own sex, with the ordinary glass or quartz flake, and not with the $\bar{e} \cdot l a-$.

7. The $. \hat{a} k \hat{k} d-k \hat{o} l$ - differ from the four tribes just mentioned, only in that they omit the centre row of the three down the back.

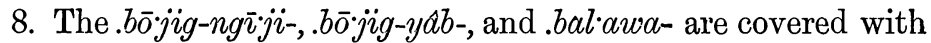
plain tattooing consisting merely of perpendicular and horizontal incisions all over ${ }^{5}$ the person, thus :

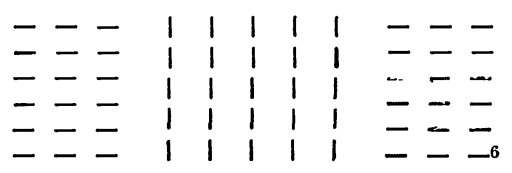

9. There is no distinction made in the mode of tattooing a chief's child and the other children of the tribe; the marks have no special significance, being merely regarded as ornamental;

1 Vide ante "Medicine," paragraphs 5, 6, 12, 16 and 17.

2 They are not raised by producing "proud" flesh.

3 Among these tribes the first and most severe operation consists in making the three rows down the back; during the time the wounds take to heal, the patient abstains from pork, in the belief that his recovery will thus be expedited.

4 Vide Appendix B, item 5.

5 The special poss. pron. denoting the various parts of the body are also used, in connection with tattooing, to express the particular limb or member to which reference is intended; thus :-

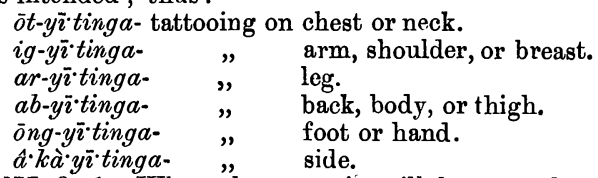

6 Vide Plate VIII, fig 1 . Where," however, it will be seen that they do not quite attain to the regularity in marking here represented by the printing press. 
no coloured pigments or other preparations are rubbed into the wounds, which are left to heal of themselves: before leaving this subject I would mention that the face is never tattooed.

Painting.-1. Besides the permanent tattooing decorations, these savages employ three kinds of pigments for the further adornment of their dusky persons ; and from the mode of their application it can be at once ascertained whether the individual be sick, or sorry, or whether he has taken, or is about to take, part in a merry-making.

2. No distinction with regard to rank or sex is made in the designs executed, yet, though these are not very numerous, no two jersous are ordinarily painted exactly in the same way, as the pattern traced may be in one case on the chest, in another on the arm, in a third on the face, and so on ; a temporary restriction is, however, laid upon the unmarried, who are not permitted to use the paint to their necks, either by way of ornament, or to relieve their pains. ${ }^{1}$

3. We have seen that according to their traditions ${ }^{2}$ this was one of the arts in which Püluga-instructed their first parents, and though temporarily lost after the Deluge it was revived by the accidental re-discovery of the necessary pigments: it might, therefore, be reasonably inferred that the practice is a very ancient one among these tribes.

4. The materials used are $\bar{o} g$-, $t a \cdot l a-\bar{o} g$-, and $k \grave{o} i \cdot o b-$, which are applied, respectively, as a wash and in designs, more or less minute, with the nail or the tips of the fingers.

5. The first ( $\bar{o} g$-), is a pale "olive-coloured" clay, ${ }^{3}$ which is mixed with water and smeared thickly over the entire person with the palms of the hand, to denote mourning ; ${ }^{4}$ a lump of the same compound (del:a-) is also placed on the head at these times: hence the term $a \cdot k \dot{d}-\bar{o} g-$, a mourner.

6. After eating pork or turtle they are also in the habit of smearing $\bar{o} g$ - over their bodies with their fingers, in the belief that it affects their breath, and that evil spirits will be unable to detect, and therefore will not be attracted to, them by the savoury smell of the food of which they have partaken. Again, when heated by travelling, or by hunting or dancing, they have recourse to the same wash, but in these cases it is applied thinly. ${ }^{5}$

1 Vide ante "Medicine," paragraph 2.

2 Vide ante "Mythology," paragraphs 9 and 27.

3 "I may remark that the natives far West . . . . when mourning for the dead, paint the whole of the body of a white or yellow colour; while in the East of New Guinea the natives for a similar event paint themselves with black" (vide paper by Signor S. M. D'Albertis : "Travels in New Guinea," Journ. Anthrop. Inst., vol. vi., p. 215.)

4 Vide ante " Death and Burial," paragraph 2.

$5 \mathcal{I}^{\prime}$ de "Anatomy and Physiology," paragraph 5. 
7. $t a \cdot l a \cdot \bar{o} g$ - is a pure white clay, which, being comparatively scarce, is more prized than $\bar{o} g$-, and consequently more sparingly used; it is applied ornamentally, usually with the nail of the forefinger, in fine tattoo-like patterns, to the cheeks, body, and limbs; the designs are invariably executed by women, who, when adorning their relatives ${ }^{1}$ for a jeg-or other festivity, ${ }^{2}$ vie with one another, both as regards the variety and the neatness of their work.

8. kòi ob-consists of burnt yellow ochre mixed with the melted fat of the pig, turtle, iguana, or dugong, and occasionally with oil obtained from a species of almond called $\bar{e} \cdot m e j-;$ this unguent is much used ${ }^{3}$ in decorating both the living and the dead $^{4}$ and is also employed as a remedy in certain forms of suffering $;{ }^{5}$ but it is never applied to the person when in mourning, or, as has been so often asserted, in order to protect the body from the stings of insects. ${ }^{6}$

9. Both $t a \cdot l a-\bar{o} g$ - and $k \grave{o} i-o b$ - are used to adorn their weapons and various utensils, \&c., in daily use.

10. With kòi $\circ b-$, of course, no delicate patterns can be worked, but rough zig-zags and stripes are made with the finger tips all over the body: judging from the appearance of a person who had been shortly before painted with kòi $\circ b-$, one might easily suppose that the unguent had been smeared over his person, but this is not the case, for it is always applied in some sort of design, which, however, is speedily effaced, as the heat of the body causes the oleaginous pigment to liquify.

shaving:- 1 . Under an earlier section ${ }^{7}$ shaving was necessarily, to a great extent, included; it remains, however, to be here added that it is commenced at a very early age: indeed, within a few hours of its birth the Andamanese baby has its head shaved and painted with $k o i^{\circ} \circ b_{-},{ }^{8}$ while its diminutive face and body are adorned with a design in $t \hat{\alpha} \cdot l a-\bar{o} g-:^{9}$ this latter, as may

1 These substances are not employed with a view of improving the texture of the skin; they never stain their nails or apply cosmetics to their eyes to increase their lustre.

${ }_{2}$ Though $t \hat{a} \cdot l a-\bar{o} g$ - is never used by mourners on their own persons it is always applied, as is kòi $o b$-, to a corpse before it is interred (vide ante "Death and Burial," paragraph 3 ).

3 The jär awa-are believed to use kòi $\cdot a b$ - only for the ornamentation of their implements and weapons.

Fide ante "Death and Burial," paragraphs 3 and 8.

5 Vide ante "Medicine," paragraph 2.

6 It may, however, be said to be used also as a perfume, for it is often applied to the upper lip after a feast on pork or turtle, as the odour of the unguent at such times is apparently particularly agreeable to them. This act of painting

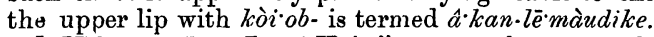

7 Vide ante Part I: "Hair," paragraphs 2, 3, and 5.

8 Tride ante " Puirting," paragraph 7.

9 Vide ante "Painting," paragraph 6. 
be supposed, is soon obliterated, and requires therefore to be constantly renewed.

2. Only in very exceptional cases, when the services of a woman are not obtainable, will men consent to operate upon one another, for among these savages shaving is regarded as essentially a feminine occupation $:^{1}$ the instrument used for this purpose is effective, if rude, and consists merely of a flake of quartz, or now more generally of glass; the manner in which these primitive razors are made is described under "Stone Implements."

3. Previous to shaving an infant, the mother usually moistens the head with milk which she presses from her breast, but when operating upon bigger children and adults, water only is used.

Deformations. - 1 . Unless tattooing can be so regarded these savages do not intentionally produce any deformities, or practice artificial deformations in any way. ${ }^{3}$ No attempt is made to alter the shape of the nose by Hattening or pinching it, nor is the cartilaginous septum ever perforated for the purpose of inserting ornamental bars or rings.

2. In this, as in many other respects, the Andamanese differ greatly from their neighbours, the Nicobarese, who not only flatten the occiputs of their children in infancy, but, from the period of puberty, blacken their teeth, ${ }^{4}$ and perforate the lobes of their ears to such an extent as to enable them, by the time they are full grown, to insert a wooden cylindrical instrument three-quarters of an inch thick.

3. There is, however, a deformity of the skull observable in most Andamanese women, but it is caused unintentionally, and arises from the practice, to which allusion has already been made, ${ }^{5}$ of placing the cane or cord by which a load is borne across the anterior portion of the cranium: this habit, especially when commenced at an early age, cannot fail to produce a more or less deep indentation. ${ }^{6}$

1 Vide ante "Social Relations," paragraph 3.

2 Vide post "Stone Implements," paragraph 4.

3 Mutilation, such as the amputation of a part, or whole, of the fingers, which is practised among certain African tribes, is quite unknown to this race, as are also the customs of circumcision and castration.

4 "Men and women use so large a quantity of betel-nut lime and betelleaves that their teeth are as black as ink, and the space between them being filled with that matter they appear as a solid piece, much like the horn inserted in the jaws of the tortoise " (vide "Notice of the Nicobar Islands," by the Rev. P. Barbe).

5 Vide ante "Physical Powers and Senses," paragraph 2.

6 So strongly marked is the deformation in most cases, that the late Dr. J. Barnard Davis, being unaware of its true cause, in a letter to me on the subject, wrote as follows :- "The skull shows unmistakably that she has been subjected to the same barbarous treatment which the women among Australians have to submit to: every Australian woman's skull that I have 
weights and Measures. -1 . When speaking of their physical powers I stated that $40 \mathrm{lbs}$. is ordinarily the maximum of a man's burden; but this is, of course, only an approximate estimate, for among these savages there is no recognised standard of weights or measures, corresponding to the nail, finger-joint, thurrb, span, or pace.

2. In referring to the size, shape, or weight of a small object, they would, if possible, liken it to some seed, such as that of the Entada pursoetha, or fruit, such as mangosteen, jack-fruit, or cocoanut; of larger weights they would say, "as much as" or " more than one man could carry" or "lift"; for expressing capacity or quantity they would say " a bucketful," "basketful," "handful," " canoe-load," as the case might be.

3. There is no prescribed or uniform size for any mat, tool, weapon, or utensil, the dimensions of each and all being dependent on the will of the maker, and on the material at his disposal.

4. No tallies are kept of numbers of articles, nor are counters such as seeds, stones, \&c., employed in counting.

5. In speaking of a short distance, as, for example, 50 yards, they would compare it to "a bowshot," but in describing the distance of a certain spot it would be defined as equal to that separating two places, well known to the speaker and the person addressed; any distance over 15 miles would be said to " exceed a day's journey."

Astronomy. - 1. It has been stated by Dr. Day that the Andamanese "divide the day into three portions, sunrise, mid-day, and sunset, recognising no subdivisions"; this is, however, incorrect, for though they are naturally content with a, to us, rough method of reckoning time, there are no less than thirteen periods of the day and night distinguished by definite terms, viz. :-

$w \alpha$ ngala-, the first appearance of dawn.

$e l a-w \hat{a} n g a-$, between dawn and sunrise.

$b \bar{o} \cdot d o-l a-d \bar{o} \cdot a t i n g a-$, sunrise. ${ }^{1}$

$l \bar{\imath} \cdot l i-$, or $d \bar{r} \cdot l m a-$, from sunrise to about 7 a.m.

$b \bar{o} \cdot d o-l a-k \hat{a} \cdot g a l n g a-$,

$b \bar{o} \cdot d o-l a-k \hat{a} \cdot g n g a-$, or $\}$ forenoon.

$b \bar{o} \cdot d o-c h \hat{a} \cdot n a g-$,

bō'do-chàu-, noon.

met with has borne ineffaceable marks of injuries from which the living woman has suffered during her lifetime. And this is clearly the fate of the Mincopie woman also."

1 Although they are aware of the variation in the sun's position at the same hour at different seasons they do not take the fact into consideration. 


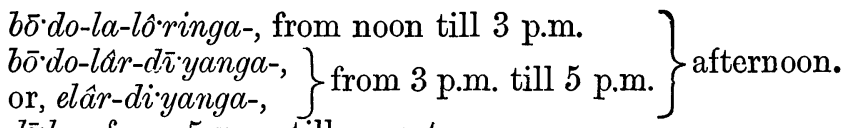

$d \bar{r} \cdot l a-$, from 5 p.m. till sunset.

$b \bar{o} \cdot d o-l a-l \hat{o} \cdot t i n g \alpha-$, sunset.

elâk kà-dàu'ya-, twilight.

elâr-yītinga-, after dark till midnight.

gü'rug-chàu-, midnight.

2. Of the property of the sun-dial they possess no knowledge, nor can they indicate short intervals of time, such as fractions of an hour, save by some such vague term as-"wait a little" (tốlaba!), "it will soon be finished" (kan'ya!), "it is close at hand" (wai lag'iba!).

3. As they have no method of numeration, it of course follows that they are unable to denote the number of lunations occurring during a solar year, which with them consists of three main

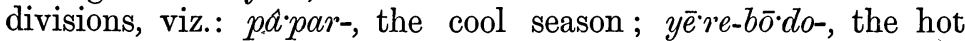
season; and $g \bar{u} \cdot m u l-$, the rainy season. These again are subdivided into twenty minor ${ }^{1}$ seasons, named, for the most part, after various trees which, flowering at successive periods, afford the necessary sources of supply to the honey bees that are so numerous in these islands.

4. They have distinct terms for indicating the four phases of each lunation, i.e.:

$\bar{o} \cdot g a r-d \bar{e} \cdot r e k a-y a b \bar{a} \cdot-$, new moon (lit., moon-baby-sma!l);

$\bar{o} \cdot$ gar-chânnag-, first quarter (lit., moon-big);

$\bar{o} \cdot$ gar-chdu-, full moon (lit., moon-body);

$\bar{o} \cdot g a r-k \bar{\imath} \cdot n a b$-, last quarter (lit., moon-thin);

and that they further recognise the influence of this luminary upon the tides may be gathered from their words denoting high and low tide at full and new moon, viz.:

$\bar{o}$ gar-ka.la-, ${ }^{2}$ high tide at the springs at full moon.

$y \bar{e} \cdot c h a r-k \alpha \cdot l \alpha-,{ }^{3}$ high tide at the springs at new moon.

$\bar{o} \cdot$ gar-pad $d i-{ }^{4},{ }_{1}$ low tide at the springs at full moon.

ye्echar-padil-, low tide at the springs at new moon.

tarbo'rong-k $\alpha^{-} \cdot l \alpha$-, flood tide at full and new moon (in the evening) from 3 to 9 p.m.

$g \bar{u} \cdot m u l-k \hat{x} \cdot l a$-, flood tide at full and new moon (in the morning) from 3 to 9 a.m.

$e l \cdot a-b \bar{u} \cdot n g a-$, or $k \hat{a} \cdot l a-b \bar{u} \cdot n g a-$, flood tide.

1 Vide Appendix $\mathrm{H}$.

2 Lit., moon-tide.

3 Lit., dark-tide.

${ }^{4} p \hat{a} \cdot d i$ does not apparently occur alone, or in connection with any other word : its meaning may, therefore, be inferred from the context.

VOL. XII 
$e l \cdot a-\bar{e} \cdot r n g a-$, or $k \hat{a} \cdot l a-\bar{e} \cdot r n g a-$, ebb tide.

nô.ro-, neap tide.

tô.ya-, ${ }^{1}$ low tide at daybreak.

5. The four cardinal points of the compass are distinguished; the names indicating these are not derived from prevalent winds, but, as far as the east and west are concerned, have reference to the sun, the word for the former signifying " the appearing face place" (elârmü'gu-), and for the latter "the disappearing face place" (tôr-mügu-); the term for south is the "separate place" (el-iglä-), while the meaning and derivation of that denoting north (elâr-jan'a-) is unknown to the present inhabitants.

6. For the winds, too, they have distinctive names, viz.:

chall-jōtama-, north-west wind.

$P \bar{u} \cdot l u g a-t \hat{t}$-, north-east wind (lit., "The Creator His wind"). $d \bar{e} \cdot r i a-$, south-west wind.

$\operatorname{ch} \bar{\imath} \cdot l a-t \hat{a}-$, south-east wind.

Of these the second ( $P \bar{u} \cdot l u g a-t \hat{a}-)$ only, now-a-days, possesses any special significance; it is called "The Creator's (or God's) wind," because it proceeds from that part of heaven where the connecting bridge ${ }^{2}$ between this world and the next is supposed to be situated.

7. They identify three forms of clouds, and indicate them thus :

tô'wia-, cumulus.

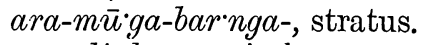

$y \bar{u} m-l i-d \bar{r} \cdot y a-$, nimbus.

8. Of all the stars and constellations Orion's belt alone is found to bear a name (bélla-), but this is not to be wondered at, as they never venture upon any distant voyages, and do not therefore experience any necessity for studying the bearing of the various planets and constellations at different seasons, or for distinguishing them by name. Their astronomical observations have, however, extended to the discovery of the milky way, which they call $i g-y \bar{o} \cdot l o w \alpha^{-3}$, and poetically describe as the road used by the angels (môtrowin-). ${ }^{4}$

Trade, Exchangeable values and Property. -1 . It is evident, from the accounts of various writers, that for many years prior to our present occupation, these islands were visited by trading vessels manned by Malays, Burmese, and Chinese, who were said to traffic with the Andamanese for edible birds'-nests and bêche de

1 Vide post " Hunting," paragraph 39 (footnote).

2 Vide ante "Religious Beliefs," \&.., paragraph 25.

3 The Chippeways call the milky way "the path of the ghosts" (vide "Travels in the Interior of North America," by Maximulian, Prince of Wied).

4 Vide ante " Religious Beliefs," \&c., paragraph 9. 
$m e r ;$ but it seems more than probable that they obtained their supplies without any assistance from the aborigines ; their visits were, moreover, in later years attended with considerable risk, owing to the malpractices of some of the traders in kidnapping such of the race as they could entice on board their vessels, for the purpose of carrying them away into captivity.

2. Even at the present day, with the exception of procuring turtles, shells, honey, bows, arrows, and a few other articles which are sold, for their own benefit, by the inmates of the homes in and near the harbour, to visitors and residents at Port Blair, the natives attempt nothing in the way of trade, and this much is only done by dint of constant inducements being offered in the shape of presents of tobacco, files, \&c. ${ }^{2}$

3. Of our imports they prize chiefly:- - dogs, iron, bottles, tobacco, pipes, and matches, all of which have for many years past been freely distributed among the coast people throughout Great Andaman, by whose means they have, doubtless, either by barter or in the form of presents, reached many of the communities inhabiting the interior. ${ }^{3}$

4. In respect to barter, in their transactions with each other, some weapon, utensil, or other common article, such as $k o ̀ i \cdot o b$-, or $t a \cdot l a-\bar{o} g{ }^{-4}$ (used for painting their persons and for general decorative purposes), serves as the medium of exchange.

1 Captain J. H. Miller, in a communication to the Nautical Magazine, 1842, says: "The islands in the west side of the Andumans are frequented during the fine season, from December to A pril, by a mixed and mongrel race of Malays, Chinese, and Burmese fishermen for bếche de mer and edible birds'-nests, who are of very doubtful honesty; and it is necessary to take a few muskets and cutlasses, just to show them that you are prepared for mischief in case of need. These fellows are also 'fishers of men,' and to their evil deeds much of the hostility of the islanders may be attıibuted; they carry off children, for whom they find a ready market as slaves in the neiuhbouring countries. I have been told that for merly they were friendly, and assisted these fishermen, until a large party was invited on board a junk or prow (the Chinese got the blame of it), and after being intoxicated, were curried off and sold at Acheen; and the practice is still carried on by these fellows, who land and carry them off whenever they can catch them. The Andamanians have retaliated fearfully whenever any foreigner has fallen into their power, and who can blane them?" (Sailing Directions for the principal ports in the Bay of Bengal, by W. H. Ros: er and J. F. Imray).

"Formerly, both Malays and Burmese procured at the Andamans a considerable quantity of these nests : collecting them themsclves, or receiving them from the irlanders in exchange for their tobacco, \&c." ("Notice of the Nicobar Islands," by the Rev. P. Barbe).

2 Spiritous liquors would serve as the most powerfui medium in this respect, but, in view of the certain and great mischief which would result from gratifying their innate liking for alcohol, it has been rarely given and then only in small quantities medicinully, or by a few persons who are indifferent or ignorunt as to its ill effects.

3 Vide Part 1.

4 Vide Appendix B, items 60 and 58.

5 Vide ante" Painting," paragraphs 7, 8, 9, and 10. 
5. They set no fixed value on their various properties, and rarely make or procure anything with the express object of disposing of it in barter. Apparently they prefer to regard their transactions as presentations, for their mode of negociating is to give such objects as are desired by another in the hope of receiving in return something for which they have expressed a wish, it being tacitly understood that, unless otherwise mentioned beforehand, no " present" is to be accepted without an equivalent being rendered.

6 . The natural consequence of this system is that most of the quarrels which so frequently occur among them originate in failure on the part of the recipient in making such a return as had been confidently expected. ${ }^{1}$

7. All iron-pointed weapons, tools, or shell ornaments are eagerly accepted by the $\bar{e} \cdot r e m-t \hat{a} \cdot g a$ - in exchange for such things as are more easily procured by them than by the àryôto-: ${ }^{2}$ for instance, an adze would generally be considered worth two ordinary bows, or a bundle of wooden-pointed arrows ; or a man might undertake to make a canoe or bucket for one who would give him an adze.

8. But little care is taken of the utensils, weapons, canoes, \&c., in daily use, and consequently new ones are otten required, the old, when no longer serviceable, being thrown aside; as all their possessions consist of goods which need to be more or less frequently replaced, it is hardly necessary to explain that there is no accumulation of the labours of former generations; hence also it arises that they are not tied by any laws of inheritance; more as a matter of sentiment than for any other reason, the nearest of kin takes possession of all the effects left by a deceased person, and as often as not they are distributed ere long among such friends as may be in need of any of the articles in question.

9. The weapons, tools, and other property pertaining to one member of a family are regarded as available for the use of his or her relatives, but such articles as a cooking-pot, canoe, or sounding-board, when not required by the owner, are looked uporn somewhat in the light of public property by members of the same community; in short, the rights of private property are only so far recognised that no one would without permission appropriate or remove to a distance anything belonging to a friend or neighbour.

Agriculture. - 1. Before the arrival of strangers in their midst,

1 Vide post " Games and Amusements," paragraph 37.

2 Further mention of this will be made at "Games and Amusements." paragraph 24. As will there be explained the occasions on which they usually barter are when they meet for a jeg- at some permanent encampment. 
the Andamanese were entirely ignorant of agriculture, and to this circumstance is primarily to be attributed their degraded condition, while it also affords evidence of the same.

2. Notwithstanding the ample opportunities that they have now had of observing the benefits derived from cultivation, and though they undoubtedly prefer such products to the spontaneous vegetation of their jungles, they still consider that the exertion necessary to obtain the former far outweighs every advantage; in short, it is their opinion, that "le jeu ne vaut pas la chaindelle."

3. We must not, however, lose sight of the fact that, as they have hitherto seen only prisoners engaged in tillage, they cannot but be strengthened in the objections entertained by most savages to all such labour, regarding it as a degrading occupation, and fit only for such as have forfeited their freedom.

4. Further, to quote from Peschel, " it must be remembered that hunting affords supreme enjoyment, and that agriculture has nothing to offer in compensation for the excitement and delights of the chase."

Training and Domestication of Animals. - 1. Prior also to our occupation of these islands, the Andamanese, as will have been already inferred, ${ }^{1}$ possessed no dogs, and it was some time (1865) before they became aware of their usefulness in the chase; but now that the intelligence of certain breeds has been proved, they prize them highly, and eagerly accept any we have to give them; at the same time, though treated with every intentional kindness, and allowed to sleep, and even to eat and drink out of the same vessel as their masters, the training to which the dogs are subjected is very severe, and their attenuated condition bears witness to the state of semi-starvation in which they are commonly kept in order to render them the more keen in hunting. The custom of summoning dogs by whistling has of course been borrowed from ourselves, as is also the practice of naming them; "Jack" or "Billy" are the names generally bestowed by these people upon their canine companions, whom also they address as lig*ala (children), and who in their turn seem greatly attached to their new owners, and tescify their affection by attacking all strangers, not being aborigines, who approach the encampment to which they belong.

2. It is regarded as a good omen to meet certain birds, while of others the contrary belief is held $;^{3}$ the absence of migratory

1 Vide ante "Trade, Exchangeable Values," \&c., paragraph 3.

2 They sometimes nickname them as follows:- $b \bar{\imath} \cdot b i-b \hat{a} \cdot r a t n g a-$ (lit., dog-

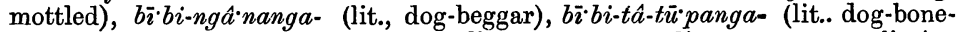

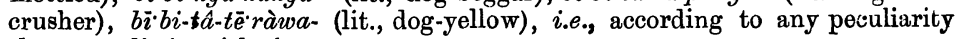
that may distinguish them.

3 Vide ante "Superstitions," paragraph 22. 
species at certain seasons is now accounted for by saying that they are visiting some of the adjacent isles.

3. Of mythological animals, ${ }^{1}$ such as dragons and unicorns, they have no knowledge, nor do they venerate or regard as sacred any quadruped, bird, ${ }^{2}$ or fish, even though the names of several are identical with those borne, according to tradition, by their antediluvian ancestors, ${ }^{3}$ who are supposed to have been transformed into, or to have assumed the forms of, such creatures. Beyond the instances already mentioned, no trace can be found of a belief in transmigration, and, now-a-days at all events, the souls of animals and men are not considered by these savages as interchangeable.

4. The names of four animals only appear to have originated in their cries, viz.: $d \bar{u} \cdot k u$-iguana, mü rud- pigeon, $b \bar{v} \cdot b i-$ dog, $r \bar{o} \cdot g o-$ pig ; of these the dog only is trained, or in any way domesticated, and they do not, as has been supposed, keep poultry.

Food.-1. Among the many erroneous statements regarding the life and habits of these islanders, none seem at the present day so devoid of foundation as that which declared that they are constantly reduced to want and even to starvation. ${ }^{5}$

2. It has been conjectured by some writers that these savages "glean a miserable subsistence," judging, it would seem, merely from the fact of their eating the larvæ of beetles, ${ }^{6}$ and certain other articles, the predilection for which seems, to civilised palates, equally revolting $;^{7}$ but evidence is not wanting to disprove this assumption, for during the season, when such things are obtainable, they may frequently be seen enjoying a handful of cooked larvæ when a quantity of pork or turtle is lying beside them, and, if questioned, they declare that they regard the former as dainties ( $\hat{a} \cdot k \hat{d}-r \hat{a} \cdot r n g a-)$, and eat them as

1 The legend regarding the $\bar{u} \cdot \operatorname{ch} u$ - can hardly be included in this category ( $v$ de ante " Mythology," paragraph 29).

2 Vide ante "Mythology," paragraph 16 (footnote).

3 Vide ante "Mythology," paragraph 29 (footnote 2).

4 "They have no dogs nor any domestic animals, unless indeed their poultry may be regarded as such " (Lubbock, "Prehistoric Times," 4t h edition, p. 450). 5 "In tempestuous weather they are reduced to the utmost want, feeding on rats, lizards, and snakes, and perishing when these resources fail "'(Grant).

"In the jungles, beyond a few berries and the wild hog, there was no food to be found" (de Röepstorff).

6 The Looshais, however, appear to be even less fastidious, for they are said to " eat everything that flies, runs, crawls, or creeps, as well as the grub in its ante-natal tomb" ("On the Looshais or Kookees," vide "Journ. Anthrop. Inst.," March, 1873).

7 "Nor are civilised Europeans justified in shuddering . . . . when they themselves do not shrink from the trail of snipe, nor from lobster and crayfish, although the latter, as water scavengers, act both as grave-digger and grave" (vide Peschel, p. 159). 
such, not because they find any difficulty in procuring other food. ${ }^{1}$

3. Both àryô to- and $\bar{e} \cdot r e m-t a \cdot g \alpha$ - find ample ${ }^{2}$ provisions for their simple wants in their immediate surroundings, without exerting themselves to any great extent, and their eagerness in the chase is induced almost as much by actual love of sport as by the necessity of obtaining food: were this not the case they would hardly be found spending so much time in dancing and singing, in personal decorations, and in the preparation of their meals, while they reject with aversion anything that has become at all tainted. Further, it may be fairly estimated that one-third of the food daily consumed by them consists of edible roots, fruits, and honey, and the remaining portion of the flesh of one or more of the following, viz. : pig, paradoxurus, ${ }^{3}$ iguana, turtle, fish, and molluscs, with rare additions of pigeons and jungle fowls ; Flying-foxes, bats, rats, sea- (not land-) snakes, the larvæ of the Great Capricornis beetle (Cerambyx heros) called òi $y u m-,{ }^{5}$ as well as two other insects, called $b \bar{u} \cdot t u$ - and $p \bar{\imath} \cdot r i g i-{ }^{6}$ are, it is true, also eaten, but they are partaken of by way of variety, and the latter are regarded as luxuries $(\alpha \cdot k \dot{d}-r \cdot d \cdot r n g \alpha$-, tid-bits) to supplement (not substitute) other fare. ${ }^{7}$

4. The Andamanese are nominally content with two meals a day, viz.: breakfast $(\alpha \cdot k \dot{a}-n d \cdot-)$ and a heavy supper ( $(\dot{k} k a n-$ $g \bar{o} \cdot$ lajnga-) after sun-down; they will, however, often help themselves to small quantities of food from time to time in the course of the day when engaged on any work ; and, when leaving on a

1 " It cannot be wondered at that these savages love the unfettered life of their own wild jungles, where their simple wants are easily supplied-a lean-to serving them for quarters, and food such as they are accustomed to being found in great abundance. Nothing comes amiss to an Andamanese maw; roots, wild fruits, berries, crabs, clams, fish, wild pigs, and turtle are all ravenously devoured, and a glance at the well-nourished bodies of men, women, and children amply convinces one that they do not starve" (vide "Bombay Gazette," 2nd August, 1881 : "The Andamans, our Indian Penal Settlement"; vide also paper by Professor Owen, F.R.S., "On the Psychical and Physical Characteristics of the Mincopies," Report of British Association, 1861, p. 246.)

2 Vide "Tribal Communities," paragraph 2, and Appendix F. (W'o $\cdot$ 's statement).

${ }^{3}$ It is presumed that Dr. Day refers to this animal when he states that " they eat cats," for they do not appear ever to have had any fancy for the flesh of $p \bar{u} \cdot c h \bar{\imath}$, the name they have adopted for the domestic cat, from the English "pussy."

4 Vide "Tabu," paragraph 2 (footnote).

5 Probably the "fat grub, about three or four inches long, much relished by the natives" (Australians), mentioned by Mr. H. W. Bates, in his "Illustrated Travels," is identical with the òi yum.

6 The $b \bar{u} \cdot t u$ - is found in rotten logs of jungle trees, especially the Dipterocarpus laevis (ấrain-), Gluta longipetiolata ( $j \hat{a}-)$, and Chickrassia tabularis $(\hat{o} \cdot r o-)$.

7 Their fancy for grubs does not extend to the Teredo navalis. 
day's hunt, they usually provide themselves with some fire and a $g \bar{o} b_{-}{ }^{1}$ of food, which they warm up and enjoy about midday : ${ }^{2}$ no difference is made between the sexes, but all fare alike.

5. The average amount eaten by an Andamanese adult appears to exceed that of a native of India, and to average three or four pounds daily, while, like many other savages, after a successful hunt, or on some special occasion, when dancing is carried on through the entire night, ${ }^{3}$ the consumption of food is surprising, and has, in some instances, been estimated at upwards of ten pounds of pork, or turtle, in the twenty-four hours, helped out by mouthfuls of some one or more of the delicacies above ellumerated. ${ }^{4}$

6. As may be assumed from foregoing sections, caste distinctions are unknown; while, however, all members of a family take their meals together, a married man is only permitted to eat with other Benedicts and bachelors, but never with any women save those of his own household, unless indeed he be well advanced in years. Bachelors as well as spinsters are required to take their meals apart with those of their respective sexes.

7. Their mode of eating meat is to cram a large piece into the mouth, and then to cut off whatever is in excess ${ }^{5}$ with a bamboo or cane (now-a-days generally a steel) knife. The same custom, carried to a more disgusting extreme, is found among the Esquimaux. ${ }^{6}$ Speaking generally of the Andamanese it may be said that water is their only beverage, for though the aborigines in the vicinity of Port Blair have acquired a strong liking for rum, \&c., they have not been permitted to gratify it; if very thirsty while on a fishing expedition, and all the fresh water supply be exhausted ${ }^{7}$ the àryô.to- pour water over their

1 Vide Appendix B, item 82.

2 This applies to the meat of the turtle, pig, iguana, and paradoxurus; the remains of a feast of fish, shell-fish, and prawns are not warmed up a second time; a further distinction is made in the case of turtle's eggs, the three insects mentioned in paragraph 3 , edible roots, and such fruits as are cooked (vide post paragraph 19), for these are left to cool before they are eaten.

3 Vide "Games and Amusements," paragraphs 21 and 22.

4 Bêche de mer and edible birds'-nests, so highly esteemed by some, and of which large supplies are obtainable along their coasts, are not regarded by the Andamanese as fit for food.

5 For the following note, which refers to a similar practice among the NapoIndians of South America, I am indebted to Mr. W. L. Distant :- " In eating meat (usually monkey, sea-cow, and peccari) we observed that they did not tear or bite it, but, putting one end of a long piece in the mouth, cut off what they could not get in, as Darwin noticed among the Fuegians" (Jas. Orton : "Andes and the Amazon," p. 168).

6 Vide Lubbock's "Prehistoric Times," p. 486.

7 They will now-a-days occasionally assuage their thirst, when away from home, by cutting off a piece of ground rattan $(b \bar{o} l-)$; this practice is only known to the people of South Andaman, and has been borrowed from the Burmese convicts. 
heads or jump overboard, and even at times try to alleviate their sufferings by swallowing salt water. ${ }^{1}$

8. In opening certain shell-fish ${ }^{2}$ the adze is not employed, but one of the valves of the Cyrena is dexterously inserted between the lips, which are thus forced apart, after which the fish is killed with a knife or bladed arrow, and boiled; the Tridacna crocea and Tridacna squamosa are opened by inserting a piece of wood as a wedge between the valves, ${ }^{3}$ afterwards the fish is despatched by stabbing it with an arrow point or blade; the various Arca species and the Mytilus smaragdinus are, however, not so treated, but are placed among a heap of burning logs for a few moments, the object being merely to part the valves, which would otherwise be a matter of some difficulty : when this is accomplished the shells are removed by means of the bamboo tongs $\left(k^{2} i^{-}\right)$, and their half-cooked contents are transferred to a pot $^{5}(b \bar{u} j-)$ in which a little water has been placed; after being boiled a short time the gravy and flesh are eaten with the help of the shells. In former times oysters were eaten cooked, ${ }^{6}$ but now their consumption appears to be confined to the inhabitants of North (and possibly also Little) Andaman : they give no reason for this change, but it may be due to their having occasionally suffered by feasting unconsciously on the poisonous, or at least indigestible, variety so commonly found in the mangrove swamps.

9. Dr. Day remarked that the mullet was their favourite fish, and "one day, having placed a quantity of different species before them, they helped themselves in the following order : . . . Chorinemus, Platycephalus, horse-mackerel or Caranx, Chrysophrys calamara, and lastly Tetrodon or frog-fish, which latter has generally the credit of being poisonous." My experience is that there are apparently no fresh-water, and but few salt-water, fish ${ }^{7}$ which they will not eat.

10. It is a mistake to suppose that pigs are ever scarce in these islands, for though it was formerly more difficult than at the present day to shoot them, there is no lack of evidence to

1 Vide ante "Medicine," paragraph 4.

2 Viz., those of the Pinna and Cyrera species.

3 This is only attempted when they succeed in surprising the fish before it has time to close its valves.

4 Vide Appendix B, item 80.

5 Vide Appendix B, item 18. [Note.-Water is boiled in a $b u \bar{u}$ - by the ordinary process, and not by heated stones being dropped into it.]

6 That Europeans should swallow these molluses raw is a matter of considerable surprise to them.

7 They prefer the fleshy part of the head to any other portion. To cut up a fish is termed chô.lke, while to remove its head, tail, and entrails is styled arwấgke. 
prove that they are, and always have been, fairly numerous. ${ }^{1}$ The pig hunts are most frequent during the rains, not only because these animals are then more plentiful and in better condition, but because it is no longer the $r a p$ - $w a b$-, or season of abundance of jungle fruit and honey; from this, however, it must not be inferred that scarcity is then experienced, for those who choose to help themselves need never be in want.

11. During the cool season, $p \hat{a} \cdot p a r-w a b-{ }^{2}$ the people themselves are alleged to become noticeably thinner: this they attribute not to a deficiency of food, but to the meagre condition of the pigs, which are then breeding, and to the fact that the edible roots (or yams), and other fruits then in season are not fattening. There are six varieties of esculent roots, viz.: the $g \bar{o} \cdot n o-$, cha $\cdot t i-, k a d-,{ }^{3} b \bar{o} \cdot t o-$, mal $a g-$, and $t \ddot{a} g \cdot i-$, which are eaten alone (preferably cold), and not with meat; their chief difference consists in the extra care in preparation which some require, in consequence of their very acrid flavour.

12. The $g \bar{o}^{\circ}$ no- is cooked in three ways: $(\alpha)$ it is placed on the fire in the condition in which it is found until it is soft, when it is freed from the burnt earth and eaten; $(b)$ the root, after being washed, is cut up into small pieces and boiled in a pot; and (c) after being washed and cut up the pieces are wrapped in large leaves and baked on burning logs.

13. The chat ti-is cooked in the first of the above-mentioned methods, or by surrounding it with hot stones, ${ }^{4}$ and covering the whole with leaves and weights, in order to confine the heat as much as possible.

14. The $k \hat{a} d$-is first cooked as found, the skin is then peeled off, and a number of thin slices are cut and placed in water for a couple of days, so as to lessen the bitterness of its flavour; afterwards it is either baked in leaves or boiled, as already described in speaking of the $g \bar{o}^{\cdot}$ no-.

15. The other three varieties are never boiled, but are placed on the fire without leaves, and the onter skin is removed before they are eaten.

16. The seed of a species of sea-weed, known to them as tônotòng-, on which turtles and dugongs feed, and which can only be obtained in small quantities, is carefully cooked and eaten as a relish.

1 In his examination of a kitchen-midden near Port Blair harbour, the late Dr. Stoliczka recorded that " the large number of bones of the Andaman pig is remarkable."

2 This is the period between the rains and the dry season, and lasts about ten weeks, between the middle of November and the middle of February.

3 go $\bar{o}^{*} n o-, c h \hat{a} \cdot t i-, k \hat{a} d-$, are very plentiful during the cool season, and are much relished.

4 Vide post "Stone Implements," paragraph 1. 
17. The fruit of three varieties of mangrove, ${ }^{1}$ known to them as $j \bar{u} \cdot m u-,{ }^{2}$ ngâtya-, and bâtaga-, are occasionally eaten, but only by way of change; they are prepared like the $k \hat{a} d$-(vide above).

18. The following table contains a fairly complete list of the different kinds of food eaten by the Andamanese during the varying seasons of the year; their ordinary diet, as will be gathered from the foregoing, consists of pigs, ${ }^{3}$ paradoxurus, iguanas, ${ }^{4}$ eggs of the hawkbill turtle, turtles, shell and other sea-fish and prawns, with occasional treats of dugong and porpoise, ${ }^{5}$ and for married persons certain birds, already named: the fruit of the Pandanus and black honey must also be added, besides which, during the dry season, fresh-water fish, shell-fish, eggs of the green turtle, honey, the bee-bread, and that portion of the comb in which the larvæ are found, as well as the Caryota sobolifera, yams and numerous fruits, about to be named, are eaten with great relish; while during the rains they vary their fare with preserved seeds of the Artocarpus chaplasha, Semecarpus," and the fallen seeds of the Entada pursotha, ${ }^{7}$ with three grubs, viz.: the $b \bar{u} \cdot t u-, p \bar{\imath} \cdot r i g i-$, and the larvæ of the Great Capricornis beetle (ò $i y u m-$ ), and certain fruits. Although on one occasion I saw a man (a member of the $. \hat{\alpha} \cdot k \dot{a}-. k e d \cdot e-$ tribe) actually eat an $\partial i$ yum- alive (!) their usual practice is to collest a quantity of the above-named insects and to wrap them up in leaves and place them on the burning embers, turning the bundle from time to time, so that its contents may be thoroughly cooked, whereupon, in the case of the $b \bar{u} \cdot t u$-, after breaking off the tails, they are consumed with evident gusto. ${ }^{8}$

19. The native names ${ }^{9}$ of most of the fruits in season during the dry $(a)$, wet and cool $(b)$ months are:-

1 Some terrible calamity, such as another Deluge, would result, so they say, from any one rashly presuming to taste the fruit of a certain species of mangrove, called tồ kal-.

2 Bruquiera gymnorhiza.

3 Not only are the sows eaten when with young, but even their unborn litter is not rejected.

${ }_{4}$ Iguanas and paradoxuri are in better condition during the rains, and are conse quently more eaten at that season.

5 There are special restrictions connected with eating either the dugong or porpoise for the first time (vide post "Tabu," paragraph 2).

${ }^{6}$ Vide paragraph 32.

7 Vide ante "Religious Peliefs," \&c., paragraph 12.

8 The oiyum- is found in newly fallen logs, and they say that they do not treat it like the $b \bar{u} \cdot t u-,-$ viz., in breaking off its tail-because it does not live in such rotten Gurjon trees.

9 The botanical names of most of these, as well as of many others, will be found in Appendix L. 


\begin{tabular}{|c|c|c|}
\hline $\begin{array}{l}* \pm m a ́ n g- \\
* \pm \bar{\imath} \cdot t i l-\end{array}$ & $\begin{array}{l}(a)_{1} \\
\text { either } \\
\text { cooked } \\
\text { or un- } \\
\text { cooked. }\end{array}$ & $\begin{array}{l}\S p \bar{u} \cdot l a i n- \\
* p \bar{\imath} \cdot d g a- \\
\S g e l \cdot d i m- \\
\text { *ốrta-tät- }\end{array}$ \\
\hline 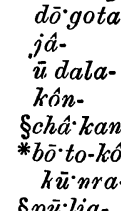 & ko- & 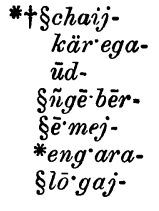 \\
\hline
\end{tabular}

(N.B.-The best fruits, and those which are most abundant, are in season during these months and at the commencement of the rains.) (b)

$$
\begin{aligned}
& \text { †ốropa- } \\
& \S p \hat{a}- \\
& \text { *tkai- } \\
& +\S k a i \cdot t a- \\
& \text { †chôb- } \\
& \text { †ódorma- } \\
& \text { *âbnga- } \\
& \S\left\{\begin{array}{l}
j \bar{u} \cdot m u- \\
n g \hat{a} \cdot t y a
\end{array}\right. \\
& \text { bâtaga- } \\
& \text { *kấpa- }
\end{aligned}
$$

During the pâar-wâb- (cool season) and $y \bar{e} \cdot r e-b \bar{o} \cdot d o-(\mathrm{d} r y$ months) the six varieties of edible roots mentioned above (vide paragraph 11) are also eaten.

(It will be understood that those fruits that are unmarked in the above list are eaten in the ordinary way).

20. Many fruits they merely suck for the sake of the flavour $;^{3}$ others are eaten with fine wood ash, ${ }^{4}$ taken from the hut fires in lieu of sugar, to diminish their extreme acidity, ${ }^{5}$ while a few are cooked, ${ }^{6}$ and the stones of several ${ }^{7}$ are cracked for the sake of their kernels. The favourite fruits are dio gota-, ôtropa-, kôn-, chôb-, ja-, pâ-, kaita-, kär'ega-, chàkan-, jü·mu-, ngâtya-, bàtaga-, $\tilde{n} g \bar{e} \cdot b \bar{e} r-$, püllia-, and pülain-.

21. The fruit of the $\tilde{n} g \bar{e} \cdot b \bar{e} r-, c h \hat{a} \cdot k a n-, p \bar{u} \cdot l i a-$, pülain-, pai:tla-, gel'dim-, lo'gaj-, and the seeds of the three above-named varieties of mangrove (i.e., jū'mu-, ngatya-, and battaga-), are freed from their husk or rind and boiled in water until quite soft; when cold they are cut in slices, and left to soak for two days or more in salt or fresh water, after which they are baked in leaves, or again boiled in a $b \bar{u} j$-.

22. The Andamanese are, now-a-days at least, ${ }^{8}$ extremely particular over the cooking of their food, and will not eat certain

1 This is a small yellow fruit, the seed of which, after being sucked, is broken, and the outer portion eaten while the kernel is thrown away.

2 This is a small red fruit, about the size of a bean or filbert, containing one stone ; it is wrapped in leaves and baked, because they say that if eaten uncooked it would cause them to forget their way in the jungle, as well as entire loss of memory on all points.

3 These are marked in the preceding paragraph by $a *$.

4 Their immunity from scurvy may not improbably be due to the chemical combination of the acid, contained in many of the fruits, with the potash of the burnt wood.

5 These are marked in the preceding paragraph by a $\dagger$.

6 These are marked in the preceding paragraph by a $\S$.

7 These are marked in the preceding paragraph by a $\ddagger$.

8 They are very expert in spearing their fish, which thev consume in a halfcooked state (Anderson) ; Symes also writes that " they throw the food on the fire, and devour it half broiled." 
fruits and vegetables, much less fish, flesh, or fowl that is raw, ${ }^{1}$ or, as far as I could ascertain, even underdone. ${ }^{2}$

23. On ordinary occasions the meals are prepared by these estimable wives in the absence of their lords, but when their labours in procuring wood and water are exceptionally heavy, as on gala days, or after a very successful hunt, the cooking is performed in the special fire-place ${ }^{3}$ set apart for the purpose in each community, by some male volunteer, who, when the meat is partly done, distributes ${ }^{4}$ it among those present, leaving them to complete over their own fires the necessary preparation of their several shares. ${ }^{5}$

24. Sometimes it happens that the animal is cut up and distributed without being even partially cooked, but the person undertaking this duty is under a tacit obligation to help the slayer of the animal and himself to the last two portions.

25. Small pigs, if caught alive, are sometimes kept and fattened up (chìlyuke) for slaughter $;^{6}$ with these, as with others killed while hunting, the same system is observed: the entrails, lungs, liver, kidneys, \&c., are first removed (jö.do-lòichrake), and replaced by leaves $(k \bar{o} \cdot k t a r-r a \cdot m k e)$, to which they set fire-care is always taken to select such as, being entirely free from scent and taste, will not affect the flavour of the meat-the object of this is that all parts may be equally heated when the carcass is placed on the burning logs, where it is left, not until thoroughly

1 A recent writer (vide "Bombay Gazette," May 24, June 7, July 1, July 5, August 2, 1881), in giving an instance of the skill of these savages in shooting fish, affirms that he observed "that most of these fish were just scorched on hastily-lit fires and devoured at once half raw, care being taken that the chlldren present (there were no women) had their full share of the spoils." I am, nevertheless, sure that he is mistaken in supposing that the fish were otherwise than thoroughly cooked, for besides having made close observations myself at the liomes, on the point in question, I have made careful inquiries of the aborigines, who assure me (as do also the Hindustani attendants, who have paid numerous visits to the tribes in Middle Andaman) that they never eat fish, flesh, or vegetable until it is thoroughly cooked.

2 Exception, however, must be made in regard to turtles' eggs, which are eaten with other food or alone, as the case may be, and which, though preferred soft boiled, are sometimes eaten raw : they are among the articles of food proscribed to an $\hat{a} \cdot k \hat{a}-y \hat{a} b-$. Dr. Day says he has :een them "cook a prawn by placing it inside the bowl of a pipe which they had been smoling!"

${ }_{3}$ This is generally an open space at one end of the encampment. [The .jär awa- have a separate hut, which is used exclusively for cooking purposes.]

"The "cook" is under an obligation to taste a morsel before all present; should the chief happen to be there he receives the first and lion's share; after him all the men are helped, and then the women and children, while the remainder falls to the share of the distributor.

5 During the process of cooking all that the Andamanese Soyer requires in the way of impedimenta are a skewer, châm, and a pair of bamboo tongs, kai. (vide Appendix $\mathrm{B}$, iterns 70 and 80 )

${ }_{6}^{6}$ If the pig should die a natural death while being thus kept it would be eaten, unless visibly diseased. 
cooked, but until the bristles have been singed and the skin dried sufficiently to allow of the dirt adhering to it being scraped off; this done, the remains of the charred leaves are removed, and the tendons at the joints being severed (pünuke), the carcass is cut up (wäratke) and distributed; while thus engaged, the operator not unfrequently helps himself to choice morsels which he may chance to find done to a turn, as his perquisite. The lining and flesh of the stomach are usually first disposed of ; the skin of the entrails, after being thoroughly cleansed, is also frequently consumed.

26. From the account given under "Initiatory Ceremonies" it will be seen that the kidney-fat and omentum (reg-jic $v i-)$ are considered as luxuries from which the young of both sexes must abstain during a certain period. The lungs, liver, and eyes are also eaten, and they are quite of a mind with the Chinese in their estimation of "crackling" which they consider one of the choicest parts, and enjoy so much that they are even willing to run the risk of offending the chôl- ${ }^{4}$ by baking their pigs, rather than eat them boiled.

27. When, from some circumstance or other-such as possibly a death from sunstroke ${ }^{5}$ - the dread of these demons is paramount, and they boil their pork, it has been observed that, as their pots are small, they remove each piece when partially cooked to make room for others, which afterwards, in the same way, are in turn replaced until thoroughly done; the reason given is that the flavour of the whole animal is thus equally distributed in every portion. On other occasions, when the pig is not broiled whole on burning logs, or apportioned among the several families of the community for cooking in their own huts, the flesh is baked in leaves by means of heated stones (la-), which are placed between alternate layers of the meat; in every case the chief concern appears to be that the whole should be so wrapped in leaves that none of the juices be dried up, though every portion be thoroughly well done. ${ }^{6}$

1 Experience and inquiries have alike failed to find an explanation of the following peculiar statement made by Dr. Day :- "The children and weakly persons eat sucklings, the bachelors and spinsters use those of medium size, whilst adults prefer the stronger boar."

2 Tide paragraphs 15-17.

3 The skin of the iguana is also eaten, but that of the paradoxurus is thrown away.

4 Vide ante "Religious Beliefs," \&c., paragraph 15.

5 Vide ante "Religious Beliefs," \&c., paragraph 16.

${ }^{6}$ In this respect they differ much from the Australians, who "never take the trouble to cook their food, but merely tear off the interior skin of the animal, and, after holding the body over the fire for a few minutes, eagerly devour it in it s uncleaned state, and frequently eat so voraciously as to be in a state of inactivity and torpor for several hours afterwards" ("A Ride across the Frontier of Victoria," by P. H. Eagle). 
28. For brains and marrow they have a great penchant, and, in order to extract the latter, will often crush the smaller bones with their teeth, while they break up the larger ones with a stone hammer.

29. The blood of the turtle only are they careful not to spill, ${ }^{1}$ and this, though not preferred to the flesh, is considered a dainty, and is eaten separately, after it has been boiled in its own shell until quite thick.

30. They do not preserve the carapace of either description of turtle, but, having removed the flesh, place the shell over the fire, that all the remaining fat may be melted, when-with an appreciation worthy of a City alderman-they ladle it into their mouths with Cyrena shells, which thus serve as spoons. So great a delicacy do they consider this that the shell is finally broken up and divided, that no particle may be lost! This fat is largely used in the manufacture of $k o i^{\circ} \circ b-$, and it may be judged how highly they prize the unguent since they are willing to deny themselves this dainty rather than allow their supply to run short.

31. Food is preserved by placing it on the small grating (yat-leb-t $\hat{a}-g a-)^{2}$ above the hut fire, ${ }^{3}$ or in the following rather peculiar fashion:-having procured and cleaned a length of bamboo (fem. sp.), they heat it over a fire that the juices contained in it may be gradually absorbed. When this is satisfactorily accomplished, half-cooked pieces of pork, turtle, or any other food, ${ }^{4}$ are packed tightly into it, and the vessel is again by degrees put over the fire, in order to heat it slowly, lest the rapid expansion of the meat should cause a crack; when steam ceases to issue forth, the bamboo is taken off the fire, and, after the opening has been closed by leaves, is set aside with its contents until a meal is required, when it is replaced on a fire, for, as I have remarked in another place, it is a peculiarity of these savages to eat their food in an almóst boiling state. $^{5}$ As soon as the meat has been once more thoroughly baked, the bamboo is split open with an adze or other

1 To kill a turtle they pierce the eye with a skewer or arrow ( $\bar{i}^{\cdot} d a l, j \bar{e}^{\cdot}$ ralike); when the flappers and belly-shell are removed (tốlatke), the animal is cut up (wâkratke) prior to distribution.

2 Vide "Habitations," paragraph 5.

3 Jean de Lery, in the acccunt of his adventures among the Indians of Brazil (about 1557), describes the "wooden grating set up on four forked posts ; . . . and as they did not salt their meat this process served them as a means of keeping their game and fish."--(E. B. 'Tylor's " Early History of Mankind," p. 262.)

* They have not acquired a liking for either beef or inutton, but are very fond of fowls, rice, dhall, sugar, and sweets of all kinds; it is strange, therefore, to find in Colonel Tickell's paper that "fish they were indifferent to, also to rice."

5 Vide ante "Anatomy and Physiology," paragraph 8. 
implement, and all take a share in the feast. ${ }^{1}$ Meat thus prepared will keep good for several days.

32. I alluded just now to their method of preparing the seeds of the Semecarpus and Artocarpus chaplasha for consumption during the rains; it is as follows:-The outer husk, or skin, having been removed, a quantity of the fruit is placed on a wooden platter, and each person present renders assistance by partially sucking (!) the various pieces, which, after this preliminary process, are half boiled in water, and then wrapped up in large bundles of leaves, and buried in moist soil; no mark is made over the spot, but there appears to be no fear of forgetting it, though several weeks usually elapse before the monsoon breaks, and these decaying deposits are dug up, when the smell, as may be supposed, is most offensive to all but those who are to the manner born; by them, however, strange to relate, it is evidently highly appreciated. The next stage through which the seeds have to pass consists in freeing them in water from the decaying matter, and drying them in the sun, or over the fire, where they are left in nets $\left(\right.$ ch $\left.\hat{\alpha} \cdot p a n g a_{-}{ }^{2}\right)$ or leaves until required for use, when they are again baked. With this exception no food is dried in the sun, nor is anything salted or intentionally smoked, though this last cannot fail to be, to some extent, the result of their mode of storing food, as described in the previous paragraph.

33. Besides the various fruits already mentioned as in season during the dry months, yams and honey are very abundant; as their method of treating both fruits and yams has been already described, it now remains for me to notice the ingenious way in which they procure boney, and to name the special trees which, flowering in succession, afford ample material from whence the bees produce a more or less abundant store.

34. At the close of the monsoon one of the large jungle trees, called by them râr- (Eugenia sp.), comes into bloom, and though no honey is made from its flowers, it is said to act beneficially on the bees as a purgative, and to prepare them for the commencement of the honey season. ${ }^{3}$ The $\bar{l} \cdot k e r a-(L e g u-$ minosa sp.), blossoming a little later, is the first honeyyielding flower; the $d \bar{u} \cdot m l a-,{ }^{4}$ ch $\bar{\imath} \cdot l i b$ - (? Diospyros densiflora), óro- (Chickrassia tabularis), and chaddak-(Rubiaceos) coming next into season, enable the bees to produce large combs, but the finest are found after the $p \hat{a}$ - (Semecarpus), $b \hat{a} \cdot j a-$

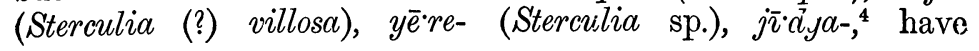

1 Vide post "Hunting and Fishing," paragraphs 30 and 31.

2 Vide Appendix B, item 22.

3 Hence rấrke, (to) clean.

4 The botanical names of these have not as yet been ascertained. 
blossomed: this is considered the height of the honey season, and is called lad $a$ chàu- ${ }^{1} \quad$ It appears that on moonlight nights just at this time the bees consume a great portion of their honey, so that the " junglees" declare it to be useless to go for combs, either by day or night, until the moon has sensibly waned.

35. When about to make a raid on the hives, the Andamanese procure a certain plant, believed to be of the Alpinia species, called $j \bar{\imath}^{\circ} n i$-, and having stripped off the leaves, chew the stem and smear the essence thus extracted over their bodies; the mouth is also filled with the same juice, and thus armed cap-a-pie they proceed to disperse the bees, who, on attempting to attack them, are at once repelled by the obnoxious odour of the $j \bar{\imath} \cdot n i$-, emitted in a fine spray from the mouths, and also attaching to the persons of their despoilers, who sometimes make further use of the chewed stalks of the offensive plant in driving off the last remaining defenders of the hive.

36. Small combs ${ }^{2}$ of both the white and black honey are commonly obtainable till about September-i.e., so long as the Dipterocarpus loevis, the Pterocarpus dalbergioides, and a few other trees continue to blossom. ${ }^{3}$

37. While I had charge of the homes (and probably ever since), a large sum was annually realised by the aborigines towards their support from the sale of honey thus obtained to the free residents at Port Blair. So much indeed did they collect that we were able to store it in barrals and bottles, and generally found we had sufficient to meet all demands until the approach of the following season.

Tabu. - 1. Besides the articles of food from which all abstain during the $a \cdot k \dot{d}-y \hat{a} p-{ }^{4}$ we have seen that there are certain fruits, edible roots, \&c., which, in supposed obedience to $P \bar{u} \cdot l u g a-' s$ commands, are not gathered at prescribed seasons of the year, ${ }^{5}$ and that mourners ${ }^{6}(\hat{a} \cdot k \hat{\alpha}-\bar{o} g-)$ also deny themselves by refusing

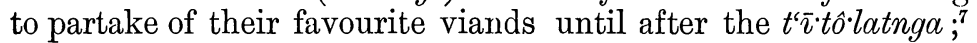
but beyond these restrictions, which are of general application,

1 Vide Appendix $\mathrm{H}$.

2 The combs produced from the blossoms of the under-mentioned trees-i.e.; .tâ'tib-(Croton argyratus), .bì bi- (Terminalia (?) citrina), and .bal'ya- are much less plentiful, and they are smaller ; this is also found to be the case with those made from the .challanga- (Pterocarpus dalbergioides), .mô'nag-(Messuaferrea), .è'mej- (Terminalia bialata), jâ- (Gluta longipetiolata), and .pâp- (Lagerstromia hypolenca (?) regina).

3 As they are not, in their savage state, in the habit of storing honey they are without any but the black honey during a great portion of the year.

4 Vide ante "Initiatory Ceremonies," paragraphs 2 and 10.

5 Vide ante "Superstitions," paragraph 12.

6 If the mourners are $\bar{e} \cdot r e m-t \hat{a} \cdot g a-$ they abstain from pork, and if they are àryốto- they abjure turtle (vide ante "Death and Burial," paragraph 4).

7 Vide ante "Death and Burial," paragraph 7.

VOL. XII. 
every Andamanese man and woman is prohibited all through life from eating some one (or more) fish or animal: in most cases the forbidden dainty is one which in childhood was observed (or imagined) by the mother to occasion some functional derangement; when of an age to understand it the circumstance is explained, and cause and effect being clearly demonstrated, the individual in question thenceforth considers that particular meat his yat-t $\bar{u} b-{ }^{1}$, and avoids it carefully. In cases where no evil consequences have resulted from partaking of any kind of food, the fortunate person is privileged to select his own $y a t t-t \bar{u} b-{ }^{2}$ and is of course shrewd enough to decide upon some fish, such as shark or skate, which is little relished, and to abstain from which consequently entails no exercise of selfdenial.

2. No one who has not attained the dignity of $g u \cdot m a,{ }^{3}$ by passing through the rites of initiation, is permitted to eat the flesh of either the dugong or porpoise; and further, it is necessary that the novice should be fed, on the first occasion of tasting either of these meats, by some friend or relative, who, having previously passed through the prescribed ordeal, is qualified thereby to admit others to the like privilege.

3. Except during the initiatory ceremonies, no prohibitions exist with regard to persons feeding themselves, or touching the food of others; after marriage the husband and wife only may eat together $; \mathbf{4}$ childless widows and widowers usually take their meals with the unmarried of their respective sexes. ${ }^{5}$

4. When an Andamanese woman finds that she is about to become a mother she abstains from pork, turtle, honey, ${ }^{6}$ iguana, and paradoxurus; after a while her husband follows her example with respect to the two last-named meats, in the belief that the embryo would suffer were he to indulge in such food. ${ }^{7}$

${ }^{1} t \bar{u} b$ - can only be applied to food, and is therefore not so generally applicable as $t a b u$ among the Polynesians. The equivalent of $y a t-t \bar{u} b$ - in the .bo $\dot{0} \cdot j i g-y a \hat{a} b$ dialect is $t \ddot{a} m^{\circ} a-t \ddot{a} p$-.

${ }^{2}$ It is believed that Püluga- would punish severely any person who might be guilty of eating his yatt-tūb-, either by causing his skin to peel off (wai'nyake), or by turning his hair white and flaying him alive!

3 Vide ante "Initiatory Ceremonies," paragraphs 1 and 9.

4 The few birds that are ever shot for food (vide post "Hunting," \&c., paragraph 27), are said to be, strictly speaking, tabued to all but married persons.

5 Vide ante " Marriage," paragraphs 17 and 18.

6 Vide ante "Initiatory Ceremonies," paragraph 14.

7 Among the Abipones, if the infant dies during the first few days, the women accuse the father of heartless frivolity, as their excesses or abstinence are believed to affect the new-born infant. A gain, Peschel states that in the Antilles, the father who is expecting offspring might not eat the flesh of the turtle or the manatee, for in the first case deafness and deficiency of brain and in the second disfigurement by small round eyes, might be apprehended for the child. 
5. When a man wishes to address a married woman who is younger than himself he may not venture to do so directly, but must find some third person to be the medium of his communication; it is also not selon les règles for a man to touch his younger brother's (or cousin's) wife, or his wife's sister ; and women are restricted in the same, way as regards their husband's elder brother (or male cousin) or his brother-in-law.

6. All titles such as mai $a$, mai ola, and $c h \ddot{a} n^{\cdot} a$ cease to be applied after death; and inquiries ignorantly made after one who has recently died are replied to in a subdued tone, thus : wai ed̄̄re (he or she "was") or wai ö.koli.re (he or she "is dead"). As little allusion as possible is ever made to deceased persons, especially for the first year or so after their death, during which period they are indicated only by reference to the tree or place where their remains are, or were, deposited; after a while the word lach i, answering to "the late," is prefixed to their defunct countrymen's (and women's) names. ${ }^{1}$

Warfare.-1. Reference has already been made to their want of true courage or daring, and it has been stated that the Andamanese seldom, if ever, venture to make an attack unless satisfied of their superiority over their foes $;^{2}$ it will, therefore, be hardly necessary to enlarge upon their mode of carrying on hostilities, or to say that they are ignorant of the most elementary rules of warfare.

2. Should a dispute arise between members of different communities in the course of a visit or $j g_{-}{ }^{3}$ the affair often grows in importance and becomes a tribal question, which may not be settled without more or less serious consequences; those wounded on such occasions generally fare badly unless speedily removed, as.they stand great risk of being shot dead or receiving the coup de grace in some other form; they are not, however, in the habit of mutilating the bodies of their victims, save in exceptional cases, where there has been very grave aggravation.

3. The assailants generally approach stealthily upon their enemies, and, though availing themselves of every advantage afforded by the density of the jungle, do not take further precautions or devise stratagems whereby to conceal their trail as they proceed on their way. They wear no breastplate, ${ }^{4}$ nor do

1 Ex. : "múnshí" .bīela (vide Plate VIII, fig. 2), whose corpse was placed on a machán beside a tree called yel-, was spoken of as yel lâk kà-tâng len teg. $\vec{\imath}$ $y \hat{a} \cdot t e$ - (he who is by the yel- tree); had he been buried he would have been

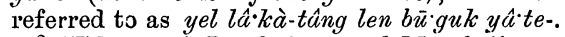

2 Viae ante "Psychology and Morals," paragraph 2.

3 Vide post "Games and Amusements," parauraphs 22-37.

4 The järawa-have been found to wear a wide belt of bark as a protection in hostile encounters. 
they use shields, ${ }^{1}$ and the idea of throwing up earth-banks, or constructing any species of defence for the better protection of their numerous encampments, does not seem to have occurred to them. ${ }^{2}$

4. Night attacks have been made now and again, but the favourite time is the break of day, when the unsuspecting enemy are sound asleep; or at a late hour when they are likely to be engaged in the preparation or consumption of their evening meal.

5. Women and children incur a like risk with men on these occasions, but it would not be considered a matter for boasting should any of them fall victims in the strife, while a child which might be captured uninjured would meet with kindly treatment, in the hope of his (or her) being induced ultimately to become a member of the captor's tribe.

6 . The property of the vanquished is of course treated with little ceremony: everything portable is appropriated, and all else is injured or destroyed.

7. No confirmatory evidence is required to prove the truth of a statement declaring a man to have slain one or more foes, but if, in hunting, he should kill at a distance from home an animal too heavy for him to carry back unassisted, he would cut off the tail or some other portion which would afford ocular demonstration of its size, and serve as an inducement to his friends to assist him in bringing in the carcass.

Hunting and Fishing.- -1 . As I stated in an earlier section, the Andamanese are, for the most part, keen huntsmen, and their eagerness in the chase is one of the chief hindrances in the way of their becoming agriculturists, for a great portion of their time being thus spent, the sites of their temporary (as of their permanent) encampments are to a great extent determined by the advantages which they offer for the pursuit of their favourite pastime.

2. There do not appear to be any omens or superstitions in this connection, nor are there special ceremonies observed previous to the start or on the return of the party, save the somewhat peculiar custom, to which I have elsewhere alluded, of maintaining a glum silence for some time at the close of the day's sport. $^{3}$

1 Their sounding or stamping boards ( $p \tilde{u} \cdot$ kuta-yem:nga-), used in their dances, have, in consequence of their resemblance to shields, been mistaken by more than one visitor as such.

2 For the weapons used in warfare ride post "Hunting," paragraph 5.

3 Vide "Journ. Anthrop. Inst.," vol. xi, p. 287. It may liere be added that the only explanation which they offer to account for this practice is that they intend thereby to convey to their friends an exaggerated notion of the fatigues they have endured for the general weal. 
3. Females take no part in these expeditions, and boys seldom accompany their elders until after their twelfth year.

4. If more than a few hours' absence is anticipated, besides a supply of provisions, a smouldering log is entrusted to some one member of the party, whose duty it is to prevent its extinction, ${ }^{1}$ and to kindle it into a blaze whenever a fire is required. No immediate honours are conferred upon the successful sportsman, but stories of feats of extraordinary prowess are related, with more or less embellishment, from time to time for the benefit of the young and the edification of strangers. No record is kept of the game killed, but, as those distant tribes who are not yet possessed of dogs (or only of a very few) still retain the primitive custom of suspending the skulls of their victims from the eaves or on poles round their huts, a fair idea of their success can be formed by themselves and others from the number thus displayed.

5. Whether in hunting game or in attacking an enemy, the bow (karama-) and arrow are employed, and these are almost ${ }^{2}$ identical in form among all the eight tribes of Great Andaman. For spearing turtles and large fish a harpoon (kowai a l'ôko $d \bar{u} \cdot n g a^{-3}$ ) is used: as a description of this serviceable weapon and of the mode in which it is employed, has been given in Appendix $\mathrm{B}$, it is unnecessary to repeat the information in this place. ${ }^{4}$ The only other weapon in use is the pig-spear

1 Vide ante "Fire," paragraph 6.

2 The comparatively slight difference existing between the form of the five .$b \bar{o} \cdot j i g$ and three $y \bar{e} \cdot r e w a-b o w s$, and the wide distinction observable between both of these and the jär'awa- (Little Andaman) bow will be best seen by referring to the "Journ. Anthrop. Inst.," vol. vii, Plate XIV, figs. 1, 4, and 3 (vide also Appendix B, item 1).

3 Vide Appendix B, item 10.

4 In reference to the subject of fish-spears an interesting discovery was made on the occasion of the last visit (October, 1882) paid by Mr. H. GodwinAusten, now in charge of the Andaman Homes, to North Andaman. Some six or more specimens of what, I believe, is quite a unique wooden fish-spear were seen in one or two of the $y \bar{e} \cdot r e w a-$ canoes. As one was fortunately brought away a sketch is here given of it. It reminds one somewhat of the fish-spears used by the Nicobarese (vide vol. vii, Plate XV), though very inferior, and is doubtless, like them, intended for spearing small fish.

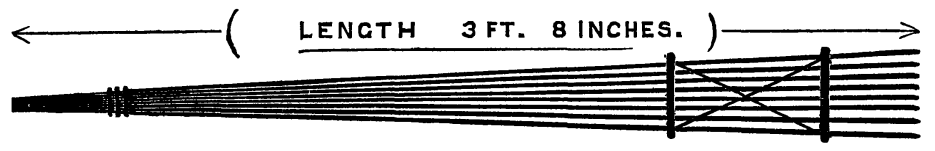

The eight long wooden spikes are not tied together in a circular form as in the case of the Nicobar hokpa $k$ but in a row, and, as will be inferred from the drawing, they are held in that position by means of twa short pieces of wood lashed to them at right angles : from the appearance of the lower end of this weapon it seems probable that it is fixed-like the kowai a $l^{6} \hat{o} \cdot k o d \bar{u} \cdot t n g a$-into a bamboo shaft when about to be hurled. 
$\left(\bar{e} r \cdot d \bar{u} \cdot t_{n} \alpha_{-}{ }^{1}\right)$, which is of comparatively recent introduction, its adoption being due to the abundance of iron obtainable for some time past by the $. \bar{b} \cdot j i g-n g \bar{\imath} \cdot j i$ - and other tribes near our settlement at Port Blair.

6. To an untrained eye no difference is noticeable in the appearance of the weapons of similar style and construction, but the aborigines are quick in detecting individual peculiarities in the manner of knotting the strings of bow's, arrows, \&c. ${ }^{2}$

7. As has been remarked by General Pitt Rivers, ${ }^{3}$ the bows of the Great Andaman tribes, especially those of the southern half, known to the islanders as the .bōjig kârama-, resemble those in use in Mallicollo, one of the New Hebrides, and in New Ireland, being of a "peculiar flattened S-shaped form, curved towards the firer in the upper part as held in the hand, and to a slight extent the reverse way at the bottom."4

8. Except in the case of boys living on or near the coast, whose toy bows are often made of the Rhizophora conjugata, the wood of the mangrove is rarely, if ever, used, and the bamboo never, ${ }^{5}$ for they find that certain other trees, ${ }^{6}$ are more suitable for their purpose.

9. No whalebone or sinews are used for the purpose of imparting additional elasticity to the bow, and no evidence is forthcoming to show that they ever applied poison to their arrow or spear-heads-in fact, the only poison known to them appears to be the $N u_{x}$ Vomica, and this they merely avoid as a noxious or useless plant.

10. It is true that certain passages in Dr. Mouat's book ${ }^{7}$ convey a contrary impression, for, from the observations made during his short trip round the islands, he seems to have entertained no doubt that these savages habitually applied poison to their arrow-heads; ; but, in the sense in which I understand his

1 Vide Appendix B, item 9.

2 For an example of this vide ante " Communications," \&c., paragraph 6 (footnote).

3 Vide "Journ. Anthrop. Inst.," vol. vii, p. 440.

4 In the ethnographical department of the museum at Maidstone, I have lately observed a bow from Banks Island (New Hebrides), which bears a striking resemblance to the commonest form of the peculiar .bo $\cdot j i g$ bow, for sketch of which see Plates VIII and IX.

5 "Their weapons are bows and lances of iron-wood. The former are bamboo. . . ." (Grant vol. ii., p. 378.) [Their spears, at least those of Great Andaman, have never yet been seen by us made of iron-wood.-E. H. M.]

6 Vide Appendix $\mathrm{B}$, item 1 .

7 Pp. 324 and 330 .

8 It may be of interest to mention in this place a curious alleged fact which has been brought to my notice by the petty officers and others connected with the homes, i.e., that the wounds which are inflicted now-a-days by the ironheaded arrows of the Andamanese are not so painful or so liable to fester as they were formerly, and this they attribute to the fact that, while it has always been the practice of these savages when sharpening their blades to 
remarks, I am persuaded that he has credited thein with more intelligence on this point than they possess.

11. The origin of the belief appears to be traceable to the fact that they generally in former times tipped their arrow-heads with fish-bones, ${ }^{1}$ more particularly the serrated tail-bone of the sting-ray, which, as is well known, is capable of inflicting a very serious wound in consequence of the liability of the fine brittle spikes to break off and remain in the flesh after the extraction of the arrow, thereby causing, in the majority of cases, bad ulcers, which, in the absence of skilful treatment, frequently resulted in the sufferer's death. ${ }^{2}$

12. The maladroitness of strangers who have failed even to bend the Andamanese bows ${ }^{3}$ has apparently been due to their having held the wrong end uppermost, for, so far from there being any difficulty in using even their strongest bows, it has been proved that after a little practice Europeans are able to compete almost on even terms with all but the few "crack" shots among the aborigines, provided at least that the object aimed at be stationary - but they less readily acquire the skill which the Andamanese display in rapid shooting, and in discharging the arrow with the full force of which it is capable.

13. The large bows (from $5 \frac{1}{2}$ to 7 feet long) are constructed chiefly for ornament and presentation to friends, and are seldom used except for shooting fish and pigs along the shore. The smaller kinds are preferred in jungle expeditions, and on most other occasions, as they are more convenient and also more easily replaced in case of accident, less time and trouble being required for their manufacture.

14. One of the chief drawbacks to the bows used by these tribes is that they cannot be fired in silence, ${ }^{4}$ in consequence

moisten them with saliva, the inmates of the homes-who are those chiefly employed as jungle police-now eat salt with their food, which was never the case fifteen or twenty years ago. Whether, assuming the story to be true, the effect can be accounted for by the circumstance stated, or, as seems more probable, is due to the improvement in the physical condition of the convicts since the early days of the settlement, is a question for medical authorities to decide.

1 Writing nearly a century ago, Colebrooke mentioned that "their arrows are headed with fish-łones, or the tusks of wild hogs; sometimes merely with a sharp bit of wood, hardened in the fire, but these are sufficiently destructive."

2 Vide footnote to Appendix B, item 53.

3 Vide Mouat, p. 321. Had Dr. Mouat's remarks applied to the Little Andaman or other järawa- bows, which are of totally different construction (vide vol. vii, Plate XIV), they would have been more readily understood, for even the aborigines of Great Andaman have experienced much difficulty in shooting with the few specimens of this weapon which have fallen into their hands ; doubtless, therefore, much knack and practice, as well as strength, are needed in using them.

${ }^{4}$ From this defect the jär awa- kow appears to be exempt, which is easily 
of the string striking the lower or convex portion of the weapon. ${ }^{1}$

15. There are five varieties of arrows, viz: the $r a \cdot t \dot{a}$-, the $t \bar{\imath} \cdot r l \bar{e} \cdot d-$, the $t \hat{o} \cdot l b \bar{o} \cdot d-$, the $\bar{e} \cdot l a-$, and the $\bar{e} \cdot l a-l a \cdot k \dot{a}-l \bar{u} \cdot p a-$-, none of which are provided with more then one point or blade.

16. 'The first of these ( $\left.r \hat{a} \cdot \hat{\alpha}_{-}-\right)$is used in their games, and is the first form which their fish arrows take; it consists of a shaft made of Bambusa nana, to the end of which is fastened a piece of hard wood, which is rendered harder and less liable to split by being gradually heated over a fire : this foreshaft also gives the necessary weight to ensure accuracy of flight, and to increase the force of penetration. The $t \bar{\imath} \cdot r l \bar{e} \cdot d$ - is merely a $r \hat{a} \cdot t \dot{\alpha}-$ with its point sharpened for use, in shooting the smaller varieties of fish. The $t \hat{o} \cdot l b \bar{o} \cdot \vec{d}$ - is a $r \hat{a} \cdot t \grave{c}$ - with an iron point, and generally a barb as well, secured to the head: it is chiefly used in fishing. The above three arrows usually measure 4 feet 6 inches to 4 feet 9 inches in length, while the remaining two, of which a sufficient description will be found in Appendix B, do not generally exceed 3 feet 6 inches.

17. The Andamanese take especial pride in keeping the bladed heads of their arrows and spears as bright as possible: the shafts are straightened by dint of pressure with teeth and fingers, but no feathers or other devices are employed to increase the velocity of flight. As illustrations of their arrows and other weapons appeared in vols. vii and xi of the Institute's Journal, and as, in Appendix B, I have described their manufacture, it is unnecessary for me here to repeat the information which can be obtained by reference.

18. There are one or two points connected with the ironbladed arrows to which, I believe, attention has never yet been drawn. I allude to the position of the barbs and the object of the seam. In the $\bar{e} \cdot l a-$ the blade is so fixed as to be in a line with the seam of the fastening at the end of the shaft, and, whether provided with one or more barbs, these are always placed in a line with the blade, the seam above referred to being used as a "sight." In the $\bar{e} \cdot l a-l ' a \cdot k d-l \bar{u} \cdot p a-$, which has no seam, the barb

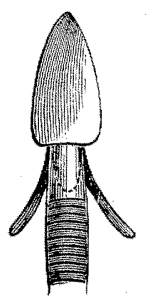
which is most in a line with the blade is used as a "sight," and accordingly placed uppermost. In forning these blades they shape them so as to allow of a small portion being inserted in the foreshaft (see fig.), and it is then fixed as firmly

accounted for by the resemblance it presents to the ordinary European pattern ; this, however, appears to be the sole advantage which it possesses over the two varieties used in Great Andaman.

1 Vide "Superstitions," paragraph 5, and "Religious Beliefs," paragraph 19, 
as possible by means of string, ${ }^{1}$ which is protected with a coating of $k \hat{\imath} \cdot n g a t a-b \bar{u} j-.^{2}$

19. It is a singular fact that the mode in which the tribes of Great Andaman discharge their arrows differs from that in vogue among the jör awa-. While the latter are said to adopt the plan usual among ourselves of holding the nock of the arrow inside the string by means of the middle joints of the fore and middle fingers and drawing the string with the same joints, it is the practice among the former to place the arrow in position between the thumb and top joint of the forefinger, and to draw the string to the mouth with the middle and third fingers. The feet are only used in stringing and unstringing the bows, and never for bending the bow in shooting, as was at one time supposed to be the practice among the jär awa-, whose long and clumsy $k \hat{d} \cdot r a m a-$ have puzzled the .bo $\cdot j i g-n g \bar{\imath} \cdot j i$-, as well as ourselves, to use with any effect.

20. In Great Andaman the waistbelt ${ }^{3}$ ( $b \bar{o} d-$ ) or other cincture often does duty as a quiver while fishing and hunting, and the arrows are placed behind, with the heads upwards, both in order to avoid causing injury or inconvenience by hindering freedom of action, and to be readily seized and brought into position for firing.

21. Their pointed arrows carry with considerable effect to a distance of 40 or 50 yards. A tôे $l b \overline{0} \cdot d$ - has been found to pierce a deal plank $1 \frac{1}{2}$ inch thick at the former range, and probably up to 100 yards one of these arrows is capable of inflicting a serious wound, but an accurate aim is scarcely possible beyond less than half that distance. In the case of the two varieties of pig-arrow much less can be attempted, as these ill-balanced, though formidable, missiles will not carry with certainty further than 12 to 15 yards, and if fired at wider ranges usually fly very wildly.

1 A better method has, however, been adopted by the jjär awa-, viz., that of making three holes in the blade, and passing through them the string which secures it to the foreshaft, thus rendering disconnection of the parts a matter of some difficulty. The precaution thus taken against loss of the blade is evidently due to the comparative scarcity of iron in their territory, which circumstance is the natural consequence of the attitude of hostility, or of avoidance of intercourse, which has been persistently maintained towards the eight Great Andaman tribes, as well as towards ourselves, by one and all of the various scattered jär awa- communities. [With reference both to this sketch and that of the.$b \bar{o} \cdot j i g \bar{e} \cdot l a$-head, in paragraph 18, it should be added that these are mere sectional

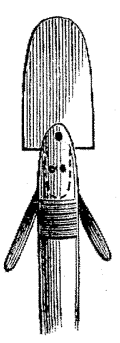
drawings of these objects. In the finished arrow the string-fastening is carried up to the base of the blade, and the whole of this string work is finally coated with $k \hat{a} \cdot n g a t \hat{a}-b \bar{u} j-$.

2 Vide Appendix $\mathrm{B}$, item 62.

3 Vide ante "Attire," paragraph 3. 
22. It is not found that they have any inclination to adopt civilised weapons or tools in lieu of their own, but they have not been slow to avail themselves of the facilities afforded them in recent years for substituting iron for shell, bone, and (?) stone, ${ }^{1}$ in the manufacture of their various implements.

23. The blow-pipe, which is used so generally by the Negritos (Semangs) of the Malayan peninsula, finds no place among the weapons of these savages. Its absence may be readily accounted for, firstly by their ignorance of poison, or at least of any method of utilising such knowledge as any of them may possess, and secondly by the fact that they are so well able to supply all their wants with the implements already referred to in the foregoing, that their inventive faculty has not been sharpened by the pangs of hunger to devise other or more effective means of destruction. It may be added that slings, throwing sticks, clubs, bird-bolts, or blunt-headed arrows for stunning animals or birds, are likewise not in use among them.

24. Although the pig is the object of their chase in their hunting expeditions, they invariably take a few of their pointed arrows, preferably the $t \hat{o} \cdot l b \bar{o} \cdot d$-, on the chance of coming across some smaller game, such as an iguana or paradoxurus. ${ }^{2}$ To facilitate rapid shooting a man will often hold a number of arrows in the hand which grasps the bow.

25. From constant practice they are, as might be supposed, very skilful at shooting fish under water. Dr. Brander has correctly observed that "they seem intuitively to have calculated with great accuracy the difference of direction to be allowed for oblique aqueous refraction"; but these shots are almost always, if not invariably, made at a distance of a few yards only, and never so far as "30 yards,"3 or "with threepronged barbed arrows," such missiles being neither made nor used, at least by any of the Great Andaman tribes. ${ }^{4}$

26 . Boys soon learn to practice at near objects with the small bows and arrows to which allusion has already been made, and many of them often contribute materially to the family larder by their early prowess. It is a common sight to see youths and children (and even their elders), when travelling, wantonly shoot at small passing objects, both on land and in the water, by way

1 Vide “Journ. Anthrop. Inst.," vol. xi, p. 271.

2 While these two animals are killed at all seasons of the year, the pig-hunts take place chiefly during the rains, when this animal is in excellent condition, and their diet, owing to the comparative scarcity of fruit and honey, less varied; even if with young the pig is not spared.

3 The well-nigh impossibility of ever seeing from the shore or from a canoe a fish swimming at such a distance would sufficiently account for this.

4 It is possible that Dr. Brander saw the single specimen of an arrow answering to this description which was obtained in 1880 from North Sentinel Island. 
of practice or to display their skill. No reproach is offered by the bystanders to one who wounds an animal without killing it.

27. Pigeons, waterfowl, ducks, and flying-foxes are sometimes shot, but never while on the wing, or when perched in such a position as to risk the recovery of the arrow.

28 . In addition to the bows and arrows, their hunting gear consists generally of a hone $\left(\operatorname{tat}_{\mathrm{lag}}{ }^{1}\right)$, a Cyrena shell $\left(\bar{u} \cdot t_{-}{ }^{2}\right)$, an adze $\left(w \bar{o}^{\cdot} \cdot l_{0-}{ }^{3}\right)$, and often now-a-days a spear $(\bar{e} r-d \bar{u} \cdot t n g a-4)$; sometimes a knife $\left(c h \hat{o}-\right.$ or $\left.k \hat{o} \cdot n o_{-}^{-}\right)$is also taken, but as the blade of the pig-arrow or spear can be made to serve this purpose, it is not regarded as an essential part of their equipment.

29. They employ no stratagems for deceiving or decoying game, nor do they prepare snares or pitfalls for it.

30 . When unaccompanied by dogs the hunters usually follow the pig's tracks, evincing while doing so their accurate knowledge of its habits. Immediately the object of their search is sighted they endeavour to surround it as noiselessly as possible-taking no precautions, however, against approaching it from windward - and, finally rushing forward and yelling vociferously, dischąrge their arrows. This practice of driving is generally adopted near the coast and in the vicinity of a belt of Rhizophora conjugata where the animals, becoming entangled among the roots or sinking into the soft soil, are easily captured or despatched. The ownership of the carcass is decided in favour of the person who inflicted the first serious wound, and he is exempt, if he please, from carrying home his prize or from any further trouble in connection with it; the cleaning, cooking, and quartering of the animal is undertaken by any one who chooses to volunteer his services, during which interval the day's adventures are narrated : those who have remained at home share equally with the hunters ${ }^{6}$ in the spoil, for they are supposed to have been engaged in contributing to the general wants of the community.

31. There are, of course, some in every encampment who, from laziness or want of skill, are of very little use in this respect, but, since any ill-natured remarks at their expense would inevitably result in a more or less serious quarrel, they are rarely twitted with the circumstance, but are permitted to partake of the feast.

1 Vide Appendix B, item 52; also post "Stone Implements," paragraph 2.

2 Vide Appendix B, item 51 ; also post "Natural Forms," \&c., paragraph 1.

3 Vide Appendix B, item 15 ; also post "Natural Forms," \&c., paragraph 2.

4 Vide Appendix B, item 9; also ante paragraph 5.

5 Vide Appendix B, item 77; also post "Natural Forms," \&c., paragraph 4.

6 On the return of the bunting party the chief is apprised of the nature and amount of the "bags"; whatever is brought in by the married men is taken to their private huts and distributed as they please, but the spoils of the bachelors are at the disposal of the chief, and are distributed according to his orders. 
32. At the conclusion of the repast, the sportsman who has most distinguished himself during a more than ordinarily successful chase is expected to entertain the company, while they dance, with an impromptu song, in the chorus of which the women join.

33. Much of the foregoing applies to the àryôto-, as well as to the $\bar{e} \cdot r e m t \hat{x} \cdot g \alpha$-, except of course that, with the former, hunting expeditions are less frequent than turtling and fishing operations.

34. Turtle-hunts take place during the flood-tide, both by day and night; the favourite hour of all is that between sunset and the rising of the waning moon, ${ }^{1}$ for then, with the aid of the phosphorescent light, called pēwo $\cdot i$-, caused by the movements of the canoe, they are often able to discover and harpoon the turtle before it is at all aware of their approach; on these occasions they select, if possible, a rocky portion of the coast, where there is little or no foreshore, giving it as their reason that turtles frequent such places on dark nights in order to lay their eggs, and are then easily captured. At other times, the localities preferred for these expeditions are those styled yàula-, where there is a fine stretch of sand with an extensive foreshore, the reason, of course, being that every dark object is so easily seen in shallow water against a clear sandy bottom.

35. The green or edible turtle (Chelonia virgata), called $y \bar{d} \cdot d \bar{\tau}-$, is hunted both by day and night, but the hawkbill (Caretta imbricata), called tàu-, only by day, as they declare the latter is never seen on dark nights. ${ }^{2}$ The flesh of the former is of course preferred, and no use being made of the tortoiseshell obtainable from the latter, it is treated after the feast with as little consideration as the valueless shell of the $y \hat{\alpha} \cdot d \bar{\tau}-{ }^{3}$

36. The practice of capturing turtles by "turning" them when on shore is unknown among these savages; whether this be due to their regarding it as mean and unsportsmanlike, as the disdainful looks and remarks of those I questioned on the subject would lead one to suppose, or whether it be because they so thoroughly enjoy their own methods of procedure, which so fully answer their requirements, I am not prepared to determine, but it is, nevertheless, certain that although well aware, from their knowledge of the animal's habits, that it could be easily surprised

1 This period has accordingly received a specific name, viz., $\hat{a} \cdot k \grave{a}-t i g-p \hat{a} \cdot l a-$.

2 An average size $y \hat{a} \cdot d \bar{\imath}$ - weighs about 80 to $100 \mathrm{lbs}$., and a tàu-considerably less. The heaviest specimen of the former which ever came under iny notice weighed about $400 \mathrm{lbs}$. The ordinary price of a full-grown turtle at Port Blair is five rupees.

3 These remarks do not of course apply to those living at the homes, as they have long since learnt to benefit considerably by disposing of their tortoiseshell to visitors and residents at Port Blair. 
and captured when frequenting the shore, they never take advantage of the opportunities thus presented.

37. Even on the darkest nights many turtles are speared at the moment when they rise to the surface in order to breathe. The sound which they then make, though slight, is sufficient at once to attract the attention of the keen-eared $\dot{a} r y \hat{o}^{\cdot} t \mathrm{o}^{1}{ }^{1}$ standing on the projecting prow, and to enable him to direct his harpoon with unerring aim; he usually jumps into the water after his victim, lest the barbed head should, in the act of dragging the line, slip out of the wound and the animal escape. When the turtle is in such deep water as to render spearing it from the canoe an impossibility, the harpooner leaps into the water feet foremost, with the spear in his hand, and frequently succeeds at once in transfixing the animal. After spearing a sting-ray, they drag it by means of the harpoon to the boat, whereupon one of the party seizes it by its tail, and holding it firmly between his teeth, knocks off, with a piece of wood or other instrument, the formidable spike or spikes which project from the root of the tail; after thus disarming their victim, they proceed to drag it into the canoe or to the shore. ${ }^{2}$

38. From the accounts of some writers respecting the prowess of the Andaman Islanders in the water, it might be inferred that they rival or even excel the "finny denizens of the deep" in their own element. This is, of course, incorrect, and due to misapprehension; the secret of their "invariably returning to the surface with some scaly prize" finds its explanation in the fact that they never think of diving ${ }^{3}$ after a fish that has not been first transfixed (according to its size) by an arrow or harpoon. ${ }^{4}$

39. The art of fishing with a hook and line was unknown to, and has not found favour among them, as they are far more successful than ourselves in catching fish by their own methods, ${ }^{5}$ which are as follow:-at low water the women and children with hand-nets capture such fish and shell-fish ${ }^{6}$ as are left by the

1 Vide ante "Tribal Communities," paragraph 5.

2 Two or three fatal accidents have, to my knowledge, occurred in recent years on dark nights to inexperienced turtle-hunters at one or other of the homes, in consequence of their having plunged on to the back of one of these fish after harpooning it, mistaking their victim in the darkness for a turtle.

3 "Should the fish be large some of those in the boat dive down, attacking the victim with knives and spears" (Dar).

${ }_{4}$ They are, morenver, not in the habit of " diving for shell-fish,"-except it be for a Tridacna crocea, which they occasionally discover in deep water-for guantities are always found in shallow water at low tide.

5 "The present writer has seen a party of Andamanese shoot and secure nearly one hundred fish during one low tide on a coral reef, and that with no very extraordinary exertion" (vide "Bombay Gazette," 2nd August, 1881).

${ }_{6}$ The farourite time for collecting shell-fish is the low tide at darbreak occurring about the third and fourth days after new and full moon, and known to them by the name of tồ $y a-$. 
receding waves in the rocky hollows on the foreshore, and at the turn of the tide the men are usually to be seen standing up to their waists in water, or poling along the shore in their canoes, and shooting with their bows and arrows at the fish as they dart past. ${ }^{1}$

40. The seeds of a plant called tốrog- ${ }^{2}$ are sometimes crushed and thrown into creeks where fish and prawns are likely to be, as it has the effect of driving the fish from their hiding place, and leads to their easy capture in hand-nets held in position for the purpose.

41. In former times, and even now in the more distant communities, large nets of about 80 feet in length and 15 feet in depth, with meshes of several inches in diameter, were spread at the mouth of creeks for catching turtles and big fish, but since iron has been so easily obtained and canoes and harpoons have become more numerous, the àryôtto- usually carry on their trade by these means in preference to the older method, which entailed much labour in the manufacture. The following is the mode employed when nets are used :-one side is sunk by means of stones, and the other is kept up by floating sticks called $t^{\prime} \alpha \cdot \operatorname{lag}$-, of the $a l \cdot a b \alpha_{-}{ }^{3}$ tree (Melochia velutina), to each of which a cane-leaf is attached; the ends are then drawn across such parts or creeks into which fish may easily be driven by beating the water with the bamboo shafts of their turtle spears. When any turtle or fish is driven into the net, the exact spot is at once indicated by the disturbance of one of the logs, with its tuft of leaves, whereupon they generally find little difficulty in despatching their captive.

Navigation. - 1 . It is a subject of surprise to all who, during the past fifteen or twenty years, have come in contact with the Andamanese, and have observed the style and capabilities of their canoes, to read the high encomiums that have been bestowed on the skill with which they are constructed, and to find that they are credited with such extraordinary speed as to distance easily a cutter, as well as a gig, manned respectively by picked crews of blue-jackets and Chinamen, ${ }^{4}$ the former of whom "said, in their own usual exaggerated style of remark, they nearly killed

1 The results obtained by the men are said to be inferior to those obtained by the women and children, but this is probably due to the large quantity of molluses and crustaceans usually collected in the hand-nets.

2 A species of Lagerstromia. This is similar to the custom among the Gaboon tribes described by Dr. Brown, who mentions that "at the Gaboon it is the leaves of a pretty leguminous plant, with yellow flowers.$\cdot{ }^{*}$ which is used. So rapid is the poison that if a handful of the bruised leaves are thrown into a pool the fish will almost immediarely die and come to the surface."

3 Vide ante "Superstitions," paragraph 7, and post "String," paragraph 1.

Vicie Mouat, pp. 315-321. 
themselves in their effort to maintain the credit of their ship, their cutter, and their flag."

2. Nowhere on Great Andaman, at all events at the present day, have any aborigines been found capable of propelling a canoe at more than half the speed of one of the ordinary gigs in common use at Port Blair; moreover, in respect to the extreme buoyancy of their skiffs, but little $\kappa$ íos seems due to the Andamanese boat-builder, for having had, until quite lately, no other implement than a rude, though tolerably effective, adze with which to form them, he was compelled to solect for his purpose the lightest and softest woods that were procurable. At the same time there is no doubt that if they possessed the requisite knowledge, and the means were available for constructing stronger and more seaworthy craft, they would lose no time in employing them; for they fully recognise the inferiority of their boats, both in regard to workmanship and speed, to those used by Europeans, or by their neighbours the Nicobarese. In one respect only do they consider that their own canoes surpass all others, and that is in the projecting prow, which enables them to spear fish and turtle with more ease than is possible in boats of a different construction. ${ }^{1}$

3. The current tradition ${ }^{2}$ of the escape of four persons in a boat when the world was submerged, may be fairly considered as affording some evidence that this mode of transit is not regarded as of recent introduction.

4. Many conflicting opinions have been expressed by different writers under this head, and the form of canoe originally manufactured by the Andamanese has been much discussed. They themselves declare that the outrigger (chârignıa-) was adopted immediately after the Deluge, in consequence of the deterioration of a species of Pandanus tree, called mâng-, ${ }^{3}$ of which, prior to that catastrophe, they had been able to make large plain " dug-outs." Until recently the outrigger continued

1 In the South Kensington Museum there are models of canoes made by the natives of the Andamans and Nicobars, which will give to any interested in the subject a fair idea of their relative merits, as well as of the skili of their respective makers; and it may be added that in the entrance court of the India Museum (South Kensington) a specimen of a fair-sized Andamanese canoe is now to be seen minus its outrigger.

2 Vide " Mythology," paragraph 16.

3 Vide "List of Trees," A ppendix L.

4 The following information was obtained from an Andamanese chief :- "We have used outrigger canves from time immemorial. It is in recent times that we hare commenced making the large plain canoes, and this we were induced to do from the facility with which we have been able to obtain iron. Owing to their large size they do not require outriggers. When the sea is rough we prefer these large dug-outs, and the small outrigger canoes when it is calm; the latter are more easily made, but do not last many months when in constant use, whereas the foı mer will serve for a year or more." 
in use, and is still to be seen in North and Middle Andaman, but the possibility of obtaining unlimited supplies of iron has enabled those living near Port Blair to return once more to the traditional "dug-out" of antediluvian times; it also seems that this description of canoe is gaining in favour among the tribes of Middle Andaman and the Archipelago, though it had not, in 1879, when I visited that part, penetrated as far as North Andaman.

5. As is correctly stated by Dr. Mouat (p. 316) the Andamanese never venture far from the coast: this was conclusively proved by their ignorance of Barren Island ${ }^{1}$ and Narcondam, until taken past them in the settlement steamer. ${ }^{2}$

6. The safety of either the outrigger or "dug-out," and their adaptability for use as lifeboats, ${ }^{3}$ is more than doubtful, while the confidence which is reposed in them by their owners may be judged from the fact that they never venture far from land, and when crossing from one island to another do their utmost to lessen the passage through deep water as much as possible by keeping close in shore and coasting along until the narrowest part of the channel is reached.

7. A glance suffices to show the most casual observer that it would be impossible $e^{4}$ to preserve the equilibrium of these frail barques without their outriggers, which, being attached to three or four pieces of wood passing through the interior of the canoe are, moreover, not easily removable.

8. The advantages possessed by the large plain "dug-outs" over the outriggers are twofold: for in the first place they can breast a fairly rough sea, while the others are fit only for use in perfectly calm weather; and in the second place, while the former can accommodate a party of from fifteen to forty persons,

1 Visible within a short distance of the east coast of the Archipelago.

2 Since the date of the raids committed by the .jär awa- (of Little Andaman) upon the Car Nicobarese, of which mention is made (as a tradition) by Mr. G. Hamilton (vide "Asiatic Researches," vol. ii, p. 337, published 1801), no distant voyages appear to have been attempted by these savages in canoes.

3 "They would make most excellent lifeboats, such, we believe, as have never yet been constructed by any of our most experienced boat-builders" (vide Mouat, p. 317). The returns of life-boat institutions would, however, be somewhat prejudicially affected by the adoption of this suggestion; for, as the same writer goes on to say (p. 318), "the greatest adepts in rowing, steering, and guiding our ordinary boats, find themselves completely at a loss when they get into a Mincopie canoe. When any of our men recklesely got into them, and attempted to paddle out a little way to sea, they invariably succeeded in capsizing them, receiving a thorough drenching in the water as a suitable punishment for their rash and imperfect seamanship."

4 It is therefore difficult to understand the following allusion made by Dr. Mouat (p. 317) :- "When the Mincopie go to sea in them they attach to some part of the boat an outrigger, in some respects resembling that which the Cingalese fishermen attach to their boats." 
the latter are seldom large enough to carry more than four or five, and usually not more than two adults.

9. The chief excellence of both these descriptions of canoes is that they cannot sink, owing to the nature of the wood of which they are constructed, and when, as not unfrequently happens, they capsize or are filled by a heavy wave, their occupants skilfully contrive, with but little delay, to right them and bale out the water, while clinging to the sides.

10. Most of the canoe-making is carried on during the months of August, September, and October, and the average time and labour expended is that of about eight men for a fortnight in hollowing out a canoe or "dug-out," and forming the much esteemed prow ; for this purpose a trunk is selected varying in length from 10 to 30 feet, and when the bark has been removed the exterior of the proposed canoe, with its important prow, is shaped with an adze $\left(w \overline{o^{*}} l_{0^{-}}{ }^{1}\right)$, afterwards the interior is scooped out with the same implement; fire is not now-a-days employed to expedite this latter process, whatever may have been the custom in past generations, ${ }^{2}$ though I may add that there do not appear to be any traditions in support of such a theory.

11. At the bottom and water-level, canoes, though sometimes more, are never less than $1 \frac{1}{2}$ to 3 inches thick, and indeed, if this were not the case, it would be impossible for them to stand, even for a few days, the rough treatment to which they are subjected, or to bear the spoils of a successful turtling expedition.

12. Though the result of the builders' labour might, by making every allowance for the rudeness of their tool, be termed "creditable," it seems passing strange that any writer should especially commend the " finish," " perfection," and "elegance" of the work, and maintain that it surpasses that which could be wrought by Chinese carpenters, whose skill in all handicrafts is so well established.

13. The Andamanese anchor consists merely of a heavy stone, or large lump of coral, fastened securely to a stout line of a few fathoms' length. Rafts are quite unknown to them at the present day, and no evidence of their use in bygone years has been discovered. ${ }^{3}$

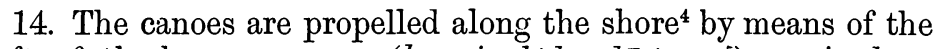
haft of the harpoon spear (kowai a lôk $k o d \bar{u} \cdot t n g a^{-5}$ ), or, in deep

1 Vide Appendix B, item 15.

2 Vide Colebrooke and "Journ. Anthrop. Inst.," vol. xi, p. 290, Appendix I.

3 "They use also rafts made of bamboos to transport themselves across their harbours, or from one island to another" (Colebrooke).

${ }_{4}$ Except when the men are engaged in turtling, the women frequently assist in propelling the canoe.

Tide Appendix B, No. 10.

VOL. XII. 
water, by paddles (wäl $\left.\cdot \operatorname{rgma}^{1}{ }^{1}\right)$, the size of which is not determined by custom, but varies according to the whim of the maker and the size of the piece of wood (generally of the Myristica longifolia) at his disposal ; all, whether small or large, are used indiscriminately, either with the outriggers or simple "dug-outs"; paddles are never made by women, to whom, however, their ornamentation with kòi $\cdot o b$ - and $k \hat{a} \cdot n g a t a-b \bar{u} j-$ is afterwards entrusted. ${ }^{3}$

Ornamentation.- 1 . While the Andamanese habitually ornament their various utensils, weapons, \&c., they never attempt to show their talent or originality by representing natural objects, or by devising a new pattern, but slavishly adhere to those which custom has prescribed for each article. ${ }^{4}$

2. These designs are executed by means of a Cyrena shell, or are painted in $k \hat{o} i \cdot o b-, t \hat{a} \cdot l a-\bar{o} g$-, or $k \hat{\alpha} \cdot n g a t a-b \bar{u} j-$; occasionally they content themselves with smearing the entire surface of the object with either of the two first-named pigments, but more often a background is thus formed for the better display of further embellishments.

3. These three substances supply their only colours, i.e. : brick red (kòi $\cdot o b-)$, white $(t a \cdot l a-\bar{o} g-)$, and brown ( $k \hat{\alpha} \cdot n g a t a-b \bar{u} j-)$.

4. Small land and sea shells ${ }^{5}$ (especially the Dentalium octogonum), certain seeds and bones are much prized, not only for making personal ornaments, but also for the adornment of weapons and implements, as well as the human skulls and jawbones which they often wear and carry about with them.

5. It may be added that the details of ornamentation are in most cases subordinate to the general form and outline of the object in question

6. The following is believed to be a complete list of the designs, ${ }^{6}$ both carved and painted, which are in use :-

I. Chevrons (jö·bo-tàrtä'nga-).

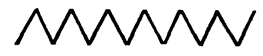

Painted with $k \grave{o} i \cdot o b$ - or $t \hat{\alpha} \cdot l a-\bar{o} g$ - on bows, buckets, canoes, and paddles.

1 Vide Appendix B, No. $11 a$.

2 Dr. Mouat states (p. 319) that they are made of three sizes, and (p. 320) that " the work of making them is entrusted solely to the women and children," but I have failed in discovering any foundation for these assertions.

3 The canoes too are often similarly ornamented, especially when new.

4 Of enamelling they possess no knowledge.

5 Beads, when offered by us, are gladly accepted for use in lieu of small shells.

${ }^{6}$ When it is stated that all these designs are executed by means of pointed sticks, shells, or even the finger-tips, it is scarcely necessary to add that they fall far short of the neatness and mathematical precision characterising most of these illustrations, which therefore can only be taken as representing the particular pattern attempted. 
II. Cross Lines (ig-yī'tinga-).

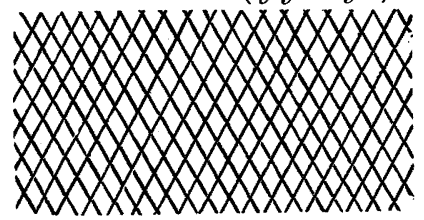

Cut by means of a Cyrena shell on the rō'gun-1 and $i j^{\circ} i \cdot g \bar{o}^{\cdot} n g a \sigma^{2}$ and painted with $t \hat{a} \cdot l a \cdot \bar{o} g-$, between parallel lines, on the sounding board ( $p \bar{u} \cdot k u t a-y e m \cdot n g a^{3}$ ).

III. CRoss LINes (ig-bar·nga-).

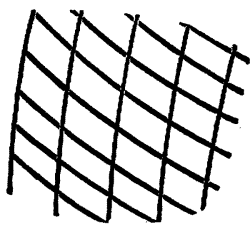

Painted on the outer surface of baskets, the vertical lines with kò ${ }^{\circ} \circ b$-, and the oblique ones with $t \hat{a} \cdot l a-\bar{o} g$ -

IV. Parallel Lines (ig-ōंinga-).

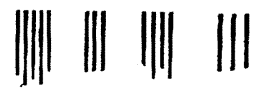

Painted with kòi ob- or $t \hat{a} \cdot l a-\bar{o} g$ - across handle of paddle.

V. Parallel Lines and Zigzag (jō'bo-tàrtä'nga or tốnanga-).

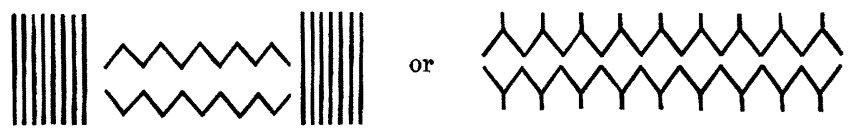

Painted with $t \hat{a} \cdot l a-\bar{o} g \cdot$ on $r \bar{o} \cdot g u n-^{4}$ and $i j^{\cdot} \cdot-g \bar{o}^{*} \cdot n g a \cdot \cdot^{5}$

VI. Lozenge Pattern.

(a) jō'bo-tàrtä'nga-

(b) ìgē unga-.
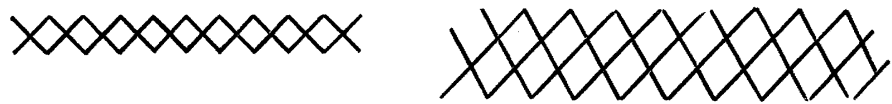

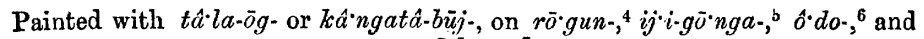
pü kuta-.7

1 Waistbelt, worn by married women only.

2 Chaplet, worn by both sexes.

3 Sounding board, used in keeping time for dancers.

4 Vide Appendix $\mathrm{B}$, item 26.

5 Vide Appendix $\mathrm{B}$, item 31.

6 Nautilus shell, used as a drinking vessel.

i pü kuta yât mäk'nga-, wooden tray used at meals. 
VII. Plait Ornament or Guilloche poliòr.nga-).

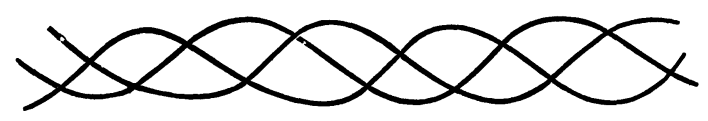

Painted with $t \hat{a} \cdot l a-\bar{o} g-$ on bows and eating trays.

VIII. FIsH-Bone (bar'nga-)..

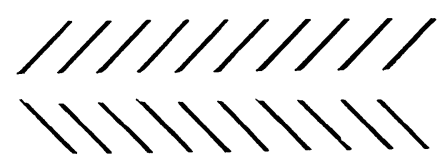

Painted on $\operatorname{chip} p-1$

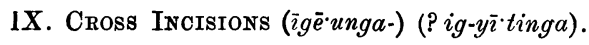

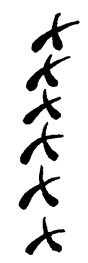

Cut by means of a Cyrena shell on bows (kâtrama-), and handles of adzes $(w \bar{o} \cdot l o-)$.

X. Loop Patteri (ōt-ē'nga-).

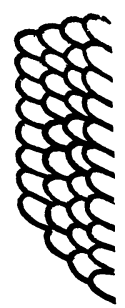

Paintıd with $t \hat{c} \cdot l a \cdot \bar{o} g-$ on the $c h \bar{i} \cdot d i^{2}$

1 Sling or belt, worn like a sash by men and women for carrying children.

2 Pinna shell, used as a plate or tray. 
XI. VANdykes with Scolloped Bands aNd Cross Lines (? ig-pòi-nyalcuga).

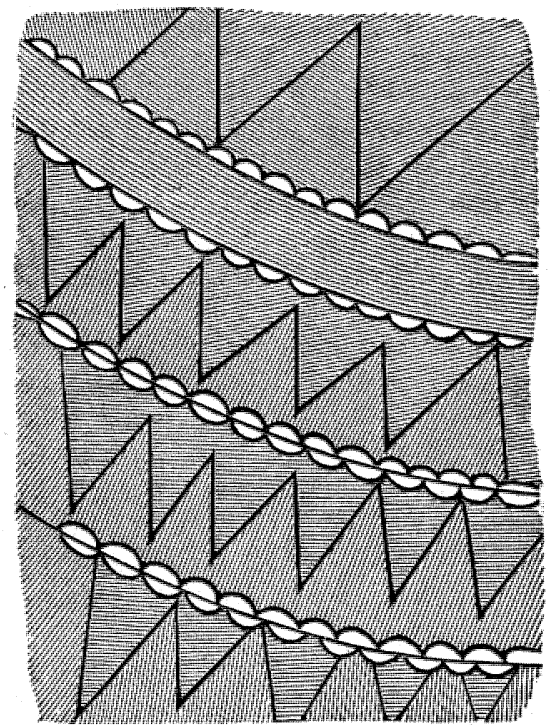

Painted with kấngatâ-büj- on $\hat{o} \cdot d o-1$

Pottery.-1. These savages evince a superiority over the Australians, Tasmanians, Fuegeans, and many of the Pacific Islanders, in possessing some knowledge of the art of making pots.

2. It was formerly believed that they had " no vessel capable of resisting the action of fire," ${ }^{2}$ but careful examination of their kitchen-middens has proved, beyond all doubt, that their present manufacture was equalled-if indeed it were not surpassed -many generations ago by their ancestors ; the traditions current among them on the subject may also be mentioned, in passing, as pointing to a like conclusion.

3. The late Dr. Stoliczka, in his interesting paper on the Andamanese kitchen-middens, ${ }^{3}$ writes as follows :- "In submitting the rude fragments of pottery . . . to an archæologist in Europe, no one would long hesitate in referring them to the

1 Nautilus shell, used as a drinking vessel.

2 Vide Symes, who is also incorreot in adding in a footnote: "The fragments of earthenware vessels mentioned by $\mathrm{Mr}$. Colebrooke were probably brought from the Nicobars or from the Continent, by the boats that often visit the Andamans for the purpose of taking the nests before mentioned" (i.e., of the Collocalia nidifi $\cdot a)$.

3 Vide Proceedings As. Soc. Bengal, January, 1870. 
stone age, at least to the neolithic period; for, indeed, they are almost identical with the fragments of pottery found in the Danish kitchen-middens, though here fragments of pottery are comparatively very rare."

4. The manufacture of pots $\left(b \bar{u} j^{1}\right)$ is not confined to any particular class, or to either sex, but the better specimens are generally produced by men, and though the result is in neither case very satisfactory as regards appearance, they yet answer the purpose for which they are intended very fairly, ${ }^{2}$ and frequently serve as objects of barter among the various communities.

5. They invariably use, unmixed with any other substance, a particular description of clay called by them $b \bar{u} j-p a-$, which is only found in a few places, where, of course, the work is usually carried on: the method pursued is similar to that practised by the Kaffirs, and the only implements employed are a short pointed stick, an Arca shell (the variety called $p \hat{0}^{\circ} r m a-$ ), and a board, which is generally either a sounding board ( $p \bar{u} \cdot k u t a-$ yem $n g a_{-}{ }^{3}$ ), or, if sufficiently large, an eating tray (pü.kutayat-mäknnga-4).

6. As nothing of the character of a potter's wheel is known among them, the shape of the vessels depends upon the skill of the operator and upon the correctness of his eye. The first step in the process of making a pot is to remove any stones that are in the clay, which is then moistened with water and kneaded until it is of a proper consistency; several lumps are next rolled out in succession on the board, by means of the fingers and palms, into strips of about fifteen inches long and half-an-inch thick: one of these is now twisted by the artist into a cup-like shape, ${ }^{5}$ in order to form the base of the pot, which he proceeds to build up, taking care the while to exert sufficient pressure to ensure a uniform thickness, by adding one roll above another, each one commencing where the last ended, until the required dimensions are attained; then, if it be sufficiently firm and consolidated, an Arca shell is carefully passed (ngdtanga-) over the inner and outer surfaces, which are thus rendered smoother, and are at the same time freed from any minute bits of stone that had previously escaped observation; the serrated edges of the

1 Vide Appendix B, item 18.

2 Vide ante "Food," paragraphs 12, 21, and 27.

3 Vide Áppendix $\mathrm{B}$, No. 19.

4 Vide Appendix B, No. 72.

5 The pots made by the yërewa- and .jär awa-tribes (i.e., North and Little Andaman) have up to the present time been found to have a more pointed base than' those of the five .böjig tribes, but I believe no Andaman pot intended for cooking purposes has yet been made of such a shape as to allow of its standing. The small cup-: (or sometimes saucer-) like pots (vide vol. vii, Plate XIII, fig. $19 a)$ are used for making and warming $k \hat{a} \cdot n g a t \hat{a}-b \bar{u} j-$. 
shell also impart a more finished appearance to the vessel ere it is further engraved ( $\bar{o} \cdot$ inga- $^{-}$) on both surfaces ${ }^{1}$ in wavy, checked, or striped designs, ${ }^{2}$ not, as has been assumed, ${ }^{3}$ by the finger-nail, but by means of the pointed stick before mentioned. The potter then places the utensil in the sun to dry, or, if the weather be wet or cloudy, before a fire, taking care to alter its position from time to time so that all parts may be equally subjected to heat. When sufficiently hardened, he bakes it thoroughly by placing burning pieces of wood both inside and around the vessel; occasionally during this process the pot cracks, which of course renders it useless, but if this does not happen it is allowed to cool, and is then considered ready for use.

7. With good management a pot is ordinarily fit for use by the close of the day on which it is made. They may be said to be all of one quality and to differ only in size so as to be suitable for the use of a single family or a large party. The largest description is usually only to be seen in permanent encampments, the smaller kinds being taken when occasion arises for a migration, as for instance on account of a death, ${ }^{4}$ or because arrangements have been made for an entertainment at some other place. ${ }^{5}$ The medium size is almost invariably provided with a rough basket-work casing, which not only renders it more portable but also serves to protect it, in some measure, from the many accidents to which it is liable.

8. The pots ordinarily made will hold about nine pints, but the larger kinds possess double this capacity, while others again are no larger than half an ordinary cocoanut-shell; these last are employed in making $k \hat{\alpha} \cdot n g a t \hat{\alpha}-b \bar{u} j-$, and also when using it ; ${ }^{6}$ with this exception none of the vessels are reserved or manufactured for any special purpose, but serve alike for all times, whether for festivals, migrations, or ordinary occasions. No substitutes for

1 Perhaps the original object of this practice may be explained by the conjecture contained in the following extract from Peschel's work :- “In examining the site of an old pottery manufactory of the Red Indians on the Cahokia, . . . Carl Rau discovered half-finished vessels, that is to say, baskets of rushes or willow, lined inside with clay. When the vessel was baked the fire naturally consumed the external covering. . . . That the Europeans of prehistoric times also originally lined basket-work with clay, may be inferred from the decorations of vessels of the stone age. These decorations consist merely of rows of marks made with the finger-nail, as if to represent the traces left by the basket-work. When some bold individual began to shape the clay by hand, his earthen vessels were perhaps regarded as not genuine, or of inferior quality, as they had not originated in the time-honoured fashion; in order to meet these doubts he may have counterfeited the impressions of the rushes with his nail."

2 Vide "Journ. Anthrop. Inst.," vol. vii, Plate XVI, for illustration of these.

3 Vide de Röepstorff.

4 Vide ante "Death and Burial," paragraphs 4 and 15.

5 Vide post "Games and Amusements," paragraph 21.

- Vide Appendix B, item 62. 
pottery are in use, as has been supposed, ${ }^{1}$ unless the fact of certain molluscs ${ }^{2}$ being cooked in their shells can be so described. Broken pottery is not buried in graves or beneath landrnarks, but is cast aside as rubbish.

9. No kind of painting or varnishing is ever attempted, and models of men or animals are never made. They are also ignorant of glazing and of making porous pottery for cooling vessels.

Natural Forms and Miscellaneous Manufactures. -1 . The natural forms of stones are employed by the Andamanese, as by other savage tribes, as anvils and hammers. Like the natives of New. Guinea, ${ }^{3}$ they always carry with them, or keep ready for use, one or more Cyrena shells ( $\bar{u} \cdot t a-)$, as these serve them in a great variety of ways : for example, in dressing and preparing the wooden portion of their arrows; in sharpening their bamboo and cane ${ }^{4}$ knives, and the inner edge of the boar's tusk, in order to adapt it for use as a plane; as a spoon, ${ }^{b}$ in eating gravy, \&c.; as a knife, in cutting thatching leaves, \&c., and in severing the joints of meat; and as a scraper in separating the pulp from the fibre of the Anadendron paniculatum and other plants, from which they manufacture their various descriptions of string and cord; these shells are likewise employed in making the ornamental incisions in their weapons, implements, leaf-ornaments, \&c., ${ }^{6}$ in preparing the peculiar $\bar{u} j{ }^{7}$ appendage (worn when dancing); and they are also frequently used for planing purposes. ${ }^{8}$ Indeed, I think I may fairly say that among their savage arts there is probably nothing so calculated to surprise and interest a stranger as the many and clever uses to which necessity has taught them to put this simple but highly effective tool.

1 This refers to the following passage in the late Dr. Stoliczka's " Note on the Kjökken-Möddings of the Andaman Islands":- "I have been informed that in some parts of the island their only cooking utensils are large specimens of Turbo marmoratus, valves of Tridacna gigas, and others."

2 Viz. :-Cyrena, Arca, Mytilus smaragdinus, Ceritheum, Patella variabilis (limpet), and a few other small varieties.

3 "They always carry with them a bamboo knife; . . . when required they sharpen the edge with a shell ( $a$ fresh water species of Cyrena), which is always carried for the purpose. . " (See a paper on the natives of the Fly River, New Guinea, by Signor L. M. d'Albertis, in the "Journ. Anthrop. Inst.," vol. vi, p. 215, 1876).

${ }_{4}$ Like the Tahitians and Fijians of former times they have also been in the habit of using bamboo knives; these are made of the outside of a piece of bamboo, are shaped into form while green, and are then dried and charred so as to render them as hard and sharp as possible.

5 "The mussel-shell suggested the first idea of the spoon, and still performs its functions on the Atlantic shores of Morocco" (Peschel).

6 Tide "Ornamentation," paragraph 2.

7 Vide Appendix B, item 76.

8 It has already been mentioned under "Food" (para. 8) that the Cyrena is also used in opening other bivalves. 
2. Arca shells, on account of their serrated lips, serve the double purpose-when a pot is being manufactured-of removing pieces of stone from the outer surface, and of imparting a more finished appearance to the vessel. Pinna shells are kept as receptacles for $t \hat{\alpha} \cdot l a-\bar{o} g$-, and as plates for food, while Nautilus shells do duty as drinking vessels. No evidence can be found in support of Mr. St. Johu's statement, ${ }^{1}$ that human skulls are used as boxes to contain small objects, for neither these nor the skulls of animals appear to have been ever so employed $;^{2}$ the former are kept and carried, as I have elsewhere explained, merely as mementoes of the departed, and the latter are stuck on poles, or hung round the eaves of their huts, as trophies of the chase. Pinna and other shells are said to have been used in former times as adze blades, but this is no longer the case, for quantities of iron are always obtainable. Strange as it may seem to some of my readers, there is no trace or tradition of stone having been utilised for this purpose.

3. The only instances in which these tribes appear to have had recourse to the natural defences of animals in the manufacture of their weapons are- $(a)$ in the use of the serrated bone at the root of the tail of the sting-ray ${ }^{3}$ for their fish-arrows; and $(b)$ of the valves of Perna ephippium, ${ }^{4}$ which were formerly -after being ground and shaped-fastened to their woodenheaded arrows, for use in hunting, and in hostile expeditions. Since, however, they have found themselves able to procure ample supplies of iron, these shell arrow-heads, like the shell adzeblades, have been discarded in favour of iron wire, nails, hoopiron, \&c.

4. The bamboo, although not employed by the Andamanese in such a variety of ways as it is by many savages, is yet in constant use in one or other of the following modes, viz:of the ordinary medium, size (male species) they form the shafts of their turtle-harpoons $;^{5}$ of the female species ${ }^{6}$ they make water-holders, and receptacles for cooked food ${ }^{7}$ when travelling $\left(g \bar{o} b-^{8}\right)$; knives $\left(p \hat{o}-c h \hat{o}-{ }^{9}\right)$, which are narrow pieces hardened

1 Transactions of the Ethnol. Soc., vol. v, p. 43.

2 Very possibly the belief originated in the manner I suggested in a previous paper (vide vol. xi, p. 273).

3 Vide ante "Hunting," \&c., paragraph 11.

4 Vide post " Stone Implements," paragraph 5 (footnote).

5 The shafts of their pig spear, being short are made of heavier material, viz., the thick rattan.

${ }^{6}$ Pieces of Bambusa gigantea, which have floated across from Burmah, or have reached their shores from wrecks, are much prized as buckets, none but the small ordinary bamboo being indigenous.

"Vide ante "Food," paragraph 31.

8 Vide Appendix $\mathrm{B}$, item 82.

9 Ibid., 69. 
over a fire, and sharpened by means of a Cyrena shell; nettingneedles (pôtòkla- $\left.{ }^{1}\right)$ and tongs $\left(k a i^{2}\right)$, which last consist merely of a strip of bamboo, bent double, with pointed ends $;^{3}$ the slender Bambusa nana, called $r \bar{i} \cdot d i$-, is generally selected for forming the hooked pole (ngztanga- ${ }^{-4}$ ), and it is likewise invariably employed for the shafts of their wooden and iron-pointed arrows.

5. Although there are materials ready to hand wherewith they might easily construct a few such simple musical instruments as are made and used by the Nicobarese, no attempt seems to have been made by them in this direction, for the rude sounding board ( $p \bar{u} \cdot k u t a-y e m \cdot n g a_{-}{ }^{5}$ ) can hardly be included under this head. This circumstance seems to find its explanation in the fact that though they are good timists their talent for music is (as will be presently shown, ${ }^{6}$ on the testimony of more than one competent authority) of the lowest type.

6. A brush, suitable for painting the stripes on their baskets $\left(j \bar{o} b_{-}{ }^{7}\right)$, baby-slings $\left(c h \bar{i} p-^{8}\right)$, \&c., is obtained from a drupe of the small fruit of the Pandanus Andamanensium (mang-), the pulp having been first extracted by means of a Cyrena shell.

7. Skins of animals, thorns, or spines of trees are not made use of by these people in any way, nor do they have recourse to caves, rock-shelters, or tree-tops for their dwellings, though they occasionally, as I have before mentioned, avail themselves of the buttress-like formations of the roots of such trees as the Ficus laccifera, Bombax malbaricum, Sterculia villosa, \&c., when travelling in bad weather, or when suddenly overtaken by a storm. Palm-leaves, as I explained when describing their habitations, ${ }^{9}$ are employed for thatching purposes.

Leather-work. - From the last sentence it will be correctly inferred that there is no evidence of their having ever possessed a knowledge of the art of dressing and preparing skins for use in any form : this may be due as much to the limited number and variety of those animals ${ }^{10}$ whose hides might be turned to account in this way as to the equable temperature of the climate, which renders such, or indeed any covering unnecessary.

1 Vide Appendix $\mathrm{B}$, item 67.

2 Ibid., 80.

3 A narrow and pointed piece of bamboo, bitten at the end so as to loosen the fibres, is made to serve as a brush in painting designs on their buckets, sounding boards, \&c.

4 Vide Appendix $\mathrm{B}$, item 17.

5 Vide Appendix B, item 19.

6 Vide post "Games and Amusements," paragraph 35, and footnote.

7 Vide post " Basket-work," paragraph 3, and Appendix B, item 21.

3 Vide Appendix B, item 24.

9 Vide ante "Habitations," paragraph 2.

10 Viz., dugong, porpoise, paradoxurus, iguana, and pig. 
Metallurgy.-Having been, till comparatively recent times, ignorant almost of the existence as well as of the uses of iron, it is not to be wondered at that smelting and forging have been to them unknown arts. Now that they are better informed, and are able to procure pieces of hoop-iron, keel-plate, \&c., they apply them to the manufacture of their blades and adzes, reducing them to the required thinness by continually striking the cold metal with a hard smooth stone (tailli-ban $\left.{ }^{\cdot} a^{-1}\right)$ on a rude anvil (rârap-) of the same substance; such portions of the iron as are then found to exceed the dimensions requisite for the weapon or tool under construction are placed over the edge of the anvil and broken off by dint of repeated blows: the new edge thus formed, being more or less jagged, is then ground on a hone till the blade assumes the desired shape. Many of the aborigines who have been living for some time at Port Blair have, however, advanced a stage beyond this, for, by using such old chisels as they may succeed in procuring, they contrive to make their arrow-heads and other implements much more speedily than by the old method. The pointed weapons, e.g., the kowai $a$ - and $t \hat{o} \cdot l b \bar{o} \cdot d$-, are made from pieces of stout wire, large nails, \&c., by dint of laborious and patient hammering on the ratrap-, and grinding on the talag-.

stone Implements. - 1. Although a great portion of the inhabitants of Great Andaman have for some time past been able through us to procure iron in sufficient quantities to substitute it for stone (not to mention bones and shells), still they can by no means be said to have passed out of the stone age; indeed, the more distant tribes still retain the use, with scarcely any modification, of most of the stone and other implements which served their ancestors. Even the inmates of the homes at Port Blair may still often be seen employing one or other of them, evidently therefore from choice: this more especially refers to the first three in the following list, ${ }^{2}$ which comprises the small number of stone implements in ordinary use among the present aboriginal inhabitants of the islands :$r a \cdot r a p-$, the anvil.

tai $l i-b a n^{\prime} a-$, the hammer (probably a smooth round piece of dolerite or fine-grained basalt).

ta.lag-, the whetstone (consisting of slightly micaceous sandstone).

tô.lma lôk $k \bar{u} g_{-}^{3}$ (lit., quartz tooth), chips or flakes for shaving, tattooing, \&c.

1 Vide next section, paragraph 1.

2 There are no special makers, or procurers, of these stones.

3 These are either fragments of opaque whitish vein quartz, or of transparent rock crystal, or are obtained from pebbles of opaque bluish-white quartz with 
$l \hat{a}-$-, cooking stones; common pebbles, about a couple of inches in diameter, which are heated, and then placed on all sides of the food which it is intended to cook.

2. When a new whetstone is required,-as no method of cutting stone is known to them,-a block of soft sandstone is chosen, which, if too large, is placed on a fire till it breaks; the piece best adapted for the purpose is then taken and shaped according to fancy, by the aid of one of the hard smooth stone hammers; after being used a short time the edges wear down, and it answers as a hone for several months. ${ }^{1}$

3. Chips and flakes are never usedmore than once; in fact, several are generally employed in each operation: those having a sharp blade-like edge are reserved for shaving, while others with a fine point being kept for tattooing or scarifying; when done with they are thrown on a refuse heap, or otherwise disposed of, lest injury should befall any one by inadvertently treading on them. Flaking is regarded as one of the duties of women, and is usually performed by them. ${ }^{2}$

4. For making chips two pieces of white quartz are needed; the stones are not pressed against the thigh, nor are they bound round tightly so as to increase the line of least resistance to the blow of the flaker; but one of the pieces is first heated and afterwards allowed to cool, it is then held firmly and struck at right angles with the other stone: by this means is obtained in a few moments a number of fragments suitable for the purposes above mentioned. A certain knack is apparently necessary in order to produce the kind of chips which are at the time required: the smallest flakes are obtained in the same manner and never by pressure.

5. Glass chips are now generally used by all who are in communication with ourselves, in preference to those of flint, as they are sharper and more effective; the method in which they are obtained is the same, the thick lump of glass forming the bottom of beer and wine bottles being selected for the purpose, and never the thinner portions.

6. It has been stated ${ }^{3}$ that formerly, for tattooing, a "sharpened flint bound to a stick" was used, and that the present instrument is a bit of broken bottle " inserted into the split extremity of a stick"; no instance has, however, been found confirmatory of the words quoted, and the Andamanese

fatty lustre, thin chips of which are translucent at the edges. (For this desuription I am indebted to Mr. F. W. Rudler.)

1 For the mode of use vide Appendix B, No. 52.

2 All women can scarify and act as barbers, but only about 50 per cent. of them undertake the more difficult task of tattooing.

3 Vide Dr. Day. 
themselves declare that they never haft the stone chips or glass flakes, and that the former are never "sharpened," but produced in the manner already described.

7. Quartz is commonly met with throughout the country occupied by the tribes with which we are in friendly intercourse; no difficulty, therefore, is ever experienced in obtaining $i t$, or, indeed, any of the other varieties of stone which they use. It is employed for no other purposes than those here indicated, as has been assumed, and the art of producing fire by its means is urknown to them. ${ }^{2}$

8. The whetstone and hammer only are offered as mediums of exchange, but no great value is attached to either of these objects, nor is any superstition associated with their usage: they are therefore-when no longer serviceable-cast aside.

9. Stones are not used by them for cutting wood or bone, the latter being usually crushed by a hammer for the sake of the marrow. Before the introduction of iron, small holes were bored with bone or pieces of shell, but rarely, if ever, with stone, and no implement has been found which might be supposed to have served as a stone saw or scraper, for which purposes shells apparently have been generally employed. ${ }^{3}$

10. In his "Note on the Kjokken-Möddings of the Andaman Islands" the late Dr. Stoliczka also refers to a celt found in one of these refuse heaps as "a small but typical arrow-head," and describes it as of Tertiary sandstone. The Andamanese, however, nnaintain that they never, even when iron was scarce, made arrow-heads, axes, adzes, or chisels of stone; they also affirm that the fragments which have been fourd in the kitchenmiddens, and which have given rise to the impression of having formerly served one or other of the above purposes are merely quartz flakes or broken pieces of cooking stones or hones which, in former times as now, were thrown among the rubbish when no longer of use. ${ }^{4}$

11. Stones are not regarded as thunderbolts or worn as amulets: they are not placed in water previous to their being worked, and holes are never bored in them, nor is the surface ever ground or polished.

1 "From the flint they manufactured knives . . . and arrow-heads" (de Röepstorff), and elsewhere he speaks of "flint hatchets," which not improbably were as much unknown in former times as at the present day. Perna ephippium $(\bar{e} \cdot l a-)$ shells were formerly sharpened and converted into arrow-heads : hence $\bar{e} \cdot l a$ - has ever since been adopted as the name of the bladed (or pig) arrow, even although iron has now been entirely or very generally substituted for shell. Adze blades were, it seems, sometimes made of Pinna shells.

2 Vide ante "Fire," paragraphs 1 and 4.

3 Vide ante "Natural Forms," paragraph 1.

4 Vide my remarks on this subject in rol. xi, p. 271 . 
Basket-work.-1. Among the few remaining industries of these savages on which I have a few words to say is that of basketmaking: these baskets are invariably made from the best specimens of the common cane called $p \bar{v} \cdot d g a$ - which is similar to, if not identically the same as that ordinarily used by our basket-makers and chair-menders.

2. After removing the leaves, part of the cane is cut into lengths of $3 \frac{1}{2}$ or 4 feet, and the "skin" or cuticle is shredded off into strips $\frac{1}{4}$ or $\frac{1}{5}$ inch wide; the remainder of the cane is split into as long pieces as possible, and the "skin" is cut into strips somewhat narrower than the others; shorter lengths of the canes form the "ribs" or "stakes," in and out of which tine strips are woven or "slewed."

3 . In order that the basket may stand steadily ${ }^{1}$ it has always a "kick" like our bottles, and to construct this is of course the first object; when the stakes have been firmly secured in the centre, they are placed over a small hole scooped out of the ground, and the heel of the basket-maker is placed on them while the weaving is commenced; when it has been carried on to a breadth of 2 or 3 inches the heel is removed, the canes reversed, and the work proceeds in the ordinary way until within an inch of the required depth, where, for the sake of appearance, the interweaving is omitted: the handle is then formed out of a strip of the bark of the Melochia velutina (al:aba-); stripes of $t a \cdot l a-\bar{o} g$ - and $k o ̀ i \cdot o b$ - are usually added by way of ornamentation; no method of rendering them waterproof is known. Baskets are not converted into moulds for pottery; but sometimes, when travelling, earthen vessels are placed in a loose wicker casing, in order to protect them, and at the same time to facilitate their removal.

4. There is a marked difference ${ }^{2}$ between the baskets made by the five.$b \bar{o} \cdot j i g$ tribes and those manufactured by the .ye'rewa-; with the latter the work is more neatly finished, and the opening is small instead of being wide, as is the case among the former. ${ }^{3}$

5 . Baskets are used for all sorts of purposes by men, women, and children, and, considering the rough usage to which they are subjected, last fairly well, for they seldom require to be renewed for several months: they are not used as strainers or colanders, the fine net (cha.panga-) serving this purpose.

string, scc- 1 . The Andamanese do not produce their stout cord ( $b \bar{e} \cdot t m a-)$, string ( $b \bar{e} \cdot t m a-b \bar{\alpha}-)$, or twine (mô $l a-)$, from animal

1 The jär*awa- baskets are generally small at the base, and having no "kick" are not usually able to stand unless placed between logs of wood or other objects.

2 'The reader is referred to the excellent sketch of an Andamanese basket, which appeared in the "Journ. Anthrop. Inst.," vol. vii, Plate XIII, fig. 17.

3 Vide vol. xi, Plate XXIII, fig. 14. 
substances, but from the bark fibres of trees and shrubs, known to them by the names of al:aba- (Melochia velutina), pīlita(Gnetum edule), and yōllba (Anadendron paniculatum). The first of these is found growing near the shore, where it seldom attains a height of 20 feet; it is from fibre obtained from the bark of this tree that their cinctures ( $b \bar{e} \cdot t m a \cdot b \bar{\alpha}-)$, harpoon-lines $(b \bar{e} \cdot t m a-)$, and turtle-nets (yô.to'te'pinga-) are manufactured. When any of the articles have to be made or replaced, it becomes the duty of some member of the male sex to procure a smooth clean branch-one which is also fairly straight and free from gnarls being preferred-and to remove the bark; the cellular integument is next scraped with a Cyrena shell $(\bar{u} \cdot t a-)$ until the fibres which it encloses are laid bare: these are then placed in the sun, or before a fire, to dry ; when ready for use (i.e., when thoroughly dry) the ropemaker ties several of the filaments to his toe and proceeds with his work by winding another strand spirally round them, adding a fresh length from time to time. When special strength or durability is needed, a coating of black wax $(t \bar{o} \cdot b u l-p \bar{c} d-)$ is finally applied. The yarn thus produced is termed be'tma-mai anga-. When a long piece of this has been made (say 30 yards), a large portion of it is wound round the two cross-sticks forming the $k \bar{u}$ tegbo-. ${ }^{1}$ The operator, having then seated himself with legs outstretched, places a stick or cane between the big toes of his feet, and over this bar he passes the $k \bar{u}$ tegbo-, thus enabling him to wind it continuously round the other half-length of the yarn, which, for convenience sake, he has previously placed by his right side, so that it is drawn behind his neck and over his left shoulder as the work proceeds. After the first foot or so of the cord has been thus made, the operator holds or clutches that portion with his toes. It will be understood that in employing the $k \bar{u}$-tegbo in the above manner, it becomes necessary at frequent intervals to unwind a certain quantity from that implement, in order to enable the work to progress. The cord thus made is called $b \bar{e} \cdot t m a-$, and this it is of which their harpoon-lines and turtle-nets are made. The $b \bar{e} \cdot t m a-b \bar{\alpha}$ - (lit., small $b \bar{e} \cdot t m a-)$, mentioned above, is made in the same way, but of course less fibre and a smaller kütegbo- are used.

2. For making hand fishing-nets $\left(k \bar{u} d d_{-}\right)$and sleeping-mats $\left(p \ddot{a r} r \cdot \bar{e} p a_{-}^{2}\right)$, the fibre of the Gnetum edule ( $\left.p \bar{\imath} \cdot l i t a-\right)$ is used; in the preparation and manufacture of these, women exclusively are concerned; the first process is to cut a number of the trailers into lengths which are determined by the distances between the knots and joints: these are held against the

1 "The cord (used for large nets, \&c.) possesses the valuable quality of hardening in the water" (vide Mouat, p. 326).

2 Vide Appendix $\mathrm{B}$, item 65. 
thigh, and the cuticle is removed by means of the Cyrena shell; the underlying white fibres are left for a week or ten days in the sun until thoroughly dry, when they separate readily, and are easily worked up into fine or coarse twine, as may be required by the manipulator.

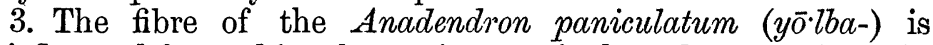
chiefly used for making bowstrings, reticules (chdpanga-), necklaces, and twine for arrow fastenings; its manufacture is accordingly not restricted to either sex. When the bark has been stripped off, in lengths of 8 to 15 inches, the operator presses the inner portion upon his (or her) thigh, and then rapidly but carefully passes a Cyrena shell along the outer surface until the fibres alone remain; these are then, as in the previous cases, dried in the sun, or before a fire; when a sufficient supply of material has been thus obtained, it is made into fine twine, or, if not required for immediate use, wrapped in leaves in order that it may be kept fresh. Although apparently free from any obnoxious properties, this plant, as well as the fibres obtained therefrom, until it is converted into twine or bowstrings, is believed by the Andamanese to render the flesh of a turtle uneatable if placed near it; consequently this meat, when inadvertently so contaminated, is thrown away; further, no one who has been collecting $y \bar{o} \cdot l b a-$, or who has been engaged in preparing the fibre, can (for a period extending to three days) be allowed to cook a turtle, or even to accompany a party engaged on a turtling expedition! Sharks and other dangerous fish are also credited with having so wholesome a horror or detestation of this plant (and also of Cyrena shells!) that the aborigines are in the habit of attaching some yo-lba-, or Cyrena shells (or both), to their cinctures as a safeguard when about to swim in parts believed to be infested by these creatures.

4. The yellow skin of the root of a certain orchid, called $r \hat{a}-$-, which is commonly found on trees near the shore, is often seen intertwined with their $y \bar{o} \cdot l b a$ - string, in personal ornaments, and occasionally in the decoration of weapons, but where strength is a requisite it is of course not used.

5. Bowstrings of $p \bar{\imath} \cdot l i t a-$ and $y \bar{o} \cdot l b a-$ are made in the manner described in the manufacture of al.aba- rope, but ordinary string is made in the following manner :-a few of the prepared filaments are twisted into a yarn on the thigh with the palm of the hand; when two lengths have been obtained, they are together rolled into string of the desired strength, and beeswax is smeared over it to make assurance doubly sure.

6 . Twine, made from the $y \bar{o} \cdot l b \alpha-$, is used in netting the fine chains $\left(r \bar{\alpha} b^{1}\right)$ and the reticules $\left(\right.$ chatpanga- $\left.{ }^{2}\right)$; for turtle-

1 Vide ante "Death and Burial," paragraph 5, and Appendix B, item 42.

2 Vide Appendix B, item 22. 
nets the stronger $a l \cdot a b a$ - is employed, while for the hand fishingnets $\left(k \bar{u} d-^{1}\right)$ string, made frorn the pi $l i t a-$, is almost exclusively reserved. In this handicraft the Andamanese are especially skilful, and regulate to a nicety the size of the mesh by using the little or forefinger; it should be mentioned that their rude netting needles of bamboo (pôt tokla- ${ }^{2}$ ) are not very dissimilar to those used in Europe. Sewing is to them an almost unknown art, but they describe needlework by the word jatke, which expresses their manner of uniting the large $k a \cdot p a$ - leaves, to form a screen, with the pliable stem of this leaf, and also iheir mode of repairing a canoe, holes being bored and strips of cane $(p \vec{\imath} \cdot d g a-)$ threaded above and below the crack, which has been previously filled in on both sides with $t \bar{o} \cdot b u l-p \bar{\imath} d-.^{3}$

Games and Amusements.-1. And now, having passed in brief review their various arts and manufactures, I will bring my account of Andamanese life to a close with a brief description of their games and amusements.

2. Unlike many Eastern races they evince from their earliest years a partiality for active pursuits in which monotony or great bodily exertion are not entailed, and great was the delight of the children in the Orphanage when they were instructed in some of our English games, especially kite-flying, and see-saw ; it is at the same time curious to note that, though not borrowed from aliens, their pastimes, in many instances, bear close resemblance to those in vogue among children in this and other lands; notably is this the case with regard to those known to us as blind-man's-buff, ${ }^{5}$ leap-frog, ${ }^{6}$ and hide-and-seek. ${ }^{7}$

3. With respect to the first-named of these, large leaves, in lieu of a handkerchief, are fastened over the eyes, and the difficulties of the "blind man" are greatly increased by its being obligatory for him to catch the person who blinded him while being pulled about, and jostled by the rest of the players.

4. In "leap-frog," instead of stooping, one man squats on his heels while his companion bounds over him without touching. him and takes the same position, to be in his turn jumped over.

5. Mock pig-hunting ${ }^{8}$ after dark is another very favourite amusement; one of the party undertakes the rôle of the pig, and, betaking himself to a distance, runs hither and thither,

YOL. XII.

1 Tide Appendix B, item 20.

2 Vide $\Lambda$ ppendix $\mathrm{B}$, item 67.

3 Vide Appendix B, item 57.

4 To this game they have given the name ad-ye-nenga-.

5 Called by them $i j \cdot \hat{i} \cdot t \hat{a} \cdot p a-l i \tilde{r}$ rnaa-.

6 Called by them koktâr-tidó-atinga-.

7 Called by them ab-âtanga-.

8 Called by them ad-reg'ignga- 
imitating the grunting of that animal, while his comrades shoot off harmless arrows ${ }^{1}$ in the direction from whence the sounds proceed until one hits its intended mark.

6. Another variety of this game is as follows:-one man leaves the encampment after dark armed with $\bar{u}$ tara- arrows, which, on his return after a brief absence, he fires off into different huts, while the occupants hide themselves or run away screaming as if attacked by an enemy. ${ }^{2}$

7. Similarly in the sea they play at turtling: one end of a long line is held firmly by some one in the canoe, the other being fastened to the arm of the man who is to represent the turtle. Diving suddenly into the water, he is at once followed by the rest, who try to capture him, while he does his utmost to elude them by swimming, doubling, and diving, till fairly exhausted.

8. Sometimes when they are assembled together in the evening one of the men will get up and exclaim, "I will go after

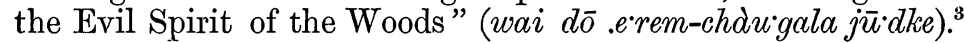
Taking nothing with him but a lighted log, he goes off into the jungle and is soon lost to sight; his friends then call to him and inquire if he has caught the demon, whereupon he begins to rush about shouting and hitting about him as if in pursuit of, or struggling with some one ; he is next asked "Who are you?" (mij:a ngoll?) - apparently to suggest the idea that during his combat with the evil one he has been transformed, or rather, has lost his identity,- the reply is given in a feigned voice, "I am ——" (naming some person long since deceased) " and have come for such and such a purpose." Something being then thrown at him he threatens them with annihilation unless they desist; still remaining in his hiding-place he amuses himself, and presumably also his friends, by singing, until at last two or three of the company search him out and bring him back to the camp, where, with a view of keeping up his assumed character, he remains silent and feigns sleep, often for the rest of the evening.

9. An impromptu swing is sometimes devised out of one of the long stout creepers, commonly found overhanging a bough perpendicularly from a height of 40 to 50 feet : clinging firmly to this they swing each other ${ }^{4}$ as far as possible, just as we swing children.

1 Made of a soft wood called $\bar{u} \cdot$ tara-, of the Alpinia species; the points are flattened with the teeth before using

2 This game is called it $\cdot$ itai $\cdot j n g a-$.

3 This game is known as .e rem-chàu gala àté pnga.

4 This goes by the name of $i g \cdot l \bar{e}$ langa-. [During a risit paid to Rutland Island, in 1881, a .jär awa- swing was seen suspended from a stout branch. It 
10. Young men often compete with one another in swimming, diving feet foremost into the water from an overhanging rock or branch with shouts of delight. Sometimes they will race together in their canoes, ${ }^{1}$ but this only happens on chance occasions, when the idea has been suddenly suggested by one of the party, and not by pre-arrangement.

11. In parts, where trees of the Alpinia species abound, they now and then vie in seeing who amongst them can force his way with greatest rapidity through the dense barrier of leaves and smooth stems which it presents, ${ }^{2}$ and thus probably they acquire, in great measure, the skill which in an early section ${ }^{3} \mathrm{I}$ mentioned they invariably display when threading their way through the jungles.

12. At times they compete in throwing upwards a short piece of string, weighted at each end with a stone, ${ }^{4}$ the object of course being to see who can fling highest. Similarly Cyrena shells are occasionally sent skimming through the air, to test their powers in throwing long distances. ${ }^{5}$

13. While wandering along the coast they may sometimes be seen playing at ducks-and-drakes ${ }^{6}$ with any small flat stones they may chance to pick up.

14. They are all especially fond of showing their skill in shooting a moving object, and for this purpose select the round root of a creeper called $g \bar{o} \cdot d a m-$, or the pod of the Carapa obovata, which they roll along the ground or down a slope, aiming at it while in motion. ${ }^{7}$

15. No special amusements are indulged in by women ${ }^{8}$ whose chief delight seems to consist in the laudable endeavour to surpass one another in adorning the persons of their relatives with the best design in $t \alpha \cdot l a-\bar{o} g$ -

16. Young boys sometimes amuse themselves with wrestling $(a d-l \bar{e} \cdot n g a-)$ on the sand, where also they may not unfrequently be observed playing at mock burials. ${ }^{9}$ On these occasions one

resembled those used by European children, but was made of cane and was provided also with a narrow wooden seat.]

1 This racing is termed $\grave{a} r$-tìrlanga-.

2 This is called tàr-lốtoknga-.

3 Vide ante "Physical Powers and Senses," paragraph 4.

4 This game is called $t \bar{u} \cdot t e m o$ -

5 This variation of the game is called $\hat{a} \cdot k \hat{a}-k \bar{e} \cdot c h i a n g a-;$ when the shell is about to be thrown the convex side is held uppermost.

6 The word to express this is che chekanga-.

7 This has also been found to be a practice among the ;iarrawa-.

${ }^{8}$ It has, however, been observed that, not unlike their fairer sisters elsewhere, they are especially fond of gathering together and chatting of the social topics of the hour ; the eagerness and volubility they display in their discussions on these occasions are quite amusing to watch.

9 These are termed $a b$-nät.nga-. 
of their number has to submit to be covered with sand until the head only is visible; fire is then placed near the spot after the custom of their race; for the like reason these sports usually take place near some landmark, such as a conspicuous tree, boulder, or overhanging rock: when the semi-interred child has had enough of it he jumps out and another companion is chosen to take his place.

17. Children may also sometimes be seen diverting themselves by tying a fine string to the leg of a toad or tree-lizard $;^{1}$ this cruel sport, unless their elders interfere, is only ended by the death of the unfortunate captive.

18. They are fond of searching for small crabs and fish, and having them cooked for a sham banquet: ${ }^{2}$ the earnestness they display in "pretending" on these occasions is irresistibly entertaining, and would be heartily appreciated by European children who have experienced the delight of preparing a "doll's feast."

19. Boys also play at seizing each other under the surface of the water, or amuse themselves with making tiny canoes and floating them towards one another; they are, as I have before mentioned, early provided with miniature bows and arrows, and encouraged to become good marksmen.

20. While the foregoing amusements are of frequent occurrence among the juvenile members of a community, ${ }^{3}$ the chief diversion of the adults consists in entertainments resembling the Australian "corroboree," when dancing and singing are kept up for many successive hours by moonlight, or by the blaze of the camp fires.

21. Any passing event, such as a successful hunt, an unexpected visit from distant relatives or friends, the commencement of a new season, the recovery of some member of the community from illness, a marriage, and even the termination of the mourning period, ${ }^{4}$ is made the excuse for one of these entertainments.

22. Besides these smaller festivities, large gatherings of a tribe are also organised from time to time by the head chief, who generally receives an offer, in the first instance, from the members of some far-off community to give a jeg-at his encampment. As these offers are only made when it is known to be convenient they are alwars accepted, and invitations for a certain day are at once sent to all living within an easy distance.

1 This is called rō.pan lik-lī.rnga-.

2 These are called gab-mäk nga-.

3 "Cats' cradle" (called by them jī.bra-) is also one of their recognised amusements.

4 Tide "Death and Burial," paragraph 7. 
23. The intervening days are spent by the proposers of the entertainment in perfecting a song and chorus, which it is intended to perform, and which generally has been composed expressly for the occasion, by some volunteer ${ }^{1}$ upon whom also devolves the responsibility of singing the solo and training the so-called chorus. As a considerable amount of distinction among his fellows may be gained by the manner in which he acquits himself in his onerous undertaking, it will be readily understood that the improvisatore spares no pains over the preparation and rehearsal of a new song, which, as he fondly hopes, will render his name, if not immortal, at all events famous for many a year. The subject is chosen in reference to some recent personal or tribal exploit or adventure, and is embodied in a distich, followed by a chorus, or rather refrain, which as often as not consists merely in a repetition of the couplet forming the solo; in this refrain women alone are instructed; the main point aimed at is apparently accuracy of time, for, as I have said in my last paper, everything, even sense, is sacrificed in their songs to rhythm. ${ }^{2}$

24 . In order to combine pleasure with profit, sundry implements or articles, which are more common in their community than in that of their hosts, are taken by the visitors on these occasions for purposes of presentation, or, to speak more correctly, of barter.

25. It is the duty of the hosts to make all necessary preparations, to provide torches, as well as food and water, for the expected guests, and to sweep the $b \bar{u} \cdot l u m-{ }^{3}$ clearing it of all rubbish, lest inconvenience or injury should be occasioned by the stones, shells, bones, \&c., which gradually accumulate, in spite of the "kitchen-middens" so invariably found in the vicinity of all permanent encampments of long standing.

26. When nearing the scene of their festivity the visitors pause, for the double purpose of a rehearsal and that the women may have time to adorn the party in their holiday suits of paint, as these would have lost their beauty and freshness if donned previous to leaving home.

27. That a weird and dramatic effect should be produced on a civilised mind by one of these entertainments, especially when occurring at night, will be readily understood if one pictures the scene :-in a small clearing in the midst, or on the bordes of a dense jungle are gathered a hundred or even more painted

1 A song that has proved a success at any of these festive tribal meetings is sometimes repeated by "special request" at one of the smaller gatherings ; "all rights" in these productions "are reserved," and no one but the composer is at liberty to sing a song, however popular!

2 Vide ante " Language," paragraph 6.

3 Vide ante "Habitations," paragraph 11. 
savages of both sexes; the moon sheds a soft light on all, while from each hut the lurid glare of a wood fire throws its fitful shadows across the scattered groups; on one side, seated in a row, are the women who are to join in the refrain; on the other, in dark relief within their several huts, are seen the audience, many of whom assist in marking time by clapping their hands or by slapping the hollow between their outstretched legs with their open palms. In a conspicuous position stands the composer and conductor : with one foot on the pointed end of a sounding board, ${ }^{1}$ and supporting himself on a spear, bow, or pole, he gives the time to the singers and dancers by kicking the board with the sole or heel of the other foot; in this wearying duty he is from time to time relieved by one of his male friends and, occasionally, even by a woman. During the solo, which partakes of the character of a "recitative," all other voices are hushed, and the listeners remain motionless, but as soon as the signal is given for the refrain, a number of men emerge suddenly from the gloom surrounding the encampment, and rushing excitedly into the arena, perform their part with frantic energy, generally adding their voices to those of the women to swell the volume of sound. Save at the $t^{i} \bar{\imath}$-tôllatnga-, ${ }^{2}$ women only occasionally take a share in the dances, but their performances are considered by some foreigners as rather suggestive of impropriety-with what justice I am not prepared to say, for modesty, at least, is satisfied by the wearing of a larger leaf apron than usual.

28. There is now-a-days ${ }^{3}$ but one description of dance in vogue with either sex, but it differs somewhat in the two sexes, and therefore must be dwelt upon briefly.

29. A man, when dancing, ${ }^{4}$ curves his back, and throws all his weight on one leg, the knee of which is bent; his hands are raised to a level with his chest, and outstretched before him, the thumb of one hand being held between the forefinger and thumb of the other, while the remaining digits are separated and extended upwards $; 5$ he then advances by sudden jerks and hops

1 These sounding boards ( $p \bar{u} \cdot k u t a-y e m \cdot n g a-)$ somewhat resemble in shape the carapace of a turtle, and might naturally be mistaken by a visitor (vide Colebrooke and Mouat) for shields, but I cannot account for Dr. Hodder's description of a "rough skin drum" (vide "Pall Mall Budget" of 20th April, 1877). See also Appendix B, item 19.

2 Vide ante "Death and Burial," paragraph 7.

3 From Lieutenant Colebrooke's description of the Andamanese dance of a hundred years ago, it would seem that since that date their style has undergone a great change, for he says they "dance in a ring, each alternately kicking and slapping his own breech ad lib."

${ }_{4}$ Vide Plate IX, fig. 2.

5 Sometimes to heighten the effect $a$ bow and arrow are carried in this position. 
taken with the leg on which he is resting, and taps the ground after every second movement with the sole of the other foot; in this manner he crosses and recrosses the entire bülum-, joining in the chorus as he proceeds, each step being taken in time with the thuds on the sounding-board, and the singing of the refrain. When fatigued, the performer makes a little variation by marking time in a rather odd manner, for the knees are bent, and the heels are raised alternately off the ground, the chief point of importance being to maintain the same time throughout.

30. Women, in dancing, swing their arms backwards and forwards; at the same time the knees are bent, and they make a succession of short bobs up and down, in perfect time; every now and then a few steps in advance are taken, and then the action is repeated.

31. To convey an accurate impression of the exact step, or of the effect of the respective performances of the two sexes, is not easy, but I trust that the above descriptions will convey a fair idea of their general character and peculiarities.

32. The alternating of solo and chorus continues for mauy hours, and generally only ceases with the first faint streaks of dawn, when those of the hosts who have managed to keep awake during the long night revel, lead the visitors to the huts they are to occupy, and then themselves sing and dance as a return compliment.

33. To a stranger not gifted with a keen ear for music, there is at first a certain amount of attraction in the oft-repeated cadence, but it must be confessed that, after a residence in the neighbourhood of one of the homes, one learns to wish that their musical performances were characterised by a little more variety, and were rather less protracted, though some compensation may be found at night, as the steady continuance of the monotonous sounds has a most soothing and somniferous effect.

34. It seems hardly necessary to say that all their songs are sung in unison, for they have no idea of choral or part-singing. They appear, however, able to distinguish between various kinds of music, and especially appreciate the performances of our regimental bands.

35. Dr. Brander gives a specimen of their monotonous chant -the compass of which will be found to include only three notes-in the following stave of our musical notation:- 

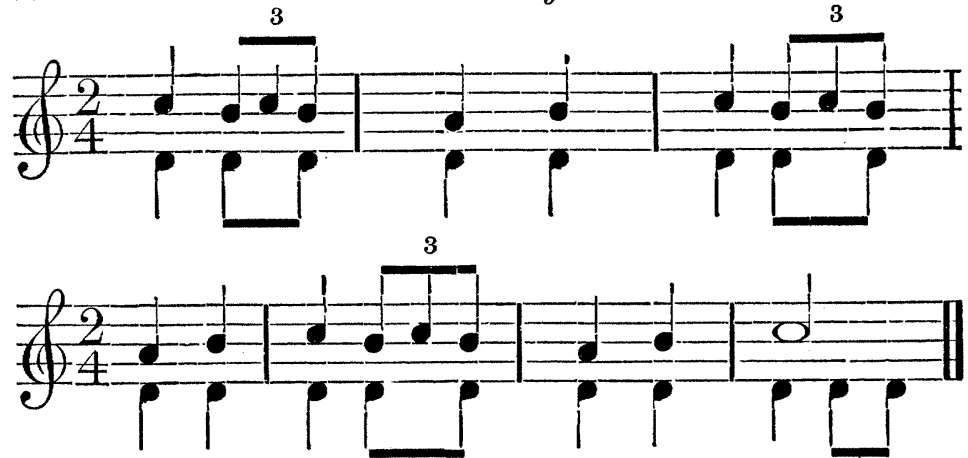

36. Every now and then, as the refrain ends, the soloist cries-

\section{$\bar{o} \cdot b a$ eboy $\bar{u} \cdot b \bar{e} \cdot d a t e,{ }^{1}(a)$}

to which the singers respond by shouting-

$t \bar{e} \hat{a} \cdot r e-\hat{a} \cdot r e-\hat{a} \cdot r e \hat{a},{ }^{1}(b)$

which seems equivalent to Tra-la-la, for it has no meaning per se.

37. When the guests have sufficiently rested from their night's exertions, they visit their special friends or relatives, and, if within the prescribed limits of affinity, ${ }^{2}$ indulge ${ }^{3}$ in weeping together ${ }^{4}$ these visits are usually followed by an interchange of gifts, the hosts taking the initiative, and a fracas not unfrequently ensues, for donor and recipient are not always of a mind as to the respective values of their "presents." Should all, however, pass off smoothly, the assemblage breaks up into various small parties for hunting or fishing, according to the situation of the encampment.

1 These are styled respectively the $(a)$ àrbè-datnga-, and the (b) $\hat{a}-r \bar{e} \cdot a n g a-$ or àryấnanga.

Further, in reference to their musical abilities, I would here quote from a friend who at my request had kindly consented to test the powers of the aborigines in this particular, as I unfortunately am not qualified to do so myself :-

"I examined five women, seven men, and three young boys as to their musical abilities, and as far as I could judge, they have not the remotest idea of pitch or tune, even the chorus of their own song, chēklü y $\hat{a} \cdot l a k \cdot u$ mé jrà? started by $. b 0^{\prime} \cdot r a-g u d$, was taken up in several keys, and it was difficult to distinguish the originai. I tried all the voices separately; it seemed quite accidental if they pitched on the keynote, but as for leaving it when once got hold of to go up and down the scale they would not! so that it was impossible for me to ascertain either the quality or the register of the voices. The boys were, if anything, a shade the best; . . . a lot of drilling may beat a few notes into their heads."

2 Vide ante "Customs, Meeting and Parting," paragraph 2.

3 "The Sandwich Islanders recognise tears as a sign of happiness" (Lubbock, p. 552).

${ }_{4}$ No greetings take place on there occasions between the performers and their bosts until after the entertainment (which often lasts many houre) is orer. 


\section{APPENDIX A.}

\section{Alphabet for writing the South Andaman Language. ${ }^{1}$}

SIGN.

\begin{tabular}{|c|c|c|c|}
\hline & & Oral & Vowel \\
\hline$a$ & .. & ide $a c u t$ & \\
\hline $\bar{a}$ & .. & cur (with un & trill \\
\hline$a$ & .. & Ital. cas $a$ & .. \\
\hline & .. & f $a$ ther & .. \\
\hline$\ddot{a}(1)$ & .. & f $a$ thom & .. \\
\hline$e(2)$ & $\cdot \cdot$ & $\begin{array}{l}\text { bed . } \\
\text { chaotic }\end{array}$ & $\ddot{. .}$ \\
\hline $\bar{e}(3)$ & .. & pair.. & .. \\
\hline$\iota$ & .. & İid ... & .. \\
\hline $\bar{\imath}$ & .. & police & .. \\
\hline & .. & indolent & .. \\
\hline $\bar{o}(4)$ & .• & pole.. & .. \\
\hline & .• & pot .. & .• \\
\hline$\delta$ & $\cdot \cdot$ & awful & ・. \\
\hline $\begin{array}{l}u \\
\bar{u}\end{array}$ & $\ddot{.}$ & $\begin{array}{l}\text { influence } \\
\text { pool }\end{array}$ & $\ddot{.}$ \\
\hline$a i$ & .. & bite... & $\ddot{0}$ \\
\hline$a u$ & .. & house & .. \\
\hline$\grave{a} u$ & .. & Germ. haus & s.. \\
\hline$\partial i$ & -. & boil .. & .• \\
\hline$b$ & .. & bed ... & .• \\
\hline ch & •• & church & .. \\
\hline$d$ & $\bullet$ & dip .. & $\cdots$ \\
\hline$g$ & 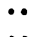 & gap .. & $\cdot \cdot$ \\
\hline & $\bullet$ & hay .. & $\cdots$ \\
\hline$j$ & .. & judge & .. \\
\hline 1 & $\cdot \cdot$ & king.. & .. \\
\hline$l$ & $\cdots$ & lap .. & $\cdots$ \\
\hline$m$ & $\cdots$ & man... & $\cdots$ \\
\hline$n$ & $\ddot{0}$ & Fr. ga gner & $\ddot{0}$ \\
\hline $\begin{array}{l}n \\
n g\end{array}$ & .. & bring & .. \\
\hline & & & \\
\hline
\end{tabular}

SOUTH ANDAMAN.

.. $a l \cdot a b a$ kind of tree

r) $b \bar{a}$ small, $y \bar{a} \cdot b a$ not

.. elâk kà region

.. $d \hat{a}^{*}-k e$ don't (imperative)

.. jär awa name of a tribe

.. $\bar{e}^{\cdot}$ mej name of a tree

.. $p \bar{u} \cdot d \cdot r e$ burn-did

.. $\quad \bar{e} \cdot l a$ pig-arrow

$\therefore \quad i g \cdot b a \hat{~} \cdot d i g-r e$ see-did

.. $y \hat{\alpha} \cdot d \bar{\imath}$ turtle, $p \bar{\imath} d$ hair

.. .bòi goli European

.. jōb basket

.. pòl-i-ke dwell-does

.. tố.go wrist, shoulder

. bu $\cdot$ kura name of a tree

$\therefore \quad p \bar{u} \cdot d$-re burn-did

.. dai-ke understand-does

.. choppau a narrow

.. chàu body

.. .bòigoli European

Consonants.

.. bū d hut

.. châk ability, mich alen why, .rūch Ross Island

.. d dö ga large

.. gōb bamboo utensil

.. $h \bar{e}$ ho! $\hat{a} w \bar{e} \cdot h$ ( $h$. sounded, see note 5) etcetera

. $\quad j \bar{a} \cdot b a g$ bad, $\bar{e} \cdot m e j$, name of a tree

.. kấgal-ke ascend-does

.. log navigable channel

.. $m \bar{u} \cdot g u$ face

.. nàu-ke walk-does, rō'pan toad

.. $\bar{o} t \bar{n} \hat{a} \cdot b a$ another, one more

.. $n g \bar{\imath} \cdot j i$ friend, ềrke $\cdot d a n g-k e$ in-treessearch-does (11)

$\tilde{n} g(6)$..

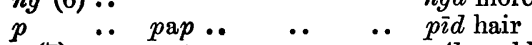

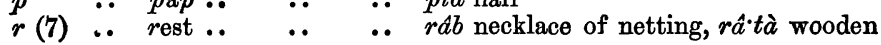

$r(8) \quad \ldots \quad$ torrent $\quad \ldots \quad$.. $\quad r \hat{a} \cdot t a$ sea water

$\begin{array}{llllll}s & . . & \operatorname{sad} & . . & . & \text {.. }\end{array}$

$t \quad$.. $t$ ten . $\quad . . \quad$.. $t \bar{i}$ blood

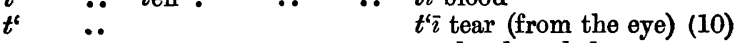

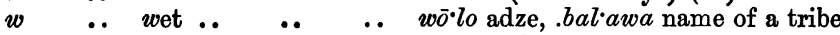

$y \quad \quad . . \quad y$ olk.. $\quad . . \quad \ldots y a b \bar{a}^{*}$ a little

1 As elsewhere mentioned, I am indebted to the kindness of Mr. A. J. Ellis, F.R.S., for the improvements and additions to the list of symbols formerly employed by me. This alphabet is an extract from his able "Report on Researches into the Language of the South Andaman Island," \&c., which formed part of the President's annual address for 1882 to the Philological Society. 


\section{RULES.}

The syllable under stress in any word is shown by placing a turned period $(\cdot)$ after a long vowel, or the consonant following a short vowel, in every word of more than one syllable.

When no stress is marked, it should be placed on every long vowel and diphthong in a word, or if there are none such, on the first syllable.

$A_{s}$ it is not usual to find capitals cast for the accented letters, the capital at the beginning of a word is for uniformity in all cases indicated by pretixing a direct period, as .bal awa.

Substantives, adjectives, and adverbs generally end in " $d a$," which is usually dropped before post positions and in construction ; hence when I write a hyphen at the end of a word, I mean that in its full form it has " $d a$. "

\section{Notes.}

(1) $\ddot{a}$ accented before a consonant, is the English $a$ in mat, as distinguished from $\grave{a}$, which is the short of $\hat{a}$ or Italian $a$ in $a$ nno.

(2) $e$ accented in closed syllables, as in bed; in open syllables unaccented, as in chaotic, or Italian padre, amore.

(3) No vanishing sound of $i$ as in English say.

(4) No vanishing sound of $u$ as in English know.

(5) $h$ is sounded after a vowel by continuing breath through the position of the mouth, while remitting the voice.

(6) $\tilde{n} g$ is a palatalised $n g$, and bears the same relation to it as $\tilde{n}$ bears to $n$. To pronounce $\tilde{n}$ attempt to say $n$ and $y$ simultaneously; to pronounce $\bar{n} g$ do the same for $n g$ and $y$.

(7) This $r$ is soft and gentse with no sensible ripple of the tongue, as very frequently in English, but not merely vocal.

(8) This $r$ is strongly trilled, as $r$ in Scotch or Italian $r$, or Spanish $r r$.

(9) The Andamanese cannot hiss, and hence they substitute ch for $s$, thus $R \bar{u} c h$ for $R \bar{u} s$, the Hindi corruption of Ross.

(10) This $t^{6}$ is a post-aspirated $t$, like the Indian $t h$, quite different from English $t h$, and hence to prevent confusion, the Greek spiritus asper is imitated by a turned comma. The sound $t^{6}$ is common in Irish-English, and may often be heard in England.

(11) When $n g$ is followed by a vowel, it must run on to that vowel only, and not be run on to the preceding vowel, either as in "finger" or in "singer," thus

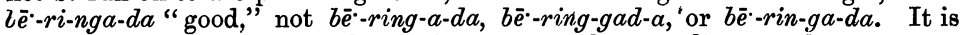
only when no vowel follows that $n g$ is run on to the preceding vowel.

\section{APPENDIX B.}

\section{List of ObJects made and USED By the ANDAManese. ${ }^{1}$}

\section{1. kấrama-. ${ }^{2}$ Bow of a flattened S-shaped form, as made and} used by the tribes of South and Middle Andaman, and the

1 In arranging this list, I have taken care to retain the numbers which are attached to each object in the Andamanese collection presented by me to General Pitt Rivers in 1878, and which is now exhibited in the South Kensington Museum. Except where otherwise specified, these objects are those used by the people of South Andaman; many of them, however, are believed to differ but slightly from such as are made by the remaining seven tribes of Great Andaman ; but greater diversities are to be found among objects made by the Little Andaman and other jär awa- tribes.

2 Vide "Journ. Anthrop. Inst.," vol. vii, Plate XIV, fig. I. 


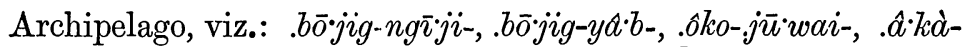

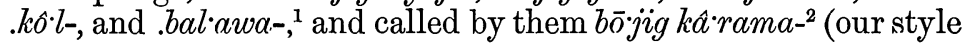
of bow), to distinguish it from the bows used by the inhabitants of North and Little Andaman: it is made of a hard wood, generally of a variety called chai-, or-though less frequently-of the

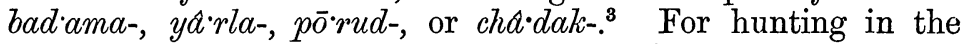
interior, the usual length of these bows, for the sake of convenience, is about 4 feet; the same or somewhat larger bows are used in the open jungle, along the coast, or when shooting fish; when made for presentation rather than for use, they are elaborately ornamented and carefully prepared in every way, and measure $6 \frac{1}{2}$ or 7 feet in length. It is customary to ornament both sides of every $b \bar{o} \cdot j i g$ bow, first by cutting a rough $\times$-like pattern along the edge from end to end with a Cyrena shell, and then with grass or leaves smearing kòi $\circ b$ - (item 60 ) over both surfaces, to form a background, upon which they finally paint a design in $t \hat{\alpha} \cdot l a-\bar{o} g$ - (item 58); the upper end, or nock, of the bow is also frequently decorated with a piece of fine netting called $r a \hat{b}$ - (item 42); the bowstring is made of the bark fibre of the Anadendron paniculatum (Andam., yō lba-, item 64 ), to which, to increase its strength, a coating of black beeswax (tố.bul-pīd-, item 57) is frequently applied. Children's bows ${ }^{4}$ only are ever made of mangrove wood, and then the Rhizophora conjugata is usually preferred. ${ }^{5}$

[Nоте.-The North Andaman bows, called chồ kio-, ${ }^{6}$ which are generally, if not always, made from the tree they call bad ama-, differ somewhat in design from those just described : they are also more neatly made, and are never painted or otherwise ornamented, and are almost invariably of a uniform size, i.e., 5 to $5 \frac{1}{2}$ feet in length. The Little Andaman and other .järawa- bows7 are of a totally different form, and appear to be commonly made of wood of the tree known to them as $l \overline{0} \cdot k$ koma-.]

2. $r a t a{ }^{-}-.^{8}$ The common blunt wooden-headed arrow, used when practising at an object: ${ }^{9}$ the shaft consists of a reed-like variety of bamboo (Bambusa nana) called $r \bar{i} \cdot d i$-, and the foreshaft is generally a piece of the hard portion of the wood of the

1 For the situation of these tribes vide "Journ. Anthrop. Inst.," vol. xi, p. 278, and the map published with Part I.

2 For the purposes of inflection and syntax, the termination $d a$, which belongs to most substantives, adjectives, and many adverbs, is invariably dropped (vide Appendix A, “Journ. Anthrop. Inst.," vol. xi, p. 269).

3 The botanical names of the various trees which have as yet been identified will be found in Appendix $\mathrm{L}$.

4 Vide "Journ. Anthrop. Inst.," vol. vii, Plate XV, fig. 2.

5 This of course is only procurable by those living on or near the coast. The bows of the $\bar{e} \cdot r e m-t \hat{a} \cdot g a$ - children are usually made of wood of the Trigonostemon longifolius.

6 Vide "Journ. Anthrop. Inst.," vol. vii, Plate XIV, fig. 4.

7 Ibid., Plate XIV, fig. 3.

8 Vide "Journ. Anthrop. Inst.," vol. vii, Plate XIV, fig. 8.

9 Vide Part III, "Games and Amusements," paragraph 14. 
Areca, or less frequently of the root of the Rhizophora conjugata : the point is usually hardened over a fire, and straightened by means of their teeth.

3. $t \bar{\imath} \cdot r l \bar{e} \cdot d-.^{1}$ The ordinary fish arrow, which differs from the $r \hat{a} \cdot t d$ - only in that the point is sharpened.

4. $t \hat{0} \cdot l b \bar{o} \cdot d-.^{2}$ Fish arrow, about $4 \frac{1}{2}$ feet long, made like the preceding varieties, but provided with an iron head and barb; the string fastenings attaching the same to the foreshaft are covered with $k \hat{a}$ ingat $\hat{A}-b \bar{u} j$ - (item 62 ). In former times the head of this arrow consisted of a fish-bone; the serrated bone at the root of the tail of the sting-ray (item 53) was often employed for this purpose.

5. $\bar{e} \cdot l a-.^{3}$ Pig arrow, about $3 \frac{1}{2}$ feet in length: the foreshaft consists of a triangular piece of flattened iron fastened to the end of a small stick about 4 inches in length; at the base of the head one or two (rarely three) iron barbs are fixed to the stick, the end of which is fitted into a socket $(\hat{\alpha}-k \hat{d}-c h \dot{\alpha} \cdot n g \alpha-)$ provided for it in the shaft; the head and shaft are connected by a flattened thong about 8 inches long, made from the fibre of the Anadendron paniculatum, and which, before the arrow is fired, is always wound round the wooden portion of the foreshaft by twisting the latter when placing it in its socket; when an animal is struck the head of the arrow is retained in the flesh by the barbs (archarga-), and as the foreshaft slips out of its socket by reason of the struggles and movements of the animal in its efforts to escape, the trailing shaft quickly becomes entangled in the brushwood, thereby detaining the victim and ensuring its capture.

6. $\bar{e} \cdot l a l ' \hat{a} \cdot k \dot{d} l \bar{u} \cdot p a-.^{4}$ This, as indicated by its name, is merely a plain pig arrow, having no foreshaft like the more elaborate $\bar{e} \cdot l a-:$ it is less effective than the latter, but more easily made.

7. $t \hat{o} \cdot l b \bar{d} d l^{\prime} \hat{a}^{\prime} r t \hat{a} m-{ }^{5}$

7a. $\bar{e} \cdot l a$ l'ấrtâm- ${ }^{6}$ (lit., ancient). Fish and pig arrows, headed

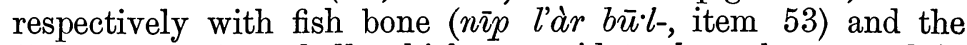
Perna ephippium shell, which are said to have been used in former times when iron was unobtainable.

8. châm-pấligma-.7 Plain wooden arrows, about $3 \frac{1}{2}$ feet in length, made of the wood of the Areca palm : it is said that when iron was scarce these were shaped somewhat like the $\bar{e} \cdot l a-$ (item 5) or tī rrle'd- (item 3), and used as pig and fish arrows.

1 Vide "Journ. Anthrop. Inst.," vol. vii, Plate XIV, fig. 7.

2 Ibid., vol. xi, Plate XXIII, fig. 3.

3 Ibid., vol. vii, Plate XIV, fig. 5.

4 Ibid., vol. xi, Plate XXIII, fig. 5.

5 Ibid., fig. 4.

6 Ibid., vol. vii, Plate XII, fig. 76.

; Ibid., Plate XIV, fig 9. 
but now they are never so employed, being apparently made only for the "sake of auld lang syne," or to display the skill of the maker.

[Nоте.-The .jär awa- are only as yet known to employ the two varieties of arrows, viz., the $\bar{e} \cdot l a-$ and the $t \bar{\imath} \cdot r l \bar{e} \cdot d-$; the latter much resembles those bearing the same name and made by the eight Great Andaman tribes, but the formar is a more formidable weapon, being larger and more strongly made.]

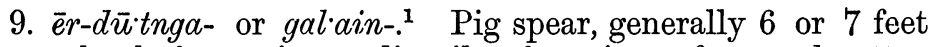
long; the haft consists ordinarily of a piece of ground rattan $(b \bar{o} l-)$, and a large double-edged blade forms the head. This weapon is rarely used, the $\bar{e} \cdot l a$ (item 5 ) being preferred.

[Note.-It appears that none of the North Andaman or .jär awa-tribes have ever been seen with such a spear; probably this is partly due to the difficulty they experience in obtaining iron.]

10. Kowai'a l'oko dütnga. ${ }^{2}$ Turtle spear: the shaft ${ }^{3}$ is a bamboo (male species preferred), often 18 feet or more in length; for the reception of the harpoon a socket is prepared at the small end, which is strengthened by pieces of mangrove wood, over which strips of cane are neatly tied. The harpoon consists of a strong barbed iron head fastened to a short piece of wood to which a long line (be'tma-) is attached. When a turtle or large fish is struck the harpoon detaches itself from the shaft, which floats and is picked up after the capture has been effected.

[NoтE.-A harpooner almost invariably follows up a successful cast by plunging into the water, lest in the act of dragging the line the harpoon should slip out of the wound and his victim should thus escape.]

11. $r \overline{0} \cdot k o-{ }^{4}$ Generic name of the various kinds of canoes made in recent years ${ }^{5}$ by the aborigines of South Andaman and adjacent parts, where, owing to the facility of obtaining iron tools, large dug-outs, called $g \bar{\imath} \cdot$ lyanga-, capable of accommodating twenty to forty persons, are constructed in place of the small outrigger canoes (charigma-) with which the other tribes have still to content themselves. They are usually made of the Sterculia villosa (Andam., bấja-), and are often ornamentally painted.

[Note.-The outrigger is called tel-, and is always made of the wood of main(one of the Sterculiacece), which is soft and light.]

11a. wäl'igma-. ${ }^{6}$ Paddle: these are not made by women, nor are they of any prescribed size, this being regulated merely by the fancy of the maker, and the material at his disposal ; they

1 Vide "Journ. Anthrop. Inst.," vol. vii, Plate XIV, fig. 12.

2 Ibid., Plate XIII, fig. 24.

3 This shaft is called tô $g$-, and is used for poling the canoe along the shore.

4 Vide "Journ. Anthrop. Inst.," vol. vii, Plate XII, fig. 69.

5 Vide Part III, "Navigation," paragraph 4, and footnote.

6 Vide "Journ. Anthrop. Inst.," vol. vii, Plate XIV, fig. 70 
are frequently adorned by women with chevrons ${ }^{1}(j \bar{o} \cdot b o$-tàrtä $\cdot n g a-)$ of kòi $\cdot 0 b$ - (item 60) or $t a \cdot l a-\bar{o} g$ - (item 58).

12. yôto-té'pinga-. Turtle-net, made by men, ${ }^{2}$ of a stout cord (bettma-), which is prepared from the bark fibre of the Melochia velutina (Andam., al:aba-); the meshes vary in size according to the fancy or skill of the maker. ${ }^{3}$

13. da kar-. ${ }^{4}$ Bucket made by the Great Andaman tribes of the wood used in constructing canoes, i.e., Sterculia villosa, with a loop of cane to form the handle; the implement used in hollowing out these vessels is the blade of the adze (wo $\cdot l_{0-\text {, }}$ item 15), which is detached from its handle and fastened to a straight piece of wood so as to form a sort of chisel.

[Note.-The Little Andaman and other .järawa-buckets are made in the same manner, but are much larger and superior in every way ; they are, moreover, neatly ornamented round the sides with strips of cane, evenly laid on and fastened at the rim by plaiting.]

14. $\hat{o} \cdot d o-.^{5}$ Nautilus shells painted with $k d \cdot n g a t d-b \bar{u} j$ - (item 62 ), and used as drinking vessels.

15. $w \bar{o} \cdot l_{0-.^{6}}$ Adze: this tool is used not only in making canoes, buckets, bows, \&c., but in digging graves. The handle consists of an L-shaped piece of mangrove wood, Rhizophora conjugata (Andam., bad $\alpha$-), and the blade is generally made of such pieces of iron as the keel-plate of a boat; formerly Pinna and such like shells are said to have been used, but strange to say it does not appear that stone celts were ever so employed.

16. $l a \cdot k d-.^{7}$ A long pointed stick of the Memecylon parviflora, (Andam., pe'taing-) or Rhizophora conjugata (Andam., bad'a-), which is used as a hoe in digging up yams and other edible roots.

[Noтв.-A similar implement is found in use among the Australians. ${ }^{8}$

17. ngatanga-.9 Pole, 12 to 15 feet long, of Bambusa nana (Andam., r' ${ }^{-} \cdot d i$-), to which a short piece of bamboo is securely fastened, with a strip of cane (Andam., $p \bar{\imath} \cdot d g a-$ ), or stout cord, to form a hook; it is used in gathering fruit-especially jack-fruit (Artocarpus chaplasha)-and is the only object of the nature of a hook made by the Andamanese.

18. $b \bar{u} j-.^{10}$ Cooking pot: these are made of various sizes by

1 Vide Part III, "Ornamentation," paragraph 7.

2 Vide "Journ. Anthrop. Inst.," vol. vii, Plate XII, fig. 60.

3 Vide Part III, "String," paragraph 2.

4 Vide "Journ. Anthrop. Inst.," vol vii, Plate XIII, fig. 14.

5 Ibid., fig. 20.

6 Ibid., fig. 13.

7 Ibid., vol xi, Plate XXIII, fig. 2.

8 Vide "Anthropology," p. 216, by Dr. E. B. Tylor, T.R.S.

9 Ibid., fig. 1.

10 Ibid., vol. vii, Plate XIII, fig. 19, and Plate XVI. 
members of both sexes, and are shaped by the hand and eye only; ${ }^{1}$ after being sun-dried they are surrounded with, and filled by pieces of lighted wood in order to complete the process of baking. When needed for travelling they are fitted with light wicker frames (bijj-ramatc-) to facilitate their removal, and to protect them from injury. The capacity of an averagesized pot is 9 or 10 pints.

[NoTE.-The .yērewa- and .järawa-pots have a conical base, and in this respect differ from those made by the tribes of South Andaman.]

19. $p \bar{u} \cdot k u t a-y e m \cdot n g a-.^{2}$ Sounding-boards-used for marking time during a song or dance--which are scooped out of the fallen trunks of the Pterocarpus dalbergioides (Andam., ch $\hat{a}$ langa-), the wood of which is very hard; they are always of the same shield-like shape, and are frequently as much as 5 feet long and 2 feet wide; the concave side is generally ornamented with designs in white clay (t $t \hat{a} \cdot l a-\bar{o} g$-, item 58$)$. When in use the convex side is uppermost; the pointed end is stuck in the ground, and kept in position with one foot; a stone is then placed under the board to enable the performer to make more noise when keeping time, which he does by thumping or kicking the board with the heel of the other foot.

20. $k \bar{u} d-{ }^{4}$ Hand fishing net constructed from the prepared fibre of the Gnetum edule (Andam., pi lita-) by women and girls, who also by its means catch large quantities of fish and prawns, both in streams and among rocks along the coast at low tide. It is about the size of an ordinary butterfly-net; the frame is made of a length of a creeper known to them as ôrtatät-, the ends being bound together to form a handle.

21. $j \bar{o} b-.^{5}$ Baskets used by all the Great Andaman tribes for carrying food and various other articles : they are generally made by women. ${ }^{6}$

[NoTE.-The baskets made by the .ye rewa- or North Andaman tribes, differ from those found among the . $b \bar{o} \cdot j i g$ tribes in having a wider base and a smaller mouth.] $]^{7}$

21a. The .jör $a w a^{-8}$ baskets differ from those in use among the Great Andaman tribes in having no firm base.

22. chapanga-.$^{9}$ Netted reticules made and used by women for carrying small objects : the string used for this purpose is

1 Vide Part III, "Pottery," paragraphs 4 and 6.

2 Vide "Journ. Anthrop. Inst.," vol. vii, Plate XIII, fig. 16.

3 Vide Part III, "Games and Amusements," paragraph 27.

4 Vide "Journ. Anthrop. Inst.," vol, vii, Plate XIII, fig. 18.

5 Ibid., fig. 17.

6 Vide Part III, “Basket-work,", paragraphs 2 and 3.

7 Vide "Journ. Anthrop. Inst.," vol. xi, Plate XXIII, fig. 14.

8 Ibid., fig. 14a.

Ibid., vol. vii, Plate XII, fig. 33. 
generally prepared from the fibre of the Anadendron paniculatum (Andam., y $y \cdot l b a-$, item 64 ), but as this is not always attainable the less-valued fibre of the Gnetum edule (Andam., pīlita-) is sometimes employed as a substitute.

23. pär $\cdot \bar{e} p a-.^{1}$ Sleeping mat made by women of strips of a species of Calamus fastened securely in the ordinary manner with string made from the fibre of the Gnetum edule (Andam., $p \bar{r} \cdot l i t \alpha-$, item 65$)$. When in use the rolled-up portion of these mats-which are generally 15 to 20 feet long-serves as a pillow.

23a! The .järawa- ${ }^{2}$ sleeping mats hitherto found have always been of short lengths, but as wooden pillows similar to those in use among the Nicobarese have been found in their huts, it is probable that the specimens obtained represent full sized mats.

24. chipp-. ${ }^{3}$ Sling or band made by women from the bark of the Melochia velutina (Andam., al $\cdot a b a-$ ), which is worn like a sash over one shoulder by women, and sometimes by men, when carrying infants. ${ }^{4}$

The plain specimens are called $c h \bar{\imath} p-l \bar{u} \cdot p \alpha-$.

Those ornamented with netting $c h \bar{p} p-r \bar{\alpha} \cdot b$ -

Those ornamented with shells chipp-yä'mnga-.

25. $b \bar{o} d-.^{5}$ Waistbelt made from the leaves of the young screw-pine (Pandanus Andamanensium); the bunch of leaves or tail is worn at the back.

[Notw.-These specimens are of the kird worn by women and girls of the eight Great Andaman tribes; the females of the jär awa-tribes appear to go entirely nude.]

25a. bōd-. ${ }^{6}$ Waistbelts of similar description, but having a less bushy tail, are worn more or less generally by men and youths of the eight Great Andaman tribes.

26. rógun-. ${ }^{7}$ Belt made from the leaves of the young screnpine, which is worn by adult married women only.

27. $t \hat{a}-c h \hat{o} \cdot n g a-{ }^{8}$ Garters, which are frequently worn by men and youths: they are made in the same way as the $b \bar{o} d-$ (item 25.)

28. tốgo-chốnga-..$^{9}$ Bracelets, also worn by men and youths, much resembling the last-named object.

1 Vide "Journ. Anthrop. Inst.," vol. xi, Plate XXIII, fig. 15.

2 Ibid., fig. $15 a$.

3 Ibid., vol. vii, Plate XIII, fig. 25.

4 Vide Part III, "Social Relations," \&c., paragraph 10.

5 Vide "Journ. Anthrop. Inst.," vol, vii, Plate XIII, fig. 27.

6 Ibid., fig. 27 a.

7 Ibid., Plate XII, fig. 29.

8 Ibid., vol. xi, Plate XXIII, fig. 9.

9 Ibid., fig. 8. 


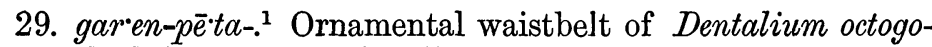
num, which is worn occasionally by both sexes.

30. bè ria- järrawa- ${ }^{2}$ waistbelts, necklets, and armlets, which are believed to be worn by men and youths only.

31. $i j^{\prime} \cdot g \bar{o}^{\circ} n g a-.^{3}$ Head-dress of Pandanus-leaf, worn occasionally by young men and women.

The following ten articles are worn by both sexes as ornaments either round the neck or head :-

32. $\bar{\imath} \cdot n \alpha-\hat{o} \cdot l \alpha-t a-{ }^{4} \quad \ldots$

33. $p \bar{e} \cdot r-t \hat{a}-\ldots \quad$..

34. $y \hat{\alpha} \cdot d \bar{\imath}-t \hat{a}-{ }^{5} \quad$..

35. bai an-tâ- ..

36. $d \bar{u} \cdot k u-t \hat{a}^{-}{ }^{-} \quad$..

37. $b \bar{e} \cdot w a-t \hat{a}-$

38. $r \hat{a} \cdot t a-\hat{o} \cdot l a-t \hat{a}-\ldots$

39. $\dot{r} \bar{e} \cdot k e t o-t \hat{a}^{-7} \quad$..

40. $n g \hat{\alpha} \cdot t y \alpha-t a-{ }^{8} \quad \ldots$

41. gar:en len $p \bar{\imath} \cdot d-$.. made of fresh water-shells. cane or wood. turtle bones. paradoxurus bones. iguana bones. red coral. small sea shells. Hemicardium unedo shells. mangrove seed tops.

Dentalium octogonum and children's hair. ${ }^{9}$

42. $r a b-.^{10}$ Fine netting, plain or ornamented with shells, worn occasionally by both sexes as necklaces, armlets, \&c. Babyslings (item 24), bows, pig-spears, \&c., are sometimes ornamented with pieces of this netting.

43. $r d$-. Ornamental cord, made by men from the yellow skin of an orchid root, and worn round the waist intertwined sometimes with fibres of the Melochia velutina (Andam., al aba-). It is also occasionally interwoven with fibres of the Anadendron paniculatum (Andam., yōolba-), in order to make ornamental fastenings ior arrows, turtle harpoons, and personal adornments.

44. chàu'ga-tâ-. ${ }^{11}$ Human bone necklaces sometimes ornamented with Dentalium octogonum. These are worn as charms during illness by friends or relatives of the deceased, and may be often seen tied tightly round the part in pain; they are also worn when in health to ward off disease. ${ }^{12}$

1 Vide "Journ. Anthrop. Inst.," vol. vii, Plate XII, fig. 35.

2 Ibid., vol. xi, Plate XXIII, figs. 13, $13 a$, and $13 b$.

3 Ibid., figs. 6 and $6 a$.

4 Ibid., vol. vii, Plate XII, fig. 42.

5 Ibid,, fig. 39.

6 Vide "Journ. Anthrop. Inst.," vol. vii, Plate XII, fig. 40.

7 Ibid., fig. 45.

8 Ibid., fig. 73.

9 An interesting description of these various necklaces will be found in a paper by Dr. Allen Thomson, F.R.S., " Journ. Antbrop. Inst.," vol. xi, p. 295.

${ }_{10}$ Vide "Journ. Anthrop. Inst.," vol. vii, Plate XII, fig. 34.

11 Ibid., fig. 46.

12 Vide Part I, " Medicine," paragraphs 2, 7, 8. VOL. XII. 
45. chàu'ga l'ôt chè'ta-. ${ }^{1}$ Human skull, carried in memoriam by relatives of the deceased. ${ }^{2}$

46. chàu'ga l'âk kà $\bar{e}^{\cdot} k i b-{ }^{3}$ Human jaw, which is carried in a similar manner. ${ }^{4}$

47. $p \bar{\imath} \cdot l i c h a-.^{5}$ Boar's tusk, used for planing bows, paddles, \&c.: as it answers this purpose, in their hands, admirably, it is much valued; when required for use the inner edge is sharpened with a Cyrena shell.

48. taili-ban'c-.6 Stone hammer, which the men now use principally in beating out iron for arrow-heads, \&c., and the women when making bone necklaces.

49. chi $\cdot d i-.^{7}$ Pinna shell, used as plates for food, or as receptacles for pigments.

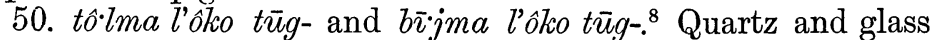
flakes and chips used for shaving, scarifying, and tattooing. ${ }^{9}$

51. $\bar{u} \cdot t a-.^{10}$ Cyrena shell: great use is made of this, and of other varieties of this class, viz., as knives for cutting thatching leaves, for making the ornamental incisions on bows, paddles, \&c., for planing, for sharpening the boar's tusk (item 47), for dressing and preparing arrows, for making the $\bar{u} j$ - (item 76), for preparing the fibres obtained from the Melochia velutina (Andam., al:aba-). Gnetum edule (Andam., pīlita-), and the Anadendron paniculatum (Andam., yōllba-); they are also used as spoons in eating the gravy of pork, turtle, \&c., and are in fact so constantly in demand that a supply is always kept and carried about ready for use.

52. tâlag-. ${ }^{11}$ Hone or whetstone, which when in use is held in the right hand and applied to the edge of the blade, which is generally held over the inner side of the left foot, the operator being seated on the ground; pointed weapons are sharpened on it in the usual way.

53. nip l'ar $b \bar{u} \cdot l$-. Serrated bone at the root of the tail of the sting-ray; in former times their tốlbōd-arrows (items 4 and 7 ) were headed with these bones, and it is believed that the early reports of the poisoned arrows of the Andamanese are entirely

1 Vide "Journ. Anthrop. Inst.," vol. xi, Plate XXIII, fig. 7.

2 Vide Part II, "Death and Burial," paragraphs 5 and 19.

3 Vide "Journ. Anthrop. Inst.," vol. xi, Plate XXIII, fig. 7a.

4 Vide Part I, "Medicine." paragraph 9.

5 Vide "Journ. Anthrop. Inst.," vol. vii, Plate XII, fig. 65.

6 Ibid., fig. 72.

7 Ibid., Plate XIII, fig. 26.

8 Ibid., Plate XII, fig. 61.

9 Vide Part III, “Stone Implements," paragraphs 3-6.

10 Vide "Journ. Anthrop. Inst.," vol. vii, Plate XII, fig. 63.

11 Ibid., fig. 56. 
due to this circumstance ; for, owing to their fragile spikes, these bones are apt to cause very serious flesh wounds. ${ }^{1}$

54. gar'en-. Dentalium octogonum used in the manufacture of various personal ornaments.

55. rim Gironniera) of that name, which is used in making $k \hat{a} \cdot n g a l \hat{a}-b \bar{u} j-$ (vide item 62).

56. $a \cdot j a-p \bar{\imath} d-$. Wax of the white honeycomb: it is one of the ingredients in $k \hat{a} \cdot n g a t \hat{d}-b \bar{u} j$ - (item 62 ), and is also used in the manufacture of the chappanga- (item 22).

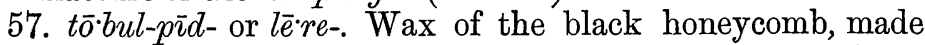
by a small description of bee in the hollows of trees: it is generally procured by men, and is applied to bowstrings, arrow fastenings, and the $k \bar{u} d$ (item 20) is used for caulking cracks in canoes and buckets.

[Nотв.-The honey is eaten, but is not so much relished as that from the white combs.]

58. $t \hat{\alpha} \cdot l \alpha-\bar{o} g-.^{2}$ White clay, used mixed with water, for ornamental painting of the person and of various articles, e.g., bows, baskets, buckets, trays, \&c.: the work is done by women : when painting their relatives they spare no pains in executing neat designs with their finger-nails.

[NoтE.-Women during pregnancy are in the habit of nibbling small quantities of this substance from time to time, in the belief that it is beneficial to their condition.]

59. $\bar{o} g$-. Common whitish clay, lumps of which are found somewhat plentifully in various parts of the islands. It is used, mixed with water, for smearing over the body when the heat is oppressive. $^{3} \quad$ A lump of it is placed on the top of the forehead as a symbol of bereavement, and kept there generally until the expiration of the mourning period. ${ }^{4}$ It is also sometimes used by way of ornament on the person, by smearing the trunk and limbs with the wash and then, before it has had time to dry, passing the outspread finger-tips over the surface so as to form some pattern. ${ }^{5}$

60. kòi $\cdot o b-{ }^{6}$ Red-ochre paint, which is made by mixing red

1 "These wounds often cause great inflammation, whence a notion has been prevalent from ancient times that the sting is charged with renom, but of this there is no evidence. Other species of the sting-ray are plentiful in the warmer parts of the world, and they are everywhere dreaded. The spine is used br the savages of the South Sea Islands to point their spears ("Chambers's Cyclop.").

2 Vide Part III, "Painting," paragraph 7.

3 Vide Part I, "Anatomy and Physiology," paragraph 5.

4 Vide Part II, "Death and Burial," paragraphs 2, 6, 8, and footnote ${ }^{1 .}$

5 Vide Part III, " Painting," paragraphs 5 and 6.

$6 k o i \cdot o b$ - is collected chiefly during the dry months; in its natural condition, as found, it is called $k \hat{o} i^{\circ} \circ b-c h \bar{u} \cdot \operatorname{lng} a^{-}$; in that condition it is applied to sores, and to the persons of fever patients ; it is administered internally for coughs, fevers, \&c. (vide Part I, "Medicine," paragraphs 4 and 5). 
oxide of iron, $\bar{u} \cdot p l a$ - (vide next item), with some greasy sub stance, the fat of the pig or turtle, sometimes of the iguana, dugong, \&c., and occasionally the oil of an almond, called $\bar{e} \cdot m e j-$, is used. This pigment is applied to the person either ornamentally or otherwise. It is accredited with hygienic properties, ${ }^{1}$ and from its mode of application it can be readily determined whether the wearer is suffering or rejoicing. The nostrils and centre of the upper lip are occasionally painted with it, as the smell of the fat is agreeable to them. ${ }^{2}$ Before a corpse is removed for burial it is smeared over the face and neck with this paint as a mark of respect, and in order to please the departed spirit.

61. $\bar{u} \cdot p l a-$. Red oxide of iron after it has been dried and baked. It is principally used in making the pigment described in the preceding paragraph. It is also employed in the manufacture of the red wax, called $k \hat{a}$ ngatâ-büj- (vide next item).

62. $k \hat{a} \cdot n g a t a-b \bar{u} j-$. Red wax, generally prepared by men, composed of $\hat{\alpha} \cdot j a-p \bar{\imath} d-$, rim-, and $\bar{u} \cdot p l a-$ (items 56,55 , and 61 ); in the absence of the last-named ingredient kòiob- (item 60) is substituted. These three substances are melted and stirred over a fire until of a proper consistency; the pigment is then poured into small pots or large shallow shells, where on cooling it soon hardens. When required for use the pot or shell is placed on the fire and the melting wax applied according to fancy. The string fastenings of fish and pig arrows (items 4,5 , and 6) the turtle harpoon (item 10), and pig spear (item 9), are protected with a coating of this wax, and it is applied ornamentally to the food trays (item 72), nautilus shells (item 14), and the outside of buckets (item 13); it is also used for closing cracks in buckets, and in canoes if not too large.

63. chü $\operatorname{lng} \alpha-$. Blue-black clay found in small springs in the jungles : in its liquid form it is applied medicinally after the manner of kòi $o b-c h \bar{u} \cdot \operatorname{lnga}$ - (vide footnote ${ }^{6}$, p. 403).

64. yōlba-. (Anadendron paniculatum), the fibre of which is much valued on account of its excellence; string made from it is used for bowstrings and arrow fastenings, for netting the chápanga- (item 22), and rab- (item 42), for making their various necklaces and other personal ornaments, and also for the fastenings of knives and turtle harpoons.

65. $p \bar{\imath} \cdot l i t a-($ Gnetum edule), from the fibre of which string is prepared and used almost exclusively by women, chiefly for the manufacture of the $k \bar{u} d$ - (itern 20), and pär $\bar{e} p a-$ (item 23); it is

1 Vide Part I, "Medicine," paragraph 2.

2 Vide Part I, "Odour."

3 Vide "Journ. Anthrop. Inst.," vol. xi, Plate XXIII, fig. 10. 
not sufficiently strong to serve as arrow fastenings, though on an emergency it is sometimes used for this purpose.

66. al:aba-(Melochia velutina). From fibre obtained from this tree rope is made for turtle-lines (bétma-), nets, and cables, the preparation and manufacture of which devolve on men; the bark of this tree also furnishes the material of which the chip(item 24) or baby-slings are made.

67. pốtòkla-. Netting-needles, made in two sizes of bamboo, and used in making nets.

[NoTE.-The turtle-net (item 12) is not made with netting-needles, but with two sticks called kñutegbo-.]

68. pô-chô-. Bamboo knives, which are shaped into form while green and then dried and charred over a fire to render them sharp and fit for use; formerly they were employed for cutting meat and other food. ${ }^{1}$

69. wai-cho-and pôr-chô-. Two varieties of cane knives, ${ }^{2}$ but similar to item 68.

70. $t \bar{o} \cdot u g-{ }^{3}$ Torch, made by women, of resin wrapped in a large leaf (Crinum lorifolium); it is used when fishing, travelling, or dancing by night: the resin is obtained from a large tree called by them maiv -, which also is often employed in the construction of their largest canoes. A larger description of torch is made by men, and used when fishing by night.

71. la pi-. Gurjon wood torch, obtained from the heart of rotten logs of the Dipterocarpus laevis (Andam., Árain-): as these do not burn so readily as the tō.ug- (item 70) they are rarely used outside their huts.

72. pūंkuta-yat-mäknga- ${ }^{4}$ Food tray, made by men of some soft wood, generally of the large flat buttress roots of the trees (Sterculiacea) of which their canoes are made.

73. $d \cdot r a-$. Long fringe-like cane-leaf wreaths, which are made by women, and suspended from trees, \&c., round an encampment or hut where a death has occurred, and round the spot where the corpse is deposited in order to warn off persons inadvertently approaching the place, which is believed to be haunted by the spirit of the deceased. ${ }^{5}$

74. kî́pa-jatnga-. Fan-like screen, made by women, of a description of palm-leaf (Andam., $k \hat{a} \cdot p a-$ ), two of which are fastened together with leaf stems : it is used for many purposes, amongst others as a protection from rain and from the direct rays of the sun in hot weather; in the absence of a pärrēpa- (item

1 Vide "Journ. Anthrop. Inst." vol. xi, Plate XXIII, fig. 12.

2 These are made of a light hard wood known as be'rewil.

3 Vide "Journ. Anthrop. Inst.," vol. vii, Plate XII, fig. 66.

${ }^{4}$ Ibid., Plate XIII, fig. 16.

5 Vide Part II, "Death and Burial," paragraph 3. 
23 ) it is often used as a sleeping mat, and it serves also as a wrapper for bundles of various kinds.

75 . $k \hat{a} \cdot p a-$. Leaf wrappers, as described above, are employed for storing and packing the red oxide of iron.

76. $\bar{u} j j_{-}^{1}$ Long brush-like shavings of the Tetranthera lancofolia, prepared by men with the sharp edge of a Cyrena shell. When dancing these are often held (by both sexes) in their hands, or are stuck in their waistbelts or other personal ornaments.

77. kô. no-. ${ }^{2}$ Iron knife used in cutting up food; to some a wooden or iron skewer is attached, they are then called cham-chô-.

$78 .^{3}$

79. $\bar{o} \cdot$ bunga-. Species of apron, consisting of one to six leaves of the Minusops Indica (Andam., dō'gota-), which are fastened to the lowest $b \bar{o} d-$ by women from motives of modesty $;^{4}$ the leaves are not spread out so as to cover a wide surface, but are laid one above the other, and removed separately as each becomes stiff and shrivelled: the reason given for the selection of this particular leaf is that it keeps green and fresh for a longer time than any other.

[NoтE.-The women of the North Andaman tribes, until recent years, appear to have worn no $\bar{o} \cdot$ bunga, or only in a very modified form; the change which is now observable among them in this respect is doubtless to be traced to their intercourse with the people of South Andaman.]

80. kai-. ${ }^{5}$ Bamboo tongs, made by women, and used for any purpose which would involve a risk of burning or scalding the fingers, such as lifting a pot or piece of cooked food off the fire.

81. ko*pöt-. Bucket made from a single joint of the Bambusa gigantea, pieces of which are sometimes found on the coast, having floated ashore from the neighbouring continent or from wrecks; they are much valued on account of their lightness and the labour saved in making a wooden bucket (dâakar-, item 13), which being, as before described, scooped out of a single piece of wood, is a laborious undertaking.

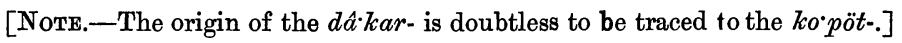

82. $g \bar{o} b$-. Bamboo vessel, of which there are two varieties, viz., $(a)$ for use as a water-holder : this is often 4 or 5 feet long, the partitions at the points being broken through with a spear head or other suitable instrument, the lowest one only being left to form the bottom of the vessel ; and (b) for use as a cooking pot and food-holder: its length consists of a single joint of

1 “Journ. Anthrop. Inst.," Plate XII, fig. 37.

2 Ibid., Plate XIII, fig. 21.

3 This No. is attached to "Specimens of Andamanese Hair."

IVide Part I, "Psychology and Morals," paragraph 8, and footnote.

5 Vide "Journ. Anthrop. Inst.," vol. xi, Plate XXIII, fig. 11. 
bamboo, into which-after it has been cleaned, washed, and dried over a fire-food is packed and cooked; as will be seen by reference to Part III, ${ }^{1}$ these vessels are only capable of serving on a single occasion, the handle is formed with a piece of be $t m a-$.

83. la - Cooking stones: the mode in which they are used is described in Part III. ${ }^{2}$

[A few other objects, omitted from this list, will be found described in "Journ. Anthrop. Inst.," vol. vii, pp. 457, 65.]

1 Vide "Food," paragraph 31.

2 Ibid., paragraph 27, and “Stone Implements," paragraph 2. 


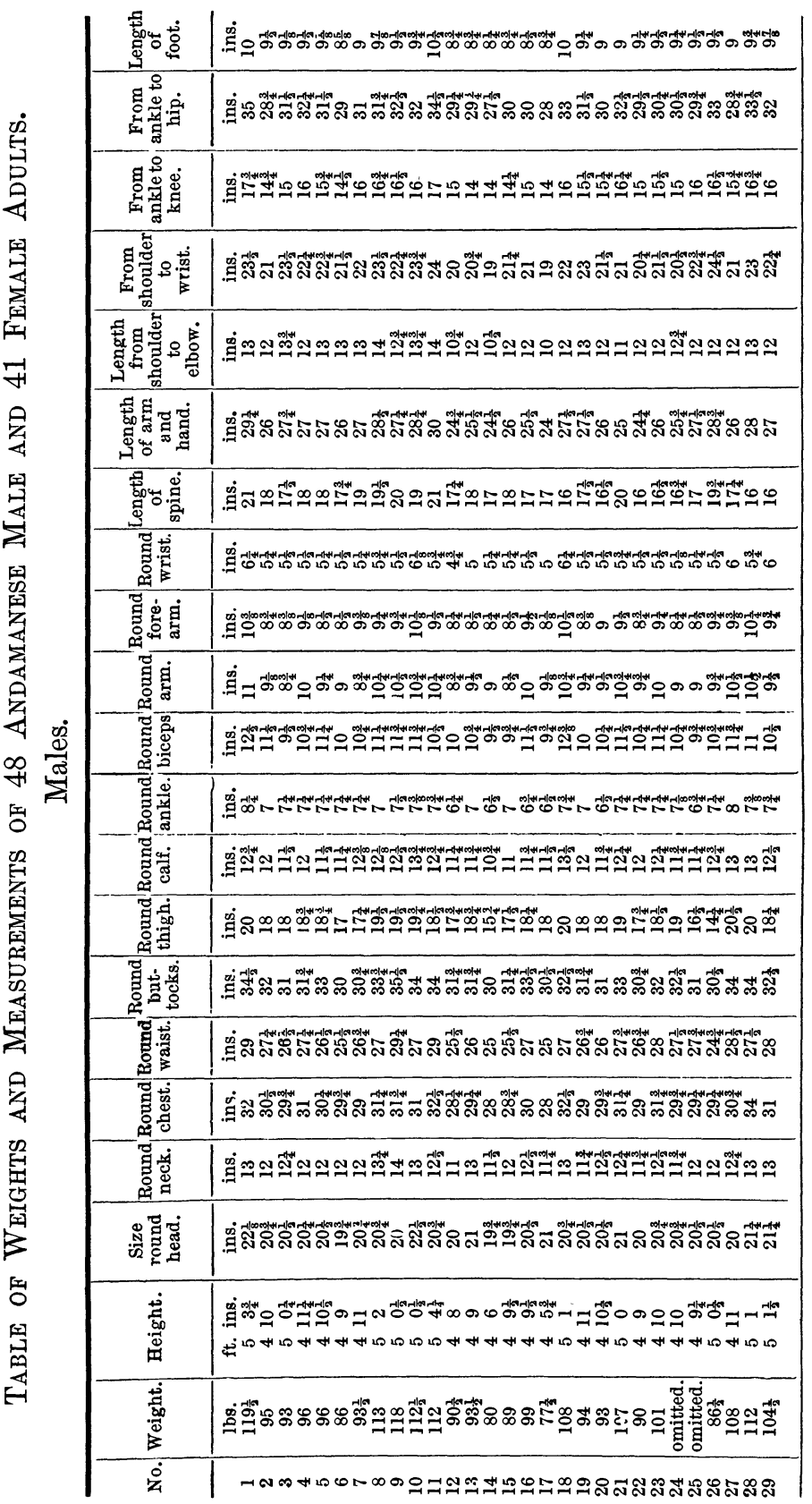


of the Andaman Islands.

\begin{tabular}{|c|c|}
\hline 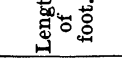 & 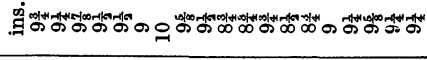 \\
\hline 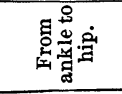 & :్రై \\
\hline 总迹 & 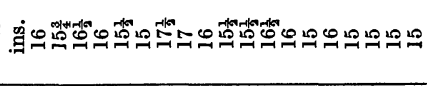 \\
\hline 总兽。商 & : \\
\hline 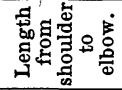 & 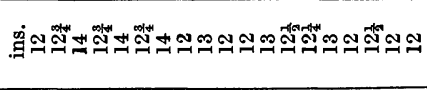 \\
\hline 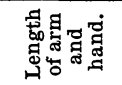 & : \\
\hline 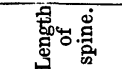 & 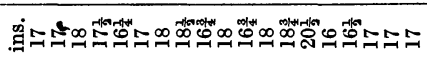 \\
\hline 蕰 & 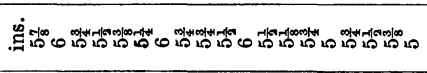 \\
\hline 实朂 & 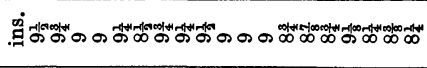 \\
\hline ถี่ & 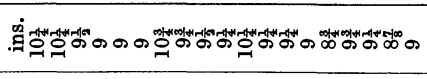 \\
\hline 㿣 & $\stackrel{\Xi}{\Xi}=$ \\
\hline 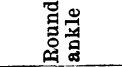 & 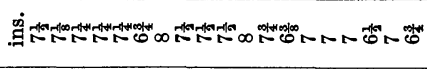 \\
\hline 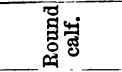 & 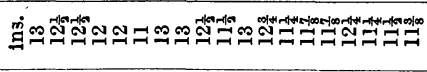 \\
\hline '气ี & : \\
\hline 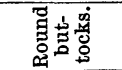 & 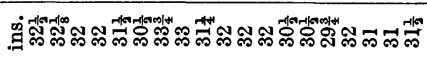 \\
\hline 㻤㙂 & ఏ్మ \\
\hline "ై & 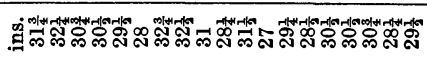 \\
\hline "ేี & $\dot{\Xi}$ \\
\hline 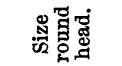 &. \\
\hline 密 & 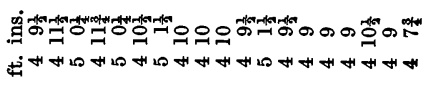 \\
\hline$\frac{\sqrt{50}}{20}$ & 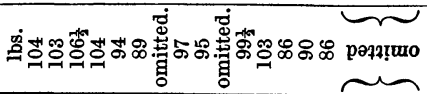 \\
\hline$\dot{0}$ & 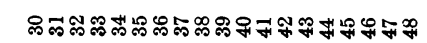 \\
\hline
\end{tabular}


E. H. MaN.-On the Aboriginal Inhabitants

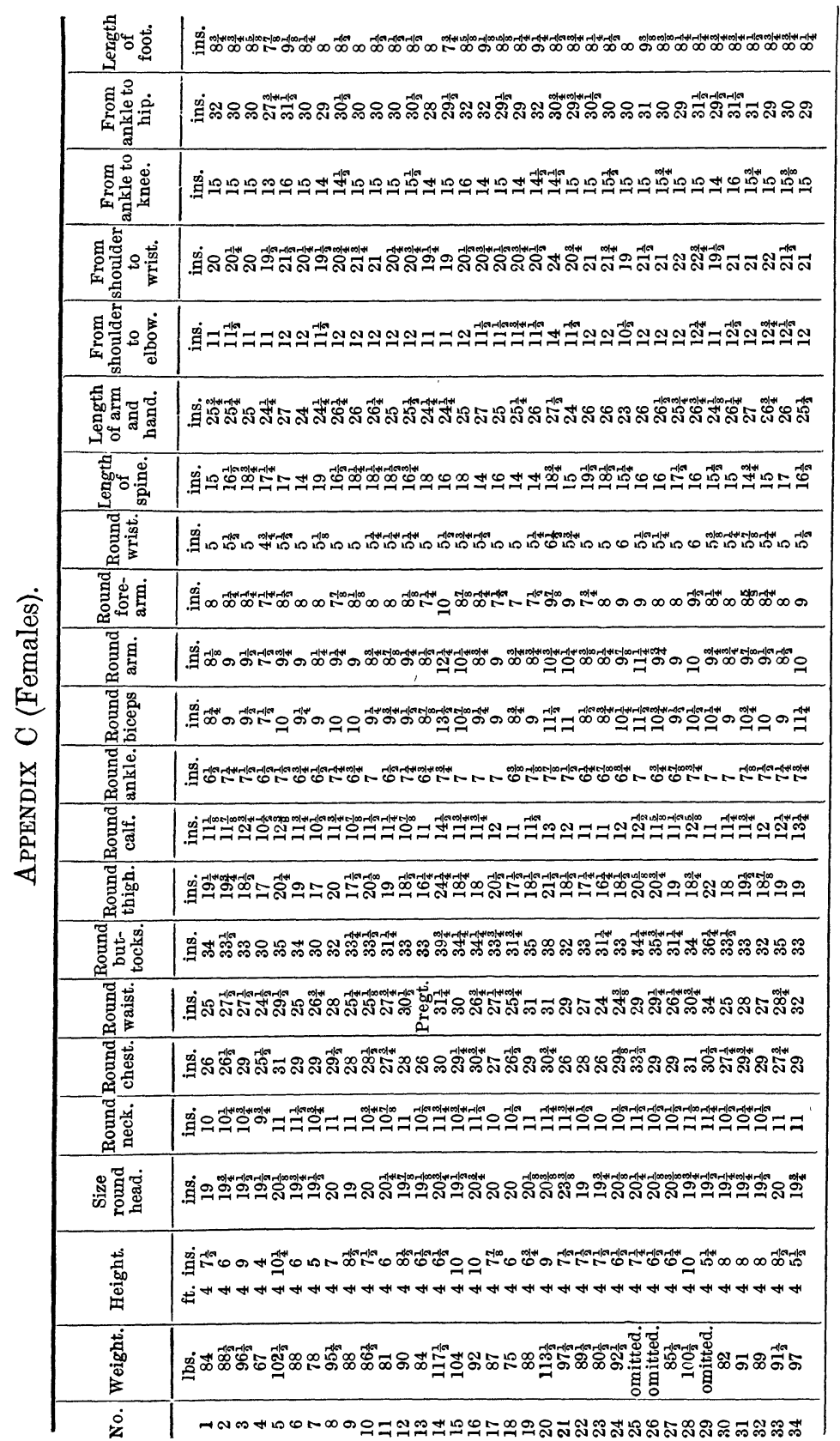


of the Andaman Islands.

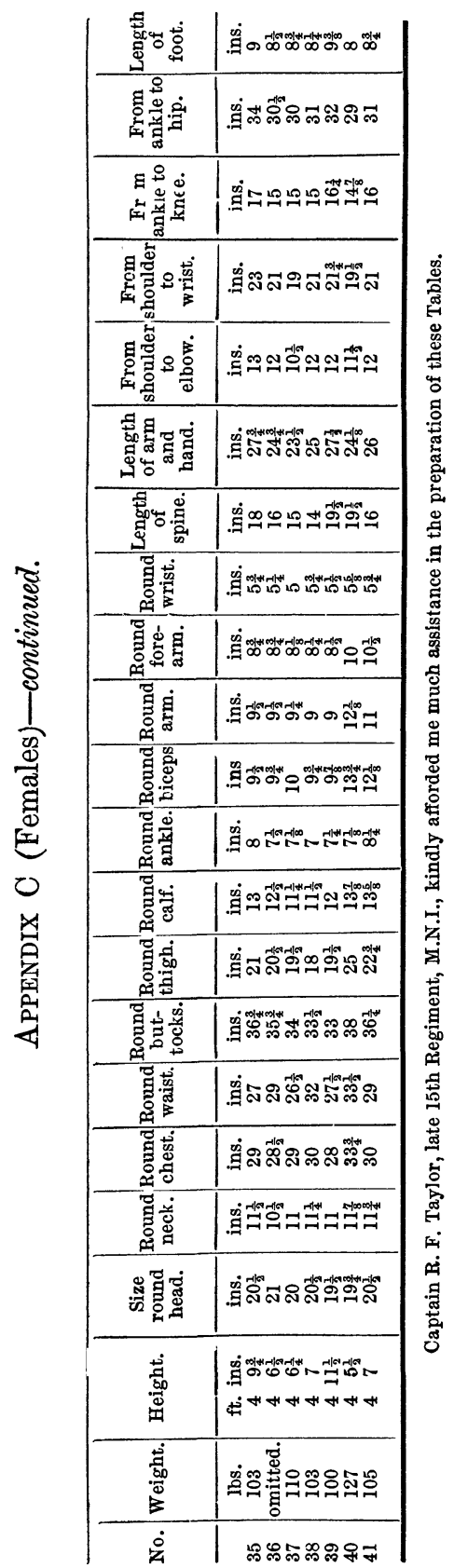




\section{APPENDIX D.}

This Appendix consists of a long extract from a paper by Mr. J. E. Calder, descriptive of the Native Tribes of Tasmania, published in the "Journal of the Anthropological Institute," vol. iii, 1874, p. 7. The extract was introduced for the purpose of illustrating the many points of striking similarity, both in physical constitution and in culture, between the extinct Tasmanians and the Andamanese. But as the members of the Institute can readily refer to the back volume for the original paper, it has been considered unnecessary to reprint the extract in this place. It is proposed, however, to issue Mr. Man's papers in the form of a separate monograph, and the extract in question will then be printed in full. 
of the Andaman Islands.

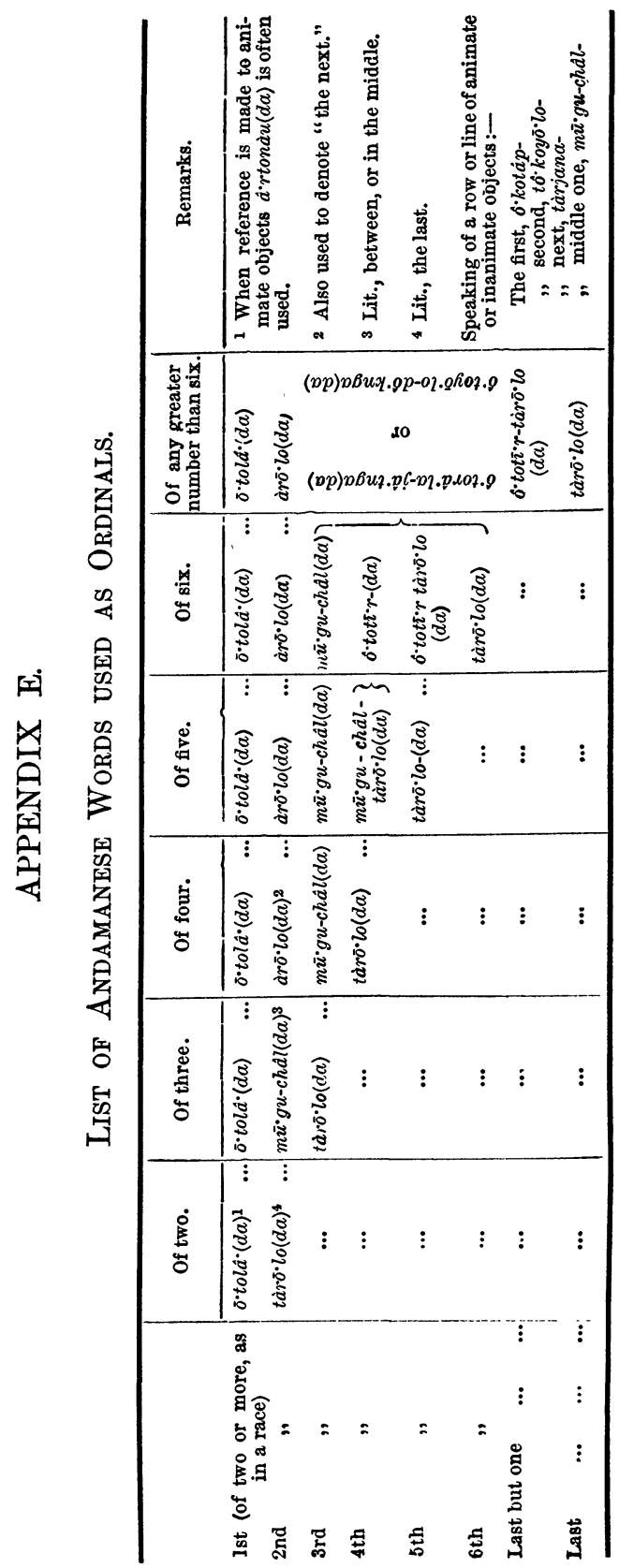




\section{APPENDIX F.}

\section{Specimen of the South Andaman Language.}

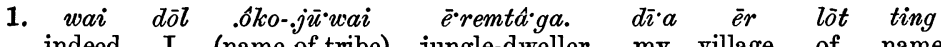
indeed I (name of tribe) jungle-dweller. my village of name

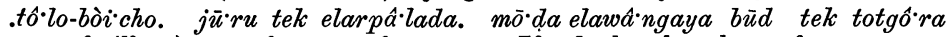
(name of village). sea from far. If daybreak at home from coast

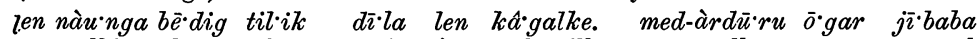
to walking by perhaps evening in reach-will. we all moons several

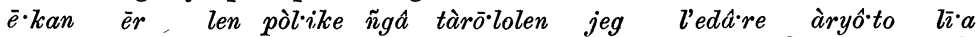
own villages in live-do then afterwards dance for sake of coastmen of

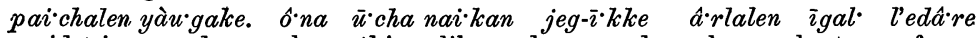
midst-in go-do. when this like dance-go-do always barter for

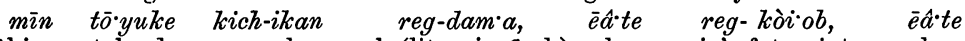
things take-do namely pork (lit., pig-flesh), also pig's fat paint, also

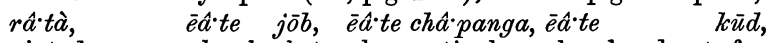

wooden-pointed arrows, also baskets, also reticules, also hand-nets for fishing, $\bar{e} \hat{a} \cdot t e \quad r a \hat{b}, \quad \bar{e} \hat{a} \cdot t e \quad t \hat{a} \cdot l a-\bar{o} g, \quad \bar{e} \hat{a} \cdot t e t \hat{a} \cdot l a g, \bar{e} \hat{a} \cdot t e \quad p \ddot{a} r \cdot \bar{e} p a$, also necklaces of fine net-work, also white-clay, also hones, also sleeping-mats, $\bar{e} \hat{a} \cdot t e \quad k \hat{a} \cdot p a-j \hat{a} \cdot t n g a, \hat{a} w \bar{e} \cdot h$.

also leaf-screens, etcetera.

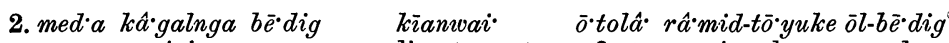
we arriving on according-to-custom first sing-do and

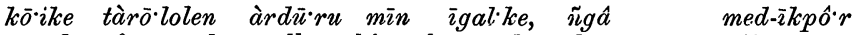
dance-do afterwards all things barter-do, then we two (i.e., some of us)

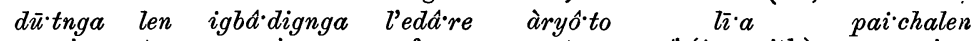
spearing to seeing for coastmen of (i.e., with) possession

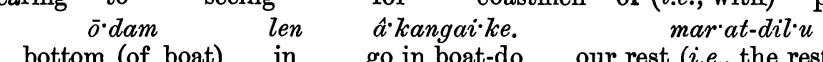
bottom (of boat) in go in boat-do our rest (i.e., the rest of us) àryô'to-ngī'ji mit'iknga '̄ंrem-del'eke. coastmen-friends accompanying in jungle-hunt-pigs-do.

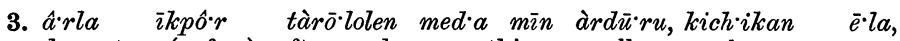
days two (a few) afterwards we things all, such as pig-arrows,

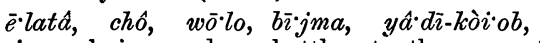

iron, knives, adzes, bottles, turtle-unguent (red paint made with turtle-fat), $y \hat{a} \cdot d \bar{\imath}-d a m \cdot a, \quad \hat{o} \cdot d o, \quad c h \bar{\imath} \cdot d i, \quad$ gar'en. re $\cdot k e t o-t \hat{a}$, turtle-flesh, nautilus-shells, Pinna shells, Dentalium octogonum. Hemicardium unedo

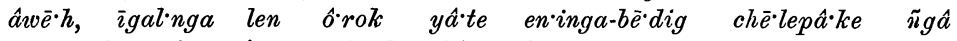
etcetera, bartering in received which having-taken take-leave-do then $\imath \bar{i}-j k e$.

return (home).

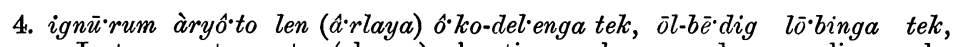
Just as coastmen to (always) hunting by, and poling by $\bar{o} l-b \bar{e} \cdot d i g \quad y \hat{a} t-d i l \cdot u \quad$ tek $e b \cdot a-k \hat{a} \cdot c h y a$ â. $k \grave{a}-w \bar{e} \cdot l a b$ y $\bar{a} \cdot b a d a, c h \hat{a}$ and means-rest (i.e., other means) by ever food-difficulty not so

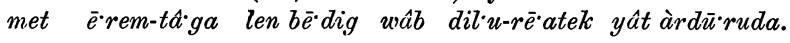
we jungle-dwellers to also season every food all (sorts).

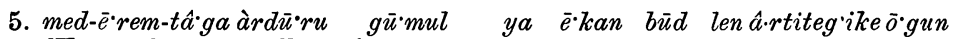
We-jungle-men all rainy season during own homes in remain only 


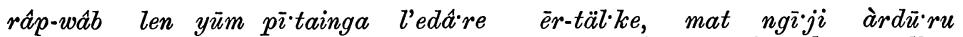
fruit-season in rain absence because-of pay-visits-do our friends all

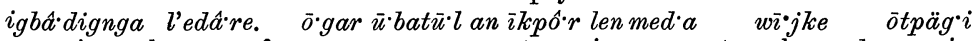
seeing because-of moon one or two in we return-home-do again

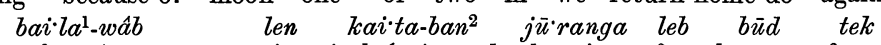

(name of tree)-season in jack-fruit-seed burying for homes from mat-tố-jīंalke. $\quad \bar{o} \cdot g a r \bar{u} \cdot b a t \bar{u} \cdot l$ len $\bar{e} \cdot k a n$ er lat wì $\cdot j k e$.

we shift-our-quarters-do. moon one in own villages to return-home-do.

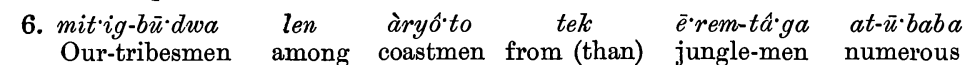

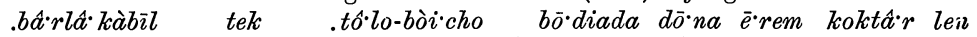
(name of village) than (name of village) large but jungle interior in

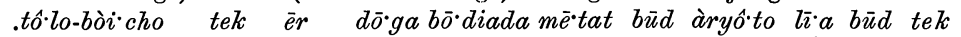
(name of village) than villages many large our huts coastmen of huts than

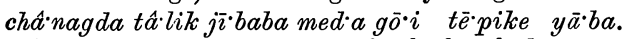

large years many we fresh thatch-do not.

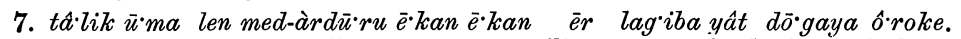
Year whole in we all own own villages near food plenty find-do.

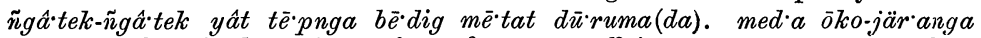
now and then food getting for for us sufficient. we constantly $k \bar{o} \cdot i k e \quad \overline{o l}-b \bar{e} \cdot d i g$ rấmid-tō'yuke. dance and sing.

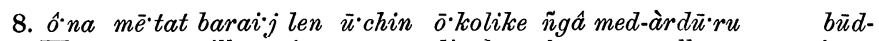

When our village in any one die-does then we-all camping-ground

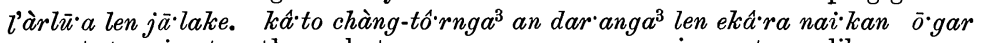
vacant to migrate. there hut or in custom like moons

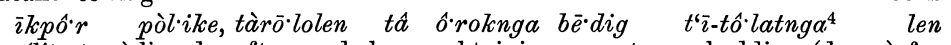
few (lit., two) live-do, afterwards bones obtaining on tears-shedding (dance) for .tốlo-bòi cho lat wì $j k e$.

(name of village) to return (home).

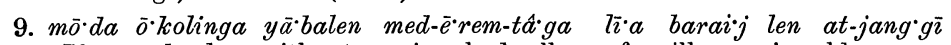

If dead without we jungle-dwellers of villages in old persons lig.ala bèdig ârlalen pòl $\cdot i k e . \bar{o} \cdot g u n$ râp-wâb len mè'tat paíchalen atpail children also always live. only fruit-season in as with women

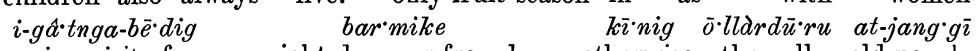
paying-visits-for pass-night-do-away-from-home otherwise they-all old people

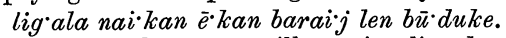

children like own villages in live-do.

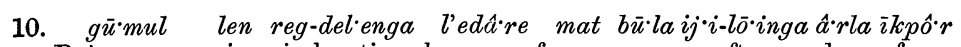
Rainy-season in pig-hunting because of we men often days few bar'mike.

pass-night-do-away-from-home.

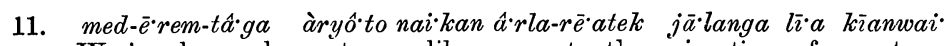
We-jungle-people coastmen like constantly migrating of custom

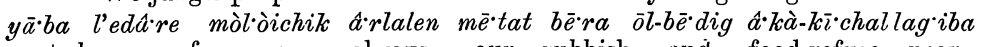
not because of we always our rubbish and food-refuse near

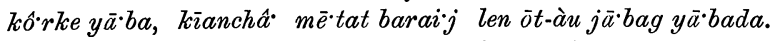
scatter not therefore our villages in smell bad not.

1 Terminalia procera, which flowers about the middle of May.

2 Artocarpus chaplasha.

3 Vide Part I, "Habitations," paragraphs 3 and 4, for description of these varieties of huts.

* Vide Part II, “Death and Burial," paragraph 7. 


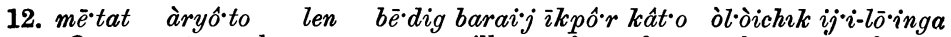
Our coast people among even villages few there they often

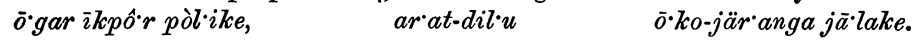
moons few dwell-do, their rest (i.e., the rest of them) constantly migrate.

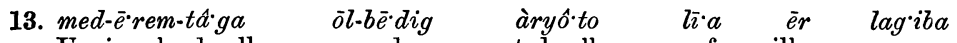
Us jungle dwellers and coast-dwellers of villages near būd-l'â'rtâm dō'gada. jū'ru l'igrấklik len â'rlaya $\bar{e}^{\cdot} \cdot r e m$ tốboda dō'na è'rem kitchen-middens many sea vicinity in always jungle dense, but jungle koktấr len tốbo y $\bar{a} \cdot b a$. middle in dense not.

14. . $\hat{a} \cdot k \grave{a} \cdot . k e d \cdot e, ~ l \bar{i} \cdot a \quad \bar{e} \cdot r e m$ koktầr len lì'rnga-bedig wai dōl (name of tribe) of jungle middle in going indeed I

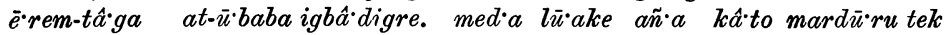
jungle-dwellers numerous see-did. we consider that there us-all than

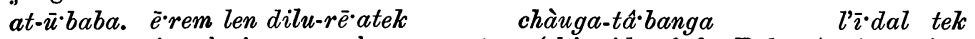
numerous. jungle in everywhere ancestors (this side of the Deluge) time since

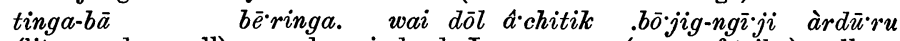
paths (lit., roads small) good. indeed I now (name of tribe) all igbâ.digre, it'ig $b \bar{u} \cdot d w a \quad d \bar{\imath} \cdot r a p-t e k$ yaba $\cdot d a$. have seen, their tribesmen now-a-days few.

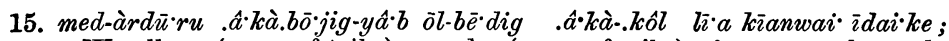
We all (name of tribe) and (name of tribe) of customs know-do

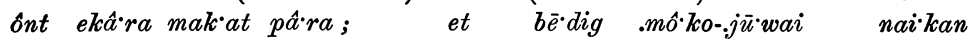
their customs ours similar; among-them also us (name of tribe) like

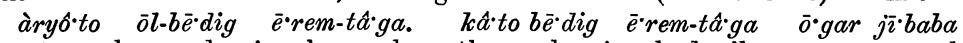
coast people and jungle people. there also jungle-dwellers moons several

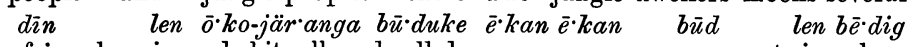
heart-of-jungle in habitually dwell-do own own encampment in also

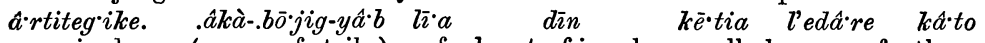
remain-do. (name of tribe) of heart-of-jungle small because of there $\bar{e} \cdot r e m-t \hat{a} \cdot g a \quad y a b \bar{a} \cdot d a$. jungle-dwellers few. 
of the Andaman Islands.

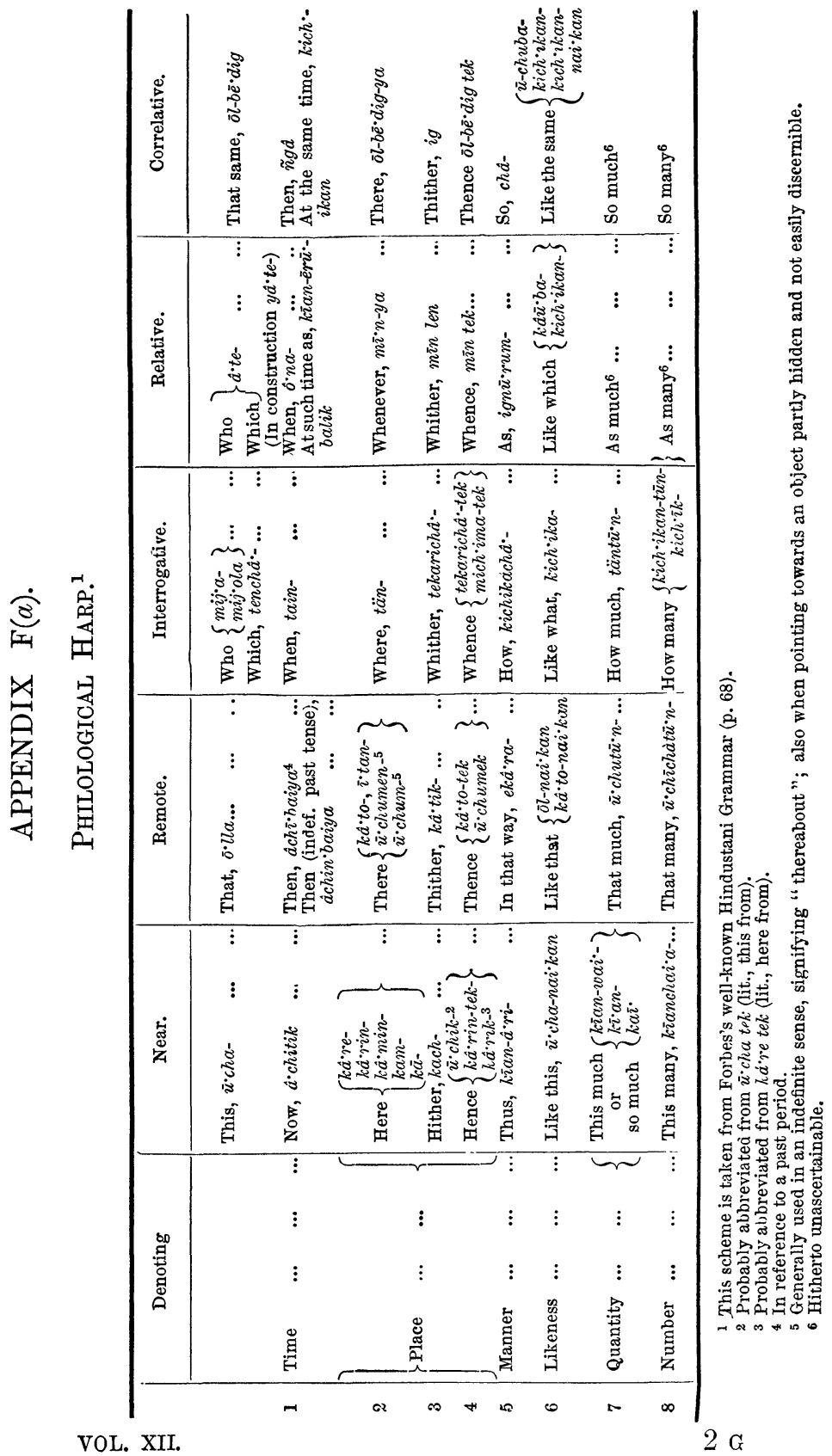




\section{APPENDIX G.}

\section{The Seven Forms of the Possessive Pronouns in relation TO PARTS OF THE BODY (HUMAN AND ANIMAL).}

\begin{tabular}{|c|c|c|c|}
\hline \multirow{8}{*}{$\begin{array}{l}\text { dōt } \\
\text { ngōt } \\
\text { ot .. } \\
\text { l'ot... } \\
\text { mō'tot } \\
\text { ngō'tot } \\
\text { o'tot } \\
\text { l'o'tot }\end{array}$} & & \multirow{3}{*}{$\begin{array}{ll}m y & \ldots \\
\text { thy } & \ldots\end{array}$} & \multirow{2}{*}{ I. } \\
\hline & $\cdot \cdot$ & & \\
\hline & .. & & chē-ta-, head; mün-, brain; yâ-, occipu \\
\hline & .. & his ... & kâkkà-, scalp; lō'ngota-, neck ; lấpta-, nap \\
\hline & .. & $-' s \ldots$ & chäl-ma-, chest; ầwa-, lung; nē-, prosta \\
\hline & . & our ... & gland; tūlēpo-, phlegm; kūg-, heart $(t)$ \\
\hline & .• & your... & seat of the affections and passions), \\
\hline & $\ddot{.}$ & $-s^{\prime}$. & bosom; ku'kta-ban'a-, heart (the organ). \\
\hline
\end{tabular}

II.

dōng $\quad$.. $\quad m y \quad$.. (kô'ro-, hand, or finger ; kồro-mū'gu-châl-, ngōng .. thy .. $\quad$ large (lit., middle) finger; i'ti-pī-, little ong.. $\quad . . \quad$ his ... finger; kô'ro-dō'ga-, thumb; el'ma-, palm of

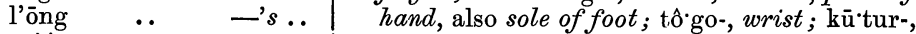
mòi ot $\quad . . \quad$ our ... knuckle; bō'do-, nail of finger, or toe; pâg-, ngòi'ot .. $\quad$ your foot; rōkoma-, toe; tū chab-, large toe; dì'ot- $\quad . . \quad$ their $\quad$ ìlam-, small toe; gū'chul-, heel; târ-, ankle; l'ò'ot $\quad . . \quad-s^{\prime} . . \quad$ châg-, kidney; tẩ'banga-, small intestine; Ex.-dōng kô·ro ngōng tâ'ga-, peritoneum.

kè'tia-. My hand is smaller than thine. my hand thy from (than) small.

III.

\begin{tabular}{|c|c|c|c|}
\hline & & & \\
\hline ka & . & $m y$ & bang-, mouth; dē-liys \\
\hline rä & & thy & â.dal-, chin; pai-, lip; pai-la-pid-, mou \\
\hline l'ầkà & & nls. & tache; ốrma-, throat; è'tel-, tongue; del't \\
\hline $\mathrm{N}_{\mathrm{a}}$ & .. & our & 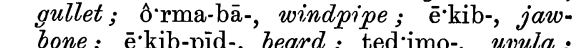 \\
\hline & $\cdots$ & your & $\begin{array}{l}\text { bone; è-kib-pid-, beard ; ted-imo-, } \\
\text { gō-dla-, collar-bone; chấ.ga-, side; }\end{array}$ \\
\hline & & therr & \\
\hline
\end{tabular}

Ex.--kâ'to .bòi'goli l'àrdū'ru l'ak'at è-kib-pĩd lâ'panga-.

There European all their beard long.

All those Europeans have long beards.

IV.

(chàu-, body ; gū·dur- and lân-, back ; gō'rob-, spine; pồdikma-, shoulder-blade ; pai cha-, thigh (also lap); pē'ke-, groin; chầlta-, skin; chầlta-dam-a-, calf of leg; kồpa-, elbow; kô.pa-dam'a-, fleshy part of fore-arm; kū'rupi-dam'a-, fleshy part of upper arm; lō-, knee; â'pita-, hough ; pầretâ-, rib; â·pa-chàu-, belly (abdominal walls); èr-, navel; ū'pta-, stomach proper; jō.do-, entrails, bowels; ji-ri-, ${ }^{1}$ supra-renal fat and omentum; mūg-, liver; pīlma-, spleen; ìjnga-, uterus ; $\hat{a} \cdot w a-$, arm-pit ; yīlnga-, tendon Achilles; nē'ma-, gall-bladder.

1 For a description of the reg-jī'ri-gü'mul-, vide Part II, "Initiatory Ceremonies," paragraphs 15-17. 
V.

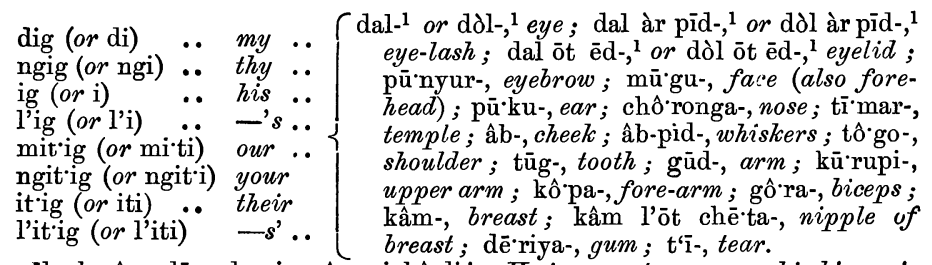

Ex.-oōl ab-gôra dō'gada, ig gồra igbâ·di! He is very strong; see his biceps !

He strong very, his biceps see!

$$
\begin{aligned}
& \begin{array}{lllll}
\text { dar } & . . & . & m y & . . \\
\text { ngar } & . . & . . & \text { thy } & . .
\end{array} \quad \begin{array}{c}
\text { VI. } \\
\text { châg-, leg; chồrog-, hip; è-te-, loin ; mäl·wit-, }
\end{array}
\end{aligned}
$$

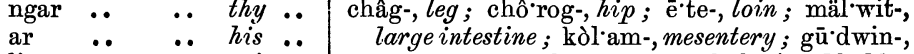

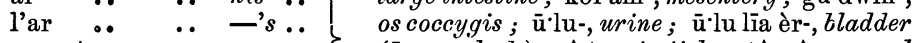

$$
\begin{aligned}
& \text { marat } \quad . . \quad \text { our .. } \quad(\overline{\mathrm{e} r}=\text { abode }) \text {; ồta-, testicle; tô-, ồno-, and } \\
& \text { ngar-at } \quad . . \text { your } \quad \text { dam'a-, buttocks; mū'ga-, rectum; tū-mur-, } \\
& \text { ar'at ... .. their anus. } \\
& \text { l'ar'at Ex.-mar'at châg-, our legs. }
\end{aligned}
$$

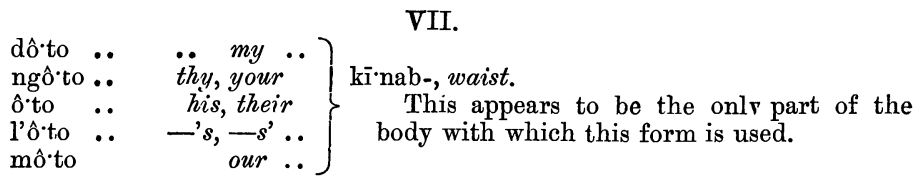

N.B.-In the case of the following words, the possessive adjective peculiar to the part referred to is taken:-pid-, hair; èd-, skin; tâ-, bone; tī-, blood; mū'rudi-, gore ; gū'mar-, sweat ; yī'lnga-, vein, muscle ; wai'nya-, cuticle ; mūn-, pus; dē'kia-, pulse.

$$
\begin{gathered}
\text { Ex.-mō'tot pìd-, the hair of our heads; } \\
\text { ngak'at ed--, the skin of your lips; } \\
\text { dìg tâ-, the bone of my arm; } \\
\text { ngar tì-, the blood of thy leg; } \\
\text { \&c.; }
\end{gathered}
$$

i.e., the above would be understood to represent mō'tot chē'ta pīd-; ngak'at pai èd-; dig gūd tâ-- ngar châg tì-.

1 These words generally take the abbreviated form, $d i, n g i, \& c$. 


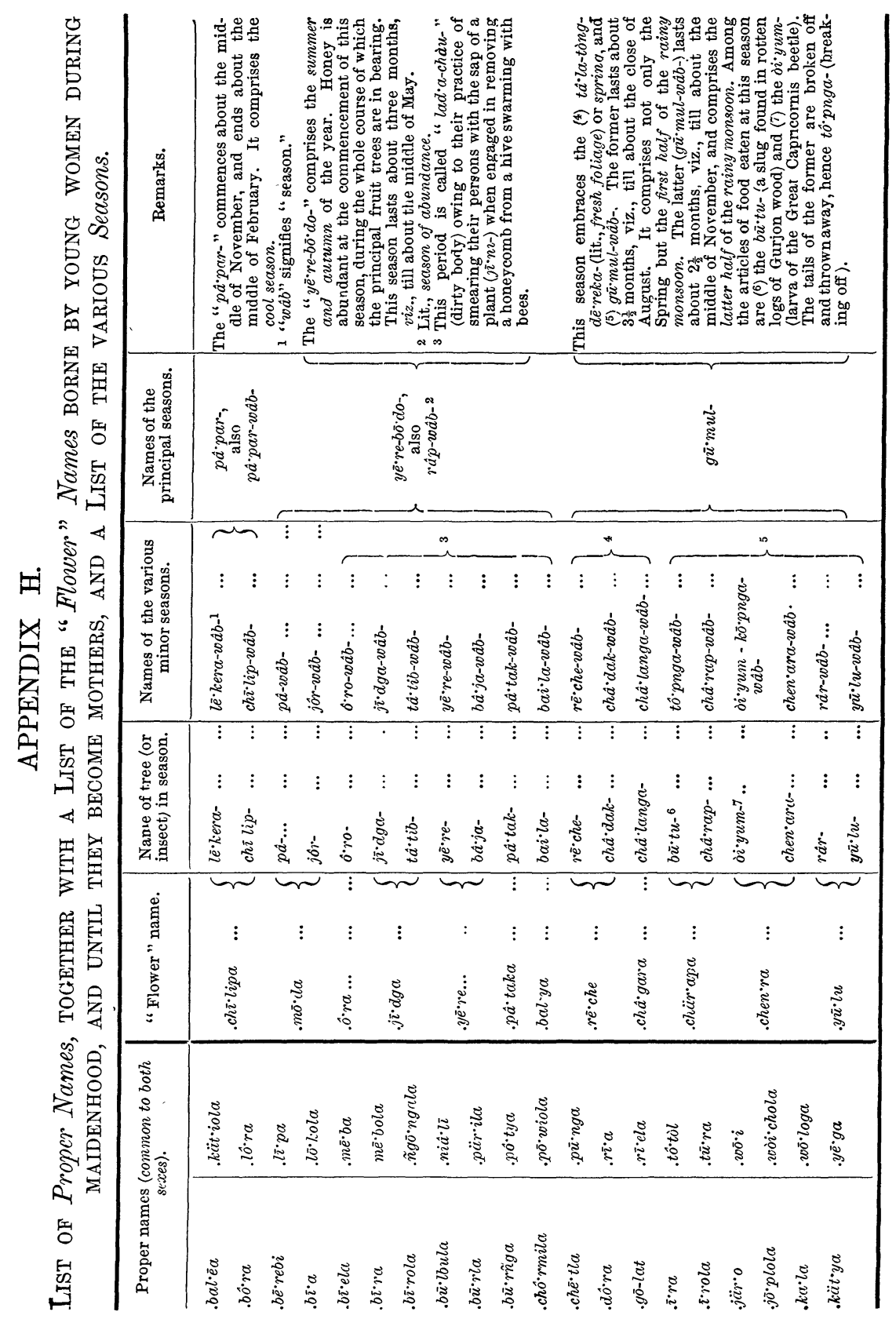




\section{APPENDIX I.}

\section{List of Terms indicating various Degrees of Relationship.}

my father (male or female speaking) .. dab mai ola; dabchấbil-; darō'dinga-. my step-father ",$\quad . . d a b$ chấbil-.

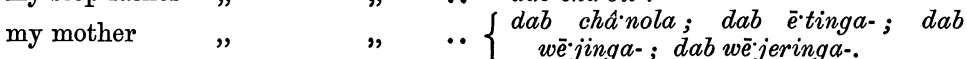

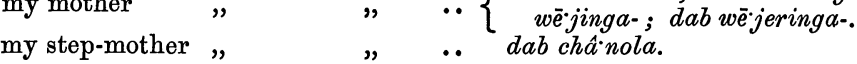

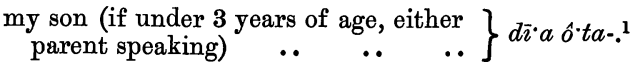

my son (if over 3 years of age, father

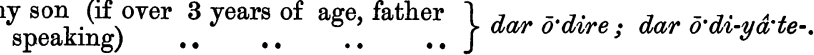

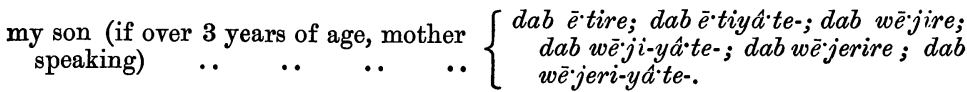
$\left.\begin{array}{ccc}\text { my daughter (if under } 3 \text { years of age, } \\ \text { either parent speaking) } & . . & .\end{array}\right\} d \bar{r} \cdot a k \hat{a} \cdot t a-.^{1}$

$\left.\begin{array}{ccc}\text { my daughter (if over } 3 \text { years of age, } \\ \text { either parent speaking) } \quad \text {.. } \quad . .\end{array}\right\} d \bar{\imath} \cdot a b \bar{a}-\cdot$

$\left.\begin{array}{cccc}\text { my daughter (if over } & 3 \text { years of age, } \\ \text { father speaking) } & . . & . . & . .\end{array}\right\}$ dar $\bar{o} \cdot$ dire-pail-; dar $\bar{o} \cdot d i$-yấte-pail-.

my daughter (if over 3 years of age) $\int d a b$ e $\cdot t i r e-p a i l-; ~ d a b \quad \bar{e}^{\cdot} \cdot t i-y \hat{a} \cdot t e-p a i l-$;

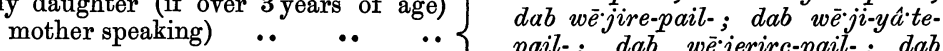

grandson (either grand-parent $\left\{\begin{array}{l}\text { pail-; dab wēंjerirc-pail-; dab } \\ \text { wēंjeri-yâtte-pail-. }\end{array}\right.$ speaking)

my brother's grandson (male or female speaking) $\quad . . \quad$.. $\quad$.. $\quad$..

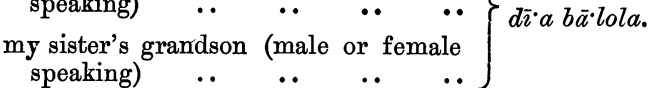

my grand-daughter (either grandparent speaking) $\quad . . \quad$.. $\quad .$.

my brother's grand-daughter (male or female speaking) $\quad . \quad$. $\quad$..

my sister's grand-daughter (male or female speaking) $\quad . . \quad \ldots \quad \ldots$

my elder brother (male or female $\{$ ad-en tốbare; ad-en tốbanga-; ad-en

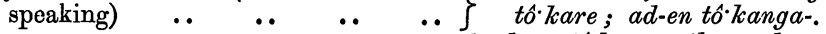

my elder sister (male or female speak- $\int a d$-en tốbare-pail-; ad-en tốbanga-

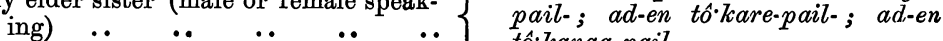

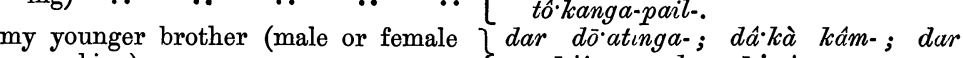

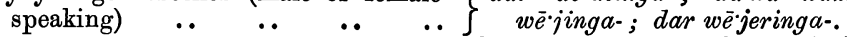

my younger sister (male or female $\left\{d a r d \bar{o}^{*}\right.$ atinga-pail-; $d \hat{a} \cdot \dot{k} \grave{a}$ kâm-

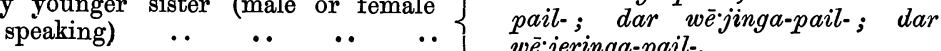

my elder brothers (male or female $\}$ am-et tóbare; am-et tô.banga-; am-et

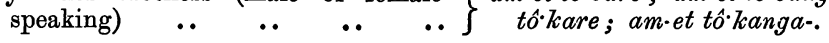

1 ride Appendix $\mathbf{K}$. 
my younger brothers (male or female $\{$ mar.at dō'atinga-; mak•at kâm-;

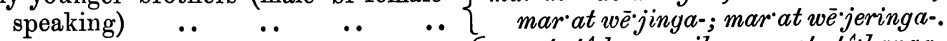
my elder sisters (male or female $\{$ am-et tốbare-pail-; am-et tóbanga-

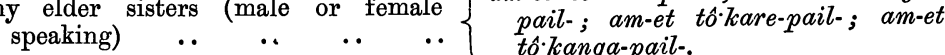

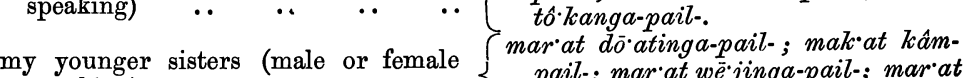
speaking) $\quad$.. $\quad$.. $\quad$.. $\quad$..

my father's brother (elder or younger) my mother's brother " my mother's sister's husband...$\quad \ldots$ my father's father's brother's ( $\ddot{\mathrm{or}}$ sister's) son .
my mother's mother's brother's (or
sister's) son .. my husband's grandfather $\quad \begin{array}{ll}\text {.. } & \text {.. }\end{array}$ my wife's my wife's sister's husband (if elder) ...
my husband's sister's husband (if elder) my father's sister (elder or younger) ..

$\begin{array}{lll}\text { my mother's sister } & , \ldots & \text {, } \\ \text { my father's brother's wife } & \ldots & \text {. }\end{array}$ my mother's brother's wife $\quad \ldots \quad$.. my grandmother, my grand-aunt .. my father's father's sister's daughter
my mother's mother's sister's daughter my mother's mother's sister's daughter
my husband's grandmother my wife's $", \quad$.... my husband's sister (if senior and a mother) $\quad . \quad$.. $\quad . . \quad$.. my elder brother's wife (if a mother).. my brother's son (male or female speaking) $\quad . . \quad \ldots \quad$.. $\quad .$.

my sister's son (male or female speaking).$\quad \ldots \quad$.. $\quad . \quad \ldots$ my half-brother's (or half-sister's) son, or my first-cousin's (male or female) son (male or female speaking) _.

my brother's son's wife (male or female speaking)

my sister's son's wife (male or female speaking) $\quad \because \quad \because \quad \because ; \quad$;

my half-brother's (or half-sister's) son's wife, or my first cousin's (male or female) son's wife (male or female speaking)

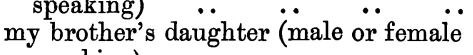
speaking) $\quad \begin{array}{llll}\text {.. } & \ldots & \ldots\end{array}$

my sister's daughter (male or female

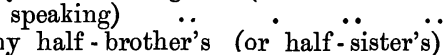

my half - brother's (or half - sister's)
daughter, or my first-cousin's (male or female) daughter (male or female

speaking) ...$\ddot{\text {. }}$ my brother's daughter's husband (male $\begin{array}{rrrr}\text { or female speaking) } & \ldots & . & \\ \text { my sister's daughter's } & \text { husband (male } \\ \text { or female speaking) } & . . & . . & .\end{array}$ $d \bar{i} \cdot a m a i \cdot a$. 
my half - brother's (or half - sister's) daughter's husband, or my firstcousin's (male or female) daughter's husband (male or female speaking)

my father's brother's son, if older (male or female speaking) .. .. my father's sister's son, if older (male or female speaking) $\ldots \quad \quad \because \quad \ldots$ my mother's brother's son, if older (male or female speaking) .. ... my mother's sister's son, if older (male or female speaking) $\quad . \quad$. $\quad .$. my elder half-brother, whether uterine or consanguine (male or female

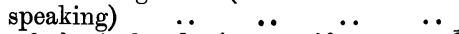

my father's brother's son, if younger (male or female speaking) .. ..

my father's sister's son, if younger (male or femal speaking) .. ..

my mother's brother's son, if younger (male or female speaking) $\quad . \quad$..

my mother's sister's son, if younger (male or female speaking) ..

my younger half-brother, if uterine (male or female speaking) .. ...

my younger half-brother, if consanguine (male or female speaking) ::

my father's brother's son's wife, if older (male or female speaking) ..

my father's sister's son's wife, if older (male or female speaking) , “

my mother's brother's son's wife, if
older (male or female speaking)

my mother's sister's son's wife, if older (male or female speaking)..$\quad \ldots$

my elder half-brother's wife, whether uterine or consanguine (male or female speaking) $. . \quad, \cdots$ my father's brother's son's wife, if younger (male or female speaking) .:
y father's sister's son's wife, if my father's sister's son's wife, if
younger (male or female speaking) ..

my mother's brother's son's wife, if younger (male or female speaking) .

my mother's sister's son's wife, if younger (male or female speaking) ..

the wife of my uterine half-brother, if younger (male or female speaking)...

the wife of my consanguine halfbrother, if younger (male or female

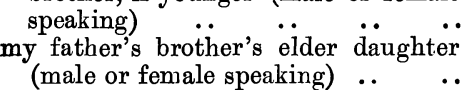

my father's sister's elder daughter (male or female speaking) .. ..

my mother's brother's elder daughter (male or female speaking) $\quad . \quad$.. my mother's sister's elder daughter (male or female speaking) .. $\quad$. )

dar châ.bil entốbare; dar chấbil entốkare.

dar dō'atinga-.

$d \hat{a} \cdot k a \grave{a} k a ̂ m-$.

dar dō-atinga-; dar wēejinga-; dar wè'jeringa-.

dar chấbil entốbare lai ǐ-yâ'te-.

dar dō'atinga lai $\grave{\imath} k-y \hat{a} \cdot t e-$.

$d \hat{a} \cdot k a ̀ a ~ k a ̂ m ~ l a i ~ i ̀ k-y \hat{a} \cdot t e-$.

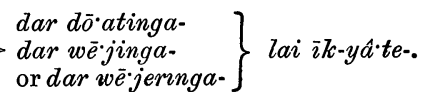

$d \bar{\imath} \cdot a c h \hat{a} \cdot n o l ~ \grave{a}-e n t o \hat{\cdot} \cdot b a y \hat{a} \cdot t e-$. 
my elder half-sister, whether uterine or consanguine (male or female speak-

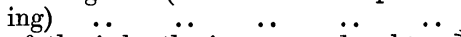

my father's brother's younger daughter

(male or female speaking) ..

my father's sister's younger daughter (male or female speaking) ... .. my mother's brother's younger daughter (male or female speaking) $\quad . \quad \quad$.. my mother's sister's younger daughter (male or female speaking)..$\quad \ldots$ my younger half-sister, if uterine (male or female speaking) .. ... my younger half-sister, if consanguine (male or female speaking) .. .. my father's brother's elder daughter's husband (male or female speaking).. my father's sister's elder daughter's husband (male or female speaking).. my mother's brother's elder daughter's husband (male or female speaking).. my mother's sister's elder daughter's husband (male or female speaking).. my elder half-sister's husband, whether uterine or consanguine (male or female speaking) $\quad . . \quad \ldots \quad \ldots$

ny father's brother's younger daughter's husband (male or female speaking). my father's sister's younger daughter's husband (male or female speaking)..

my mother's brother's younger daughter's husband (male or female speaking)

my mother's sister's younger däughter's husband (male or female speaking). .

the husband of my uterine half-sister, if younger (male or female speaking)

the husband of my consanguine halfsister, if younger (male or female speaking) $\ddot{0}$ (male or $\ddot{\text { female }}$ $\begin{array}{ccccc}\text { my grandfather } & \text { (male or female } \\ \text { speaking) } & \text {.. } & \text {.. } & \text {.. }\end{array}$ my grandfather's brother (male or female speaking) $\quad . \quad$.. $\quad$.

my grandmother's brother (male or female speaking) $\ddot{0}$.

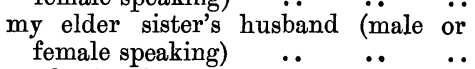

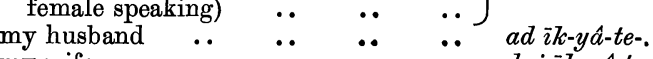

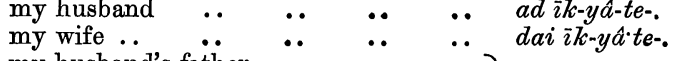

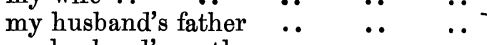

my husband's mother $\quad . \quad \quad$.. $\quad$..

$\begin{array}{llll}\text { my wife's father.. } & . & . . & . \\ \text { my wife's mother } & . & . . & \text {.. }\end{array}$

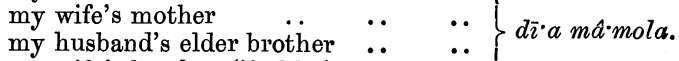

my wife's brother (if older) $\quad \because \quad \ldots$

my husband's sister's husband (if older)

my wife's sister (if older ${ }^{1}$ and a mother)

$d \bar{\imath} \cdot a \operatorname{ch} \hat{a} \cdot n o l ~ \grave{a}-e n t \hat{\cdot} \cdot b a y \hat{a} \cdot t e-$.

dar dō'atinga-pail-.

$\{d \hat{a} \cdot k \grave{a} k a ̂ m-p a i l-$.

dar dō'atinga-pail-; dar ée;inga-

pail- ; or dar we-jeringa-pail..

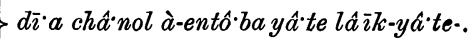

Jar dō'atinga-pail lấ $\bar{\imath} k-y \hat{a}^{*} t e-$.

$d \hat{a} \cdot k a \grave{~} k a ̂ m$ pail lầ $\mathbf{k}-y \hat{a} \cdot t e-$.

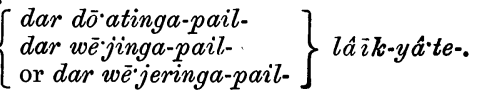

$d \bar{r} \cdot a$ mai ola.

I Otherwise her name would be employed. 
$\left.\begin{array}{l}\text { my husband's brother's wife (if older) } \\ \text { my wife's brother's wife (if older) } \ldots\end{array}\right\} d \bar{\imath} \cdot a$ mấmola. my husband's brother (if of equal standing) $\quad . \quad \ldots \quad$.. $\quad .$. my wife's brother (if of equal standing) my son-in-law (male or female speaking) my younger sister's husband (male or female speaking)

my daughter-in law (male or female speaking)

my husband's sister, if $\ddot{\text { younger (male }}$ or female speaking) ...

my husband's brother's wife, if younger (male or female speaking)

my wife's brother's wife, if younger (male or female speaking) .. $\quad .$. )

my step-son (either speaking) .. $\quad . . \quad$ deb aden irt.

my step-daughter (either speaking) $\quad . \quad$ deb aden'ire-pail-.

my adopted son ", $\quad$, . $\quad \operatorname{dot} \operatorname{ch} \hat{\alpha} \cdot \operatorname{tng} \alpha-$.

my adopted daughter", $\quad, \quad$.. döt chấtnga-pail-.

my parents $\quad " \quad, \quad \ldots \quad$ dab mai ol-chan ol.

my foster-father $\quad " \quad, \quad$.. dab mai ōt-chấtnga-.

my foster-mother $" \quad, \quad \ldots \quad d a b$ chân ót-chấtnga-.

the relationship subsisting between a married couple's fathers-in-law

the relationship subsisting between a married couple's mothers-in-law ...

my husband's brother (if younger) $\ldots d d \hat{a} \cdot k \hat{a} b \bar{a}-b \bar{u} \cdot l a-$.

my younger brother's wife $\quad . . \quad \ldots \quad d \hat{a} \cdot k a ̀$ ba $a$-pail-.

my wife's sister's husband (if younger)

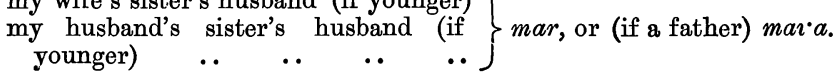

twins (whether of the same sex or not) abdì.dinga-.

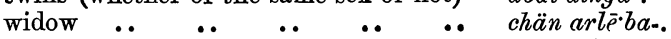

$\begin{array}{llllll}\text { widower } . . & \ldots & . . & \ldots & . . & \text { mai } a r l \bar{e} \cdot b a-\text {. }\end{array}$ 


\section{APPENDIX K.}

\section{List of Terms applied to Males and Females from birth TO OLD AGE IN ORDER TO INDICATE THEIR AGE, CON- DITION, \&C.}

Males.

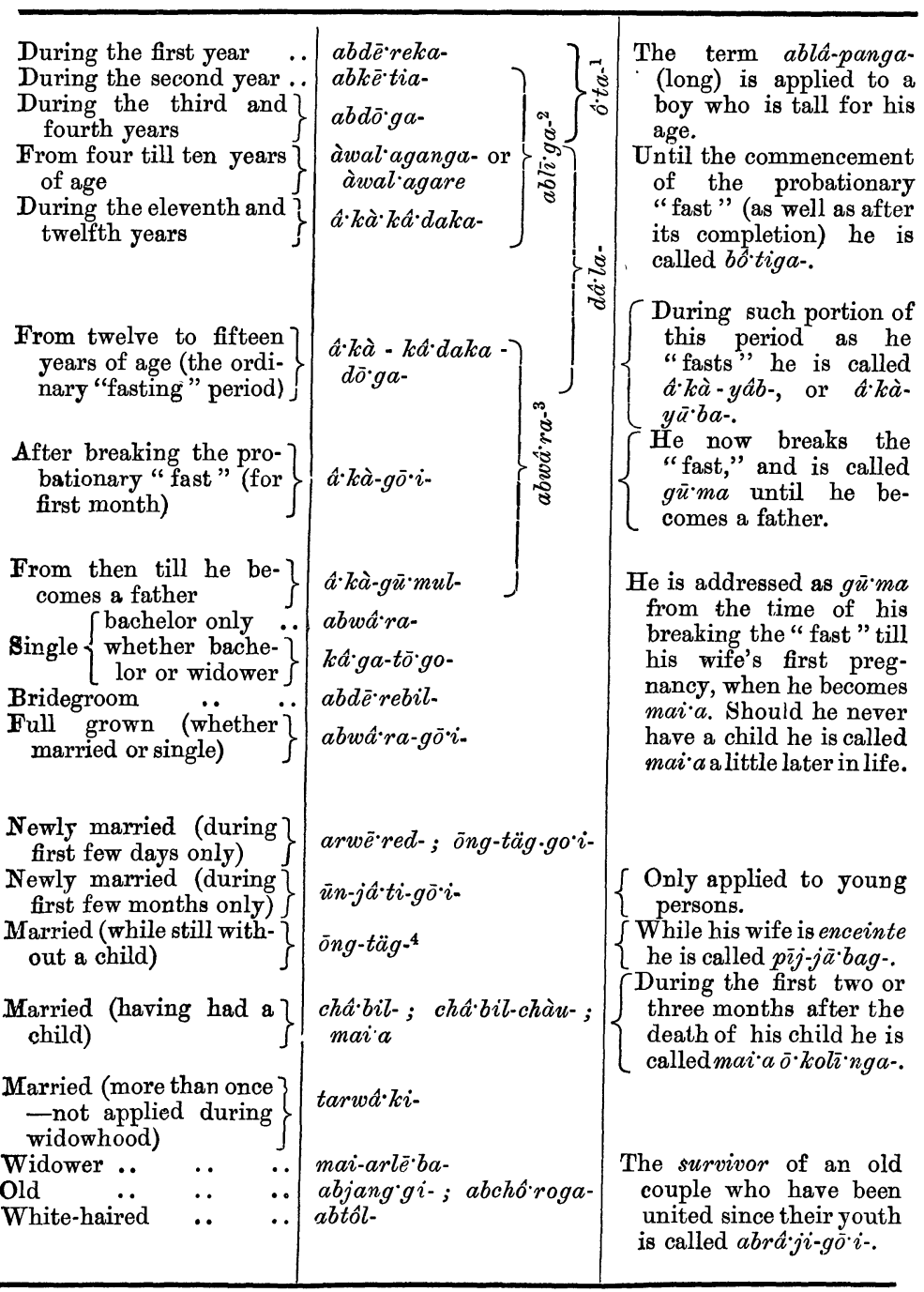

1 Signifies testicle.

2 A child.

${ }^{3}$ A bachelor.

4 Their jungle-bed of leaves is called täg-. 
Females.

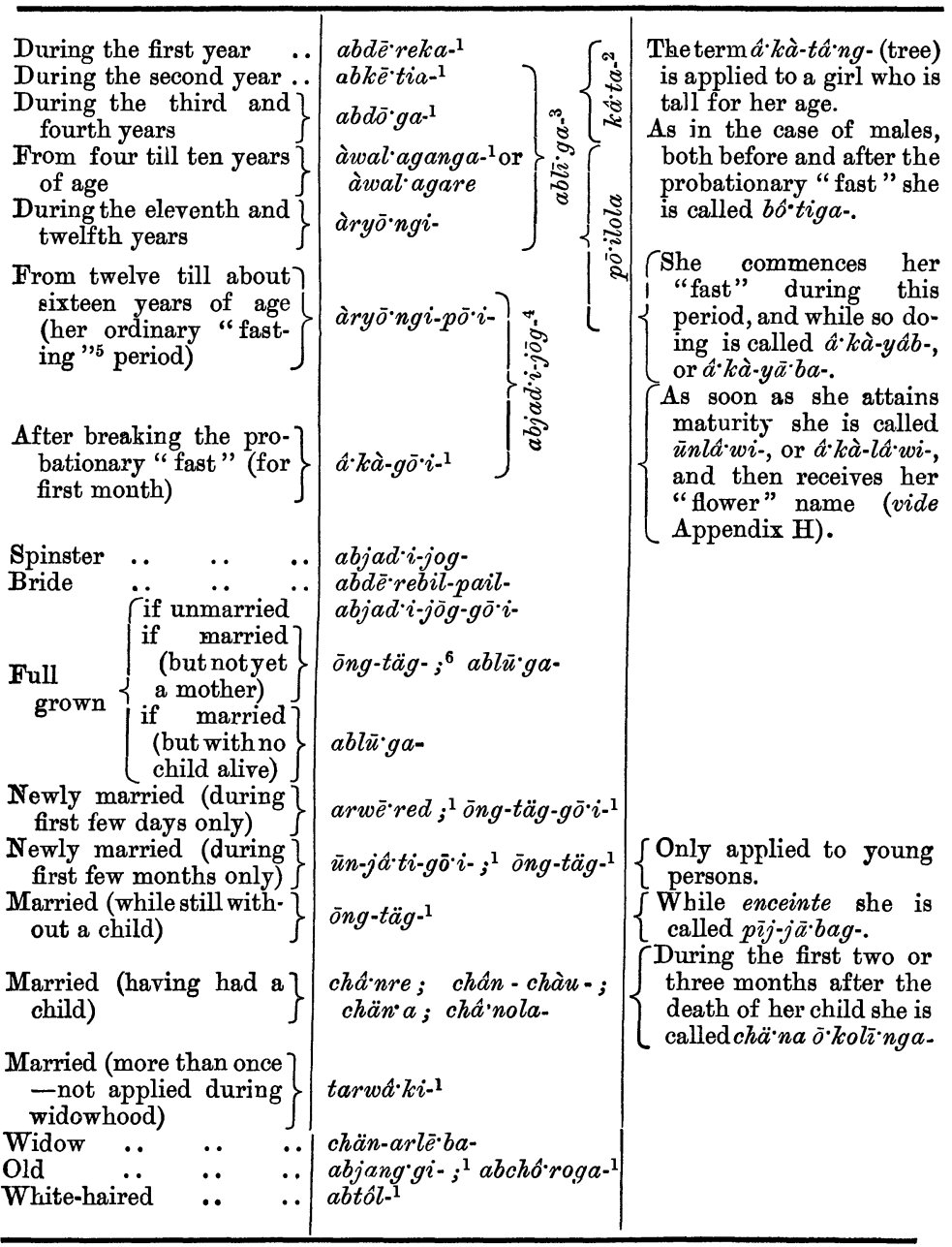

1 In those cases in which the term is common to both sexes, or ambiguity would otherwise exist, the word pail- (female) is added when a woman is referred to. Ex.: ōng-täg-pail-; abtôl-pail-.

2 Signifies the genitals of a female.

3 A child.

4 A spinster.

5 As elsewhere explained (vide Part II, "Initiatory Ceremonies") this term is used merely to imply abstention, during a period varying from one to four or more years, from certain favourite articles of diet.

${ }_{6}$ Their jungle-bed of leaves is called täg-. 


\section{APPENDIX L.}

\section{List of some of the Trees and Plants in the Andaman JUNGLES.}

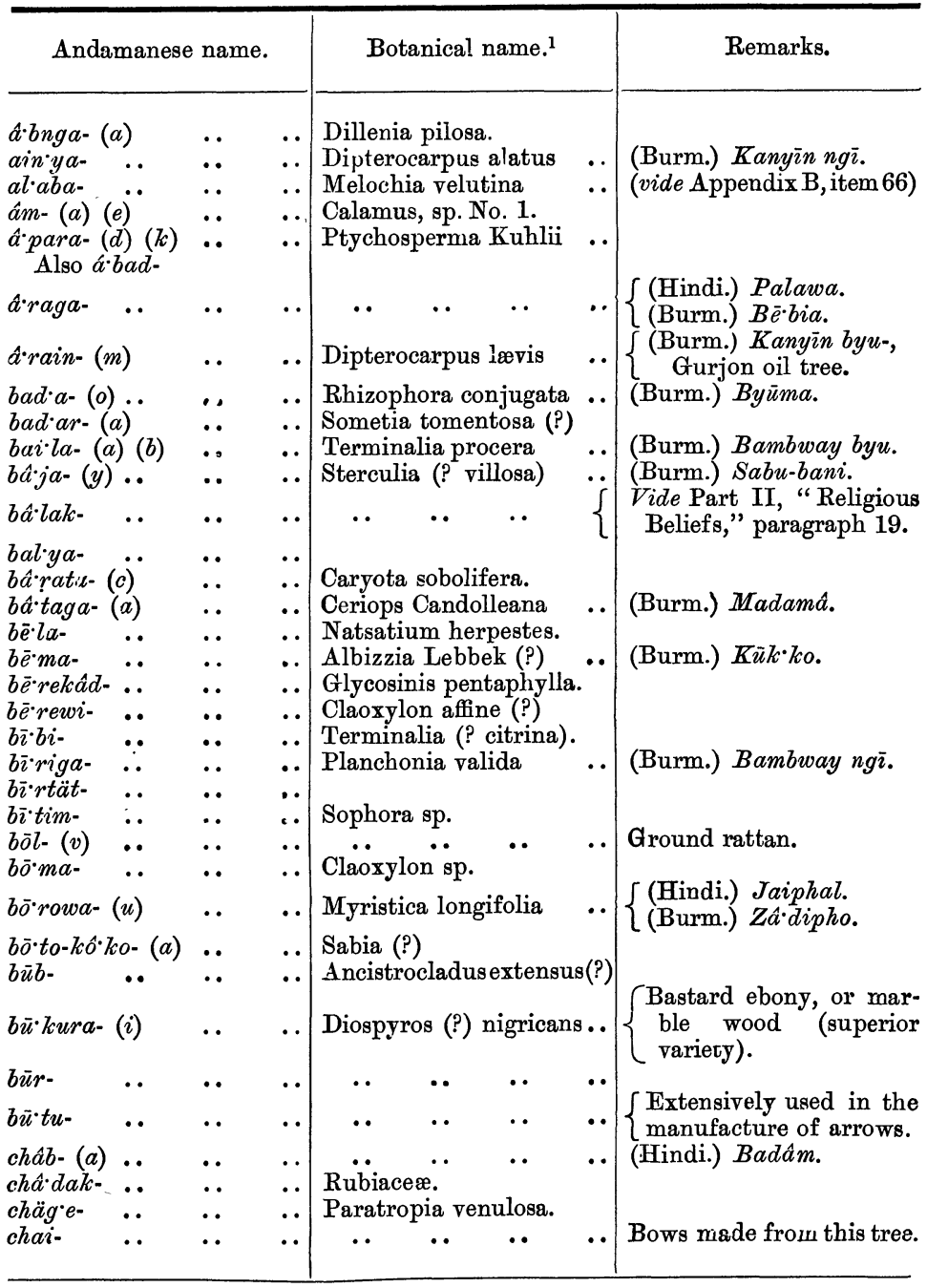

1 It has been chiefly owing to the kind assistance afforded by Dr. G. King, Superintendent of the Botanical Garden, Howrah (near Calcutta), that I have been able to ascertain the botanical names of so many of the trees in this list. 


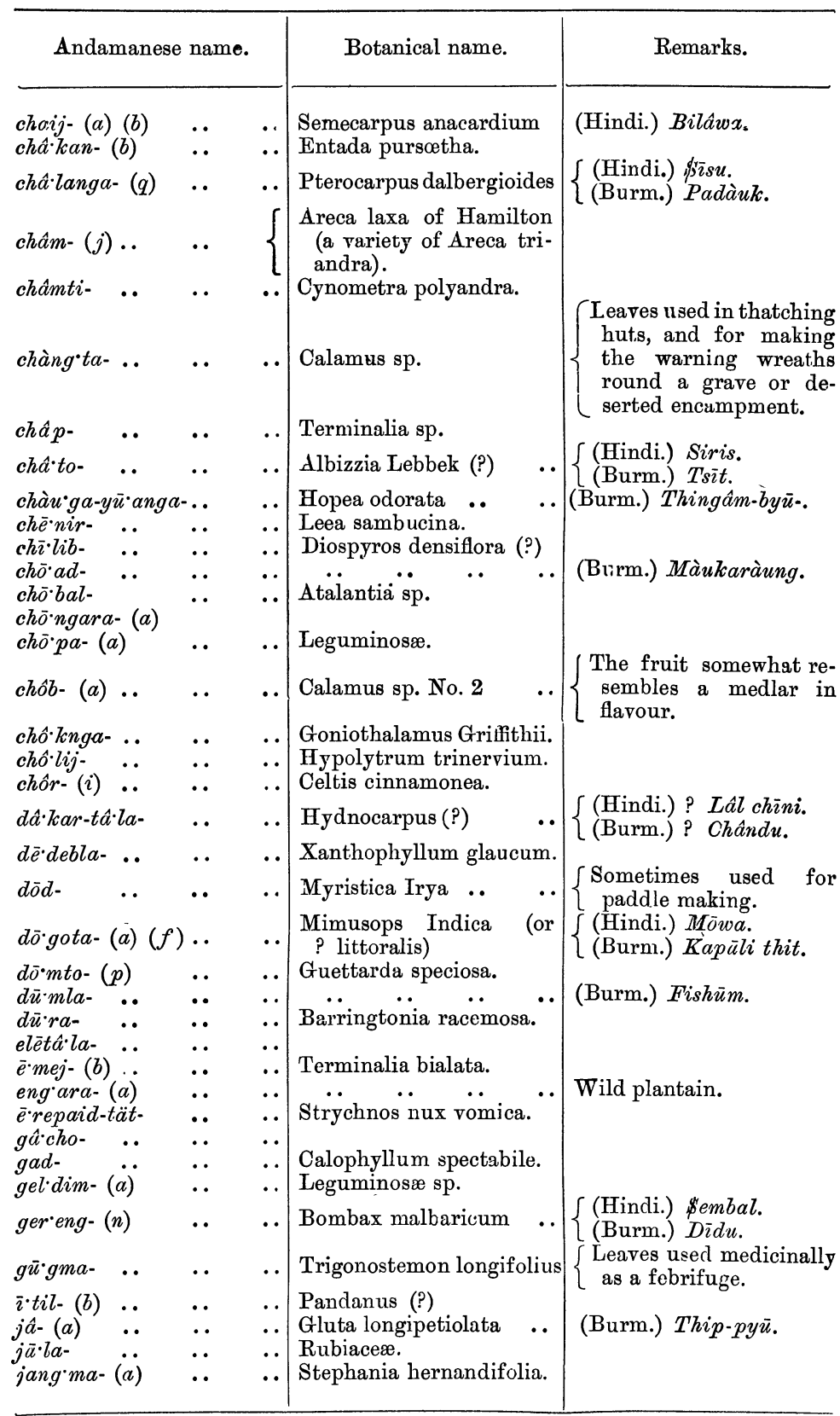




\begin{tabular}{|c|c|c|c|c|}
\hline \multicolumn{3}{|c|}{ Andamanese name. } & Botanical name. & Remarks. \\
\hline$j \bar{\imath} \cdot d g a \quad \ldots$ & .. & . & & (vide \\
\hline$j \bar{i} \cdot n i-(a) \ldots$ & .. & .. & Alpinia sp. $\quad$.. $\quad$. & $\left\{\begin{array}{c}\text { para. 4, and Part III, } \\
\text { "Food," para. } 35 .)\end{array}\right.$ \\
\hline jôr- & $\ddot{x}$ & $\begin{array}{l}. \\
. \cdot\end{array}$ & Odina Woodier .. & (Burm.) Nubbhe. \\
\hline$j \bar{u} \cdot m u-(a) .$. & .. & .. & $\begin{array}{l}\text { ? Brum } \\
\text { or Rhizphora gymnorhiza } \\
\text { or mocronata }\end{array}$ & (Burm.) Byübo. \\
\hline $\begin{array}{ll}k \hat{a} \cdot d a k a- & \ldots \\
k a i-(a) & \ldots\end{array}$ & $\ddot{. .}$ & $\begin{array}{l}. . \\
. .\end{array}$ & $\begin{array}{l}\text { Ficus hispida. } \\
\text { Mangifera sylvatica }\end{array}$ & Wild mango, \\
\hline kai.ta- $(a)(b)$ & .. & .. & Artocarpus chaplasha .. & $\left\{\begin{array}{l}\text { (Hindi.) Kathar. } \\
\text { (Burm.) Toung-peng. }\end{array}\right.$ \\
\hline$k \hat{a} \cdot p a-(a)(h)$ & .. & .. & $\begin{array}{l}\text { Hicuala (probably peltata) } \\
\text { P Sterculia (or Sanadera } \\
\text { Indica) }\end{array}$ & $\left\{\begin{array}{l}\text { The fruit contains a } \\
\text { nut which after being } \\
\text { sucked is broken, when } \\
\text { the shell is eaten and } \\
\text { the kernel thrown }\end{array}\right.$ \\
\hline $\begin{array}{l}\text { kärrega- }(a) \\
k \hat{o} \cdot k a n-(r) \\
k \hat{o} n-(a) \quad \ldots \\
k \hat{b} \cdot r t \hat{a} \cdot l a-\ldots \\
k \bar{u} \cdot d n g a-\quad \ldots\end{array}$ & $\begin{array}{l}\ddot{.} \\
\ddot{.} \\
\ddot{.}\end{array}$ & $\begin{array}{l}\ddot{.} \\
\ddot{.} \\
\ddot{*}\end{array}$ & $\begin{array}{l}\text { Diospyros sp. } \\
\text { Pajanelia multijuga. } \\
\text { Diospyros sp. } \\
\text { Griffithia longiflora. } \\
\text { One of the Rubiaceæ. }\end{array}$ & away. \\
\hline$k \bar{u} \cdot n r a-\quad \ldots$ & .. & $\cdot \cdot$ & Dracontomelum sylvestre & $\left\{\begin{array}{l}\text { The fruit being large and } \\
\text { round is often used as a } \\
\text { moving target by being } \\
\text { rolled along the ground } \\
\text { or down a slope and } \\
\text { shot at while in motion. }\end{array}\right.$ \\
\hline 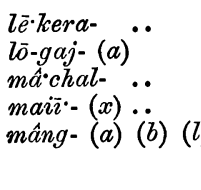 & $\begin{array}{l}\ddot{.} \\
\ddot{.} \\
\ddot{.}\end{array}$ & $\begin{array}{l}. . \\
\ldots \\
\ldots \\
\ldots\end{array}$ & $\begin{array}{l}\text { Leguminosæ sp. } \\
\text { Angiopteris evecta. } \\
\text { Atalantia sp. } \\
\text { Sterculia (?) .. .. } \\
\text { Pandanus Andamanen- } \\
\text { sium. }\end{array}$ & $\begin{array}{l}\text { (Burm.) Àuk yenż̀. } \\
\text { (Hindi.) Kéora. }\end{array}$ \\
\hline mồnag- $\quad .$. & .. & .. & Messua ferrea ... & $\left\{\begin{array}{l}\text { (Mindı.) päl. } \\
\text { (Burm.) Gangua. }\end{array}\right.$ \\
\hline 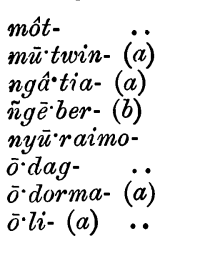 & $\begin{array}{l}. \\
\ldots \\
\ldots \\
\ldots \\
\ldots \\
\ldots \\
\ldots\end{array}$ & $\begin{array}{l}. . \\
\ldots \\
\ddot{.} \\
\ldots \\
\ldots \\
. .\end{array}$ & $\begin{array}{l}\text { Heritiera littoralis. } \\
\text { Anacardiaceæ. } \\
\text { Bruquiera sp. } \\
\text { Cycas Rumphii. } \\
\text { Ficus sp. No. } 1 . \\
\text { Eugenia sp. } \\
\text { Ficus (probably macro- } \\
\text { phylla). }\end{array}$ & \\
\hline $\begin{array}{l}\bar{o} \cdot \operatorname{lma-} \\
\hat{o} \cdot r o-\end{array}$ & $\ddot{n}$ & .. & Chickrassia tabularis $\quad$. & $\begin{array}{l}\text { (Burm.) Thisunüwe. } \\
\text { (Burm.) Ngazu. }\end{array}$ \\
\hline$\hat{o} \cdot r o p a-(a)(b)$ & & $\cdots$ & Baccaurea sapida & 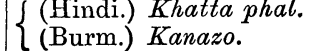 \\
\hline $\begin{array}{l}\hat{o} \cdot r t a-t \ddot{a} t-(a)(g) \\
p \hat{a}-(b) \quad \cdots\end{array}$ & $\begin{array}{l}. . \\
. .\end{array}$ & $\begin{array}{l}\cdots \\
\cdots\end{array}$ & $\begin{array}{l}\text { Uvaria micrantha. } \\
\text { Semecarpus (?) .. }\end{array}$ & (Burm.) Thikadoe. \\
\hline
\end{tabular}




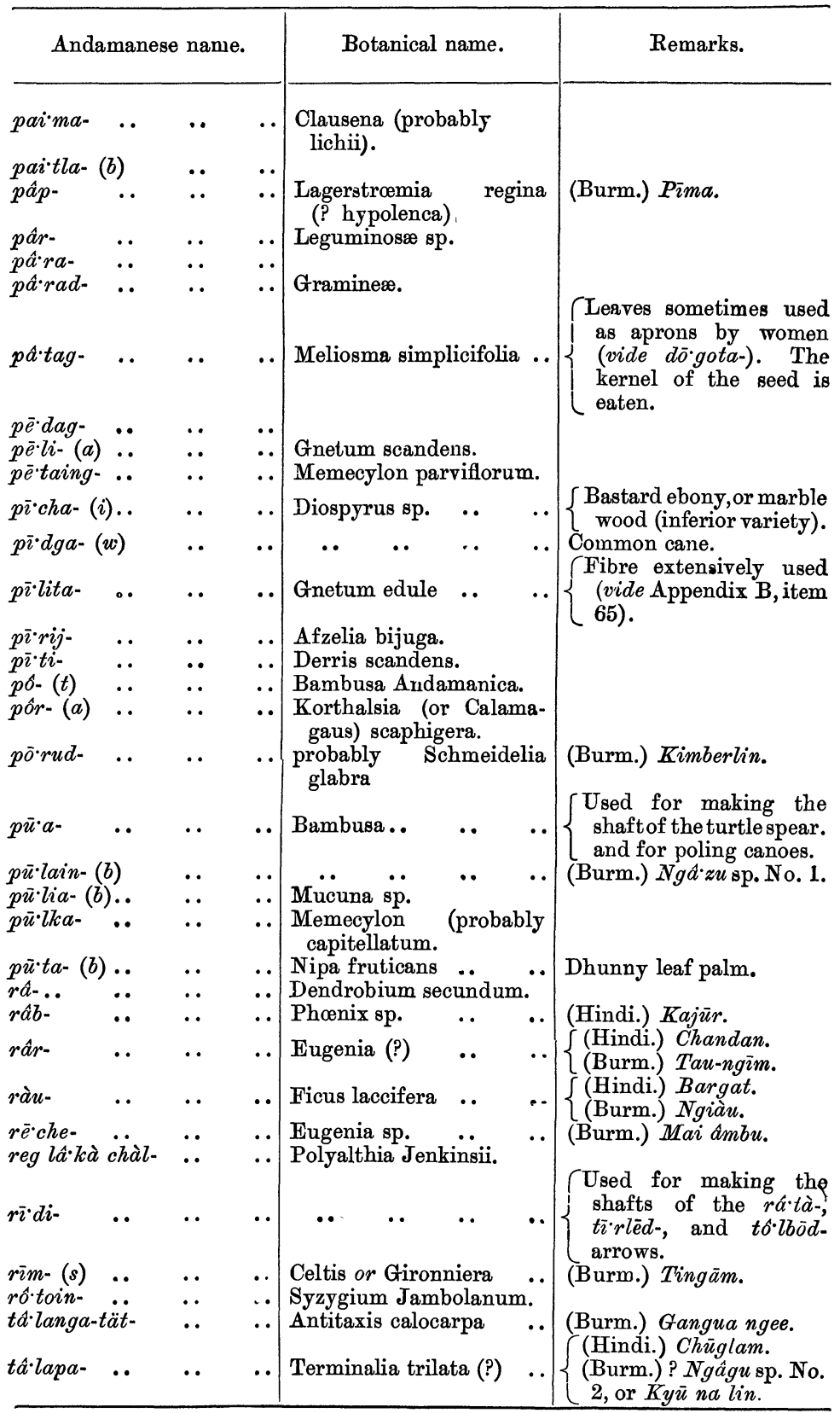




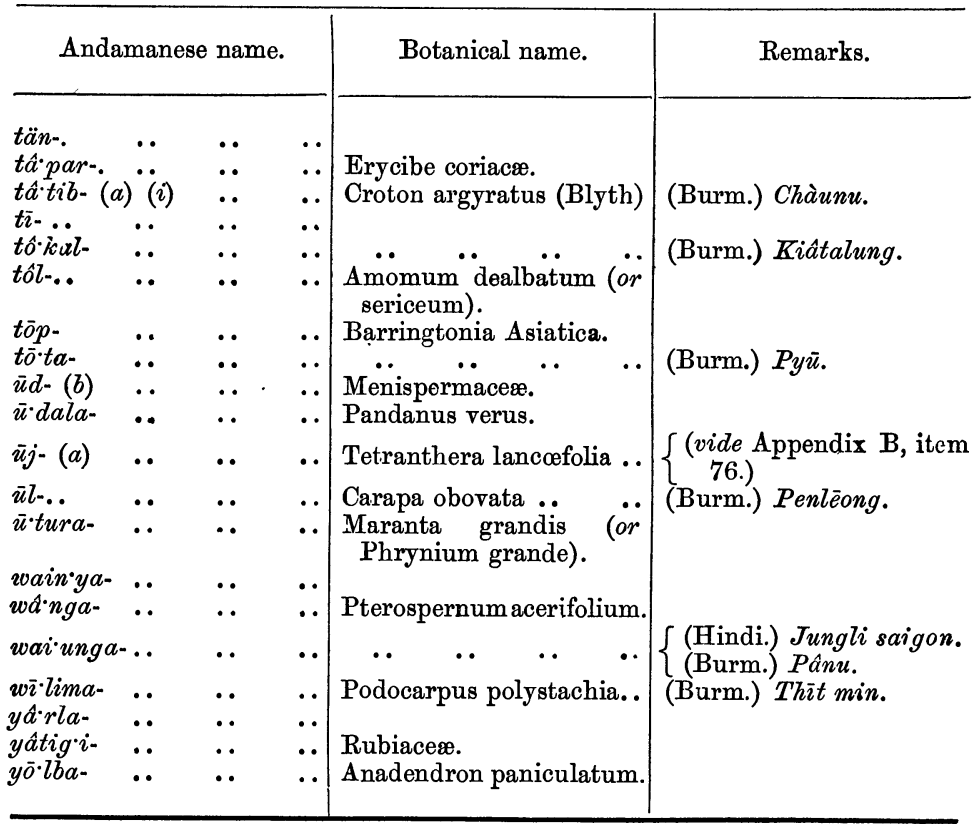

\section{Additional Notes.}

(a) Fruit is eaten.

(b) Seed is eaten.

(c) Heart of the tree is eaten.

(d) Pulpy portion of spathe is eaten.

(e) Leaf stems used in manufacture of sleeping mats. Leaves used for thatching purposes.

$(f)$ Leaves used by women as aprons ( $\bar{o}^{\circ}$ bunga-) ; rotten logs used for fuel (see also "Superstitions," para. 8).

(g) Stem of this plant used for the frame and handle of the hand-net (k $k \bar{u} d-)$ (vide Appendix B, item 20).

(h) Leaves used for thatching, for screens (vide Appendix B, item 74), for bedding, for wrapping round corpse, for packing food for journey, \&c., and prior to cooking.

(i) Rotten logs used for fuel.

(j) Used in nianufacture of the foreshaft of the $r \hat{a} \cdot t \hat{a}-, t \bar{\imath} \cdot r l \bar{e} d-, t \hat{o} \cdot l b \bar{o} d-$, and châm-arrows (vide Appendix B, items 2, 3, 4, 8), and sometimes also the skewer.

(k) Leaves used for thatching and for bedding.

(l) Leaves used in the manufacture of articles of personal attire (vide Appendix B, items 25 and 28).

$(m)$ The middle portion of rotten logs used for torches.

(n) Rarely used for making canoes.

(o) Used for adzes, sometimes for foreshafts of arrows, and for making children's bows.

(p) Leaves used for flooring of huts.

(q) Buttress-like slab roots used for making the sounding-boards employed when dancing. 
(r) Used for making canoes.

(s) Resin used in manufacture of $k \hat{a} \cdot n g a t \hat{a} \cdot b \bar{u} j$ - (vide Appendix B, item 62).

$(t)$ Used in making the $g \bar{o} b-, k a i$-, and sumetimes the tôg- (vide Appendix B, items 82,80 , and 10 ).

(u) Generally used for making paddles, and the leaves for bedding.

(v) Used for makıng shaft of hog-spear.

(w) Used for making baskets, fastenings of adze, turtle-spear, torches $\left(t \bar{o}^{\cdot} \cdot g_{-}\right)$, and of bundles ; also for suspending buckets, for stitching cracks in canoes, and in thatching.

$(x)$ Used for making canoes; the resin is employed in making torches.

(y) Used for making canoes, pails, and eating trays.

\section{APPENDIX M.}

\section{List of Shells COMmonly known to the Andamanese.}

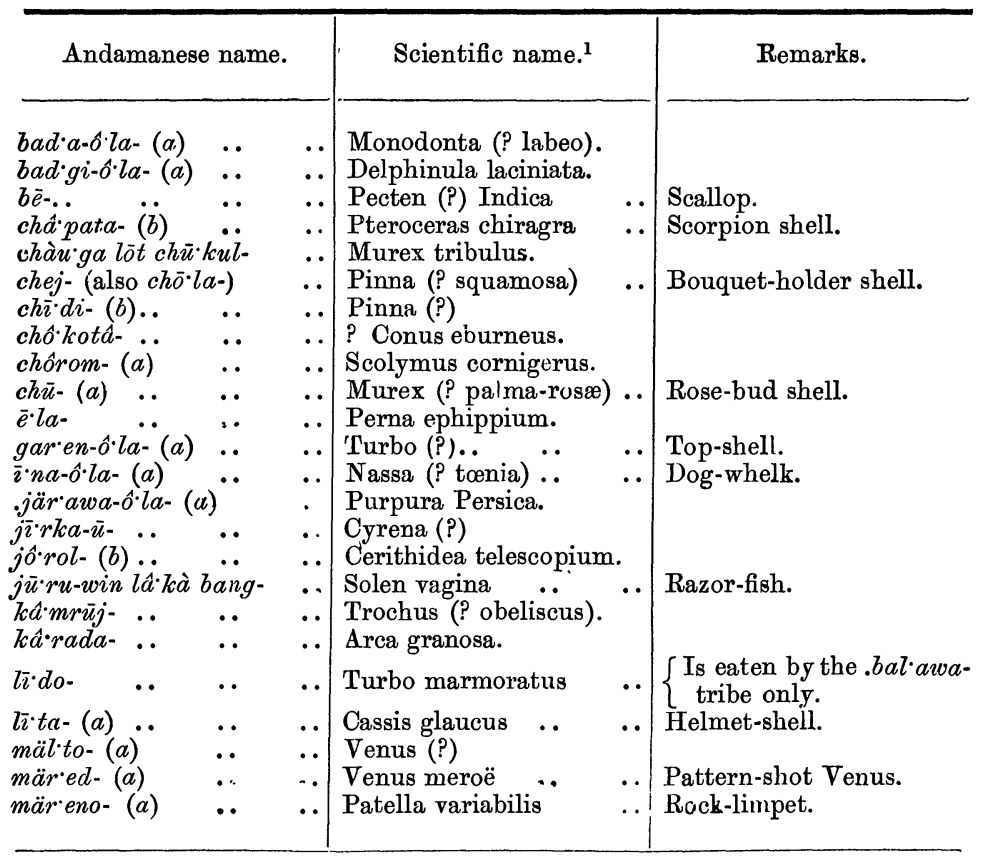

1 To the Rev. T. L. J. Warneford, formerly chaplain at the Andamans, I am indebted for the classical names of many of the shells in this list.

(a) denotes those that are cooked and eaten.

(b) denotes those that are cooked and eaten by married persons only.

VOI. XII.

$2 \mathrm{H}$ 


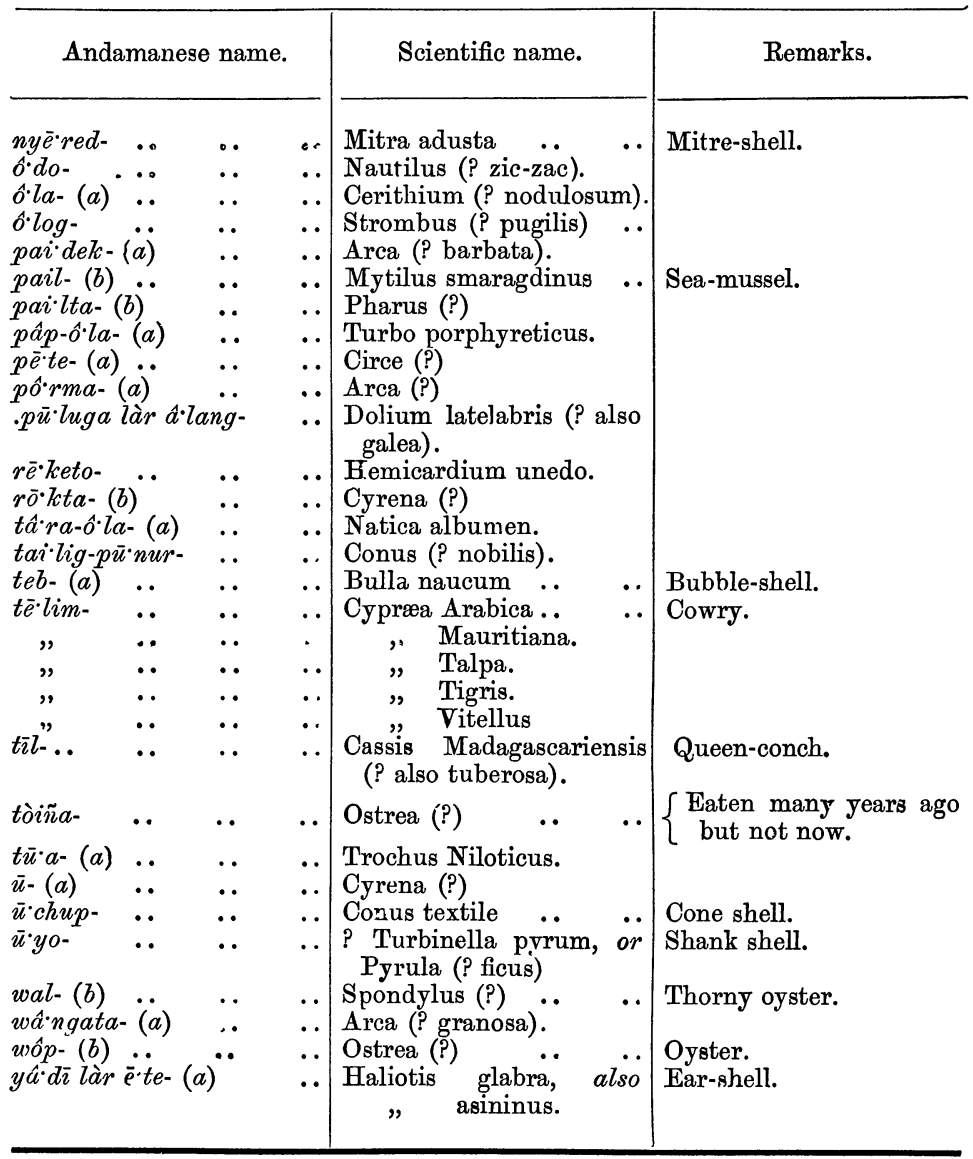

